\title{
MYCOLOGY AND INDUSTRIAL MICROBIOLOGY
}

\author{
Zs. ANTAL ${ }^{1}$, L. MANCZINGER ${ }^{2}$, L. KREDICS ${ }^{2}$, L. FERENCZY ${ }^{1,2}$ \\ Physical and functional investigation of the pThr1 plasmid \\ ${ }^{1}$ Research Group for Microbiology, Hungarian Academy of Sciences and University of Szeged, \\ ${ }^{2}$ Department of Microbiology, Faculty of Sciences, University of Szeged, Hungary
}

Trichoderma species are common soil-born fungi. These species are economically important, in part because of their mycoparasitic ability, which makes them suitable for application as biocontrol agents against soil-born plant-pathogenic fungi. Despite the importance of these fungi, little is known about their extrachromosomal genetic elements.

In addition to the high-molecular-weight band, two lower-molecular-weight bands, 1.5 and $3.0 \mathrm{~kb}$ in size, were observed in the agarose gel electrophoresis patterns of undigested mtDNA preparations purified from the isolated mitochondria of a mycoparasitic Trichoderma harzianum strain. This pattern was produced by single molecules, $2.6 \mathrm{~kb}$ in size, that were supercoiled to various degrees. There were no sequence homologies between this plasmid, called by us pThr1, and the mtDNA. The complete 2622 bp sequence of the pThr1 plasmid was determined and analysed by means of computer programs. The plasmid displayed no homology at a DNA level with any mitochondrial plasmid or other DNA sequences accessible in the Genbank database. The sequence analysis revealed that the pThr1 plasmid contained three open reading frames $(177,150$ and $1275 \mathrm{bp}$ long) and the putative protein product of the long open reading frame, for a length of $650 \mathrm{bp}$, was similar to the reverse transcriptase of the Mauriceville and Varkud plasmids from Neurospora spp. Moreover, this open reading frame had conserved sequence elements, Q, R and S, characteristic of group I introns.

This work was supported financially by grant T025849 of the Hungarian Scientific Research Fund and FKFP-0218/97 of the Hungarian Ministry of Education. 


\title{
Cloning and partial sequence analysis of the glyceraldehyde-3-phosphate gene of Mucor circinelloides
}

Department of Microbiology, Faculty of Sciences, University of Szeged, P.O. Box 533, H-6701, Szeged, Hungary

The glyceraldehyde-3-phosphate gene (gpd) of Mucor circinelloides $\mathrm{f}$. lusitanicus (ATCC 1216b) has been isolated from a genomic library by homologous hybridisation with a 350 bp fragment of the gpd gene amplified by PCR using specific primers. Until now about $70 \%$ of the entire gpd sequence has been identified. This sequence consists of 504 bp coding region from the 3' terminus and is not interrupted by introns. The amino-acid sequence encoded by the fragment shows a high degree of sequence identity with the corresponding gene products of various fungal species. Multiple alignments of fungal GPD sequences resulted in the construction of a phylogenetic tree. Results of the phylogenetic analysis of these sequences indicated a closer connection of the zygomycete $M$. circinelloides to the investigated basidiomycete than the ascomycete species. Sequence analysis of 307 bp of the 3' terminal non-coding region was also carried out and revealed the presence of fungal terminal consensus sequences.

This study was supported by OTKA grant T032738.

M. BATIČ, P. LIKAR, E. RUPNIK

\section{Effect of $\mathrm{C} / \mathrm{N}$ ratio on RNA accumulation in yeast}

\author{
Food Science and Technology Department, Biotechnical Faculty, University of Ljubljana, \\ Jamnikarjeva 101, 1000 Ljubljana, Slovenia
}

During batch bioprocess the content of ribonucleic acid (RNA) in the yeasts varied depending on growth phase and medium composition. In yeast $S$. cerevisiae and C. utilis the effect of different $\mathrm{C} / \mathrm{N}$ ratio $(5: 1,10: 1,25: 1$ and 50:1) to RNA accumulation was studied in modified yeast malt extract broth medium at $\mathrm{pH} 4.0$ and 6.0. During the bioprocess the $\mathrm{pH}$, biomass concentration and RNA was followed. Results showed negative correlation between RNA content and increasing $\mathrm{C} / \mathrm{N}$ ratio in the media. Cultivating $S$. cerevisiae and $C$. utilis 24 hours in YMB medium in side arm flasks at starting pH 4.0 and 6.0 at $28{ }^{\circ} \mathrm{C}$ on a rotary shaker with $200 \mathrm{rpm}$. The yeast biomass was followed by measurement of $\mathrm{OD}$ at $650 \mathrm{~nm}$. The dry yeast biomass was 
estimated by calibration curve prepared by filtration of the broth samples during growth. The RNA determination was performed in yeast biomass by extraction of RNA with $0.5 \mathrm{M} \mathrm{HClO}_{4}$. Extracted RNA was centrifuged at 14,000 $\mathrm{min}^{-1}$ and absorbency was measured at $260 \mathrm{~nm}$ in supernatant. Calibration curve prepared by the same procedure with RNA from Torula yeast was used for estimation of total yeast cell RNA of $S$. cerevisiae and C. utilis.

During the growth of S. cerevisiae and C. utilis in batch bioprocess the $\mathrm{pH}$ fall and biomass concentration increased with increasing concentration of carbon in the media. Contrary, nitrogen limitation caused reduction of maximal specific growth rate and RNA accumulation of both yeasts. Increased C/N ratio from 5:1 and 10:1 to 50:1 resulted in $38 \%$ to $20 \%$ reduction of RNA measured at the end of the bioprocess. Results showed that growth of yeast in YMB media with nitrogen limitation caused 20 to 40 minutes prolongation of cell doubling time $(\operatorname{tg})$ at $S$. cerevisiae. In C. utilis the RNA concentration decreased from $36 \mathrm{mg} \mathrm{RNA} / \mathrm{g}$ d.w. at C/N ratio 10:1 to 33,34 and $26 \mathrm{mg}$ RNA/g d.w. at $\mathrm{C} / \mathrm{N}$ ratio 5:1, 25:1 and 50:1 in the cultivation media. The CIN ratio in growth medium of yeast $S$. cerevisiae and C. utilis plays important role in RNA accumulation of yeast cells. The negative effect on RNA accumulation in yeast cell appeared when $\mathrm{C} / \mathrm{N}$ increased from 5:1 and 10:1 to 50:1. Contrary, biomass production increased up to $10.6 \mathrm{~g} / \mathrm{L}$ when high nitrogen limitation media was used.

\section{Zs. BenkÖ, M. MiskeI, Cs. FenYvesvöLgyi, V. BeNesocZKI, M. SiPICZKI \\ Effect of mutations causing caffeine resistance on cell cycle and their interaction with other mutations. Adaptation to caffeine}

Department of Genetics and Molecular Biology, FNS, University of Debrecen, Debrecen, Hungary

Caffeine is one of the most frequently consumed drugs. Several aspects of the effect of caffeine on living organisms are studied. Nascent resistance against medicines and various toxins cause serious problems for medical science. The latest results showed that caffeine could not cause cancer alone but it could increase effectively the carcinogen effect of several compounds. In addition the caffeine is a well-known toxin of cells with different effects on them.

To better understand the effects of caffeine we have isolated caffeine-resistant mutants that could tolerate 4-5 times higher concentration of caffeine than the wild type cells. One representative was chosen from the four-complementation groups for further studies. Analysis of these mutants revealed several dissimilarity to wild-type cells such as prolonged cell cycle, elongated cells, UV sensitivity, $\gamma$-resistance, $\mathrm{pH}$-sensitive 
growth, damaged meiosis, starvation sensitivity and brefeldin A resistance. Molecular analysis revealed that the cafl gene product is probably responsible for nuclear transport. The caf2 gene encodes an exportin protein. The caf3 gene product is an AP1-type transcription factor. The caft gene encodes thioredoxin reductase enzyme. These results suggest a very complex system existing in the cell that is able to reduce the toxic effect of caffeine.

Effect on cell cycle. It is known that hydroxy urea (HU) blocks the cells in the S phase. Addition of caffeine to the blocked wild-type cells can override the S-M checkpoint that result in cell death. We found that the HU-blocked caf mutants can tolerate the addition of caffeine. The most common changes in phenotype of S. pombe cells following addition of caffeine are the prolonged cell cycle. To understand this effect more clearly we isolated further caffeine-resistant mutants that have extremely prolonged cell cycle both with and without caffeine in the media.

Interaction with other mutation. The caf3-89 dominant mutation (AP-1-like transcription factor) increases morphological changes in phenotype caused by sep 1 mutation while the caf3-89 sepl3-572 double mutation is lethal. The caf3 gene even interacts with some auxotroph mutations especially with ade6 ${ }^{-}$. We have isolated a sterile stey mutant that causes reduced caffeine-resistance and altered cell morphology in the caf3-89 stey double mutant.

Adaptation to caffeine. We also found that $S$. pombe cells could adapt to higher concentration of caffeine. This adaptation is reversible. It has turned out that the adaptation ability due to spontaneous mutation while the wild-type strains have reduced ability to adapt to caffeine. To know more about the mechanism of adaptation we have started to study both the wild-type and the mutant strain.

\section{B. BIRÓ ${ }^{1}$, H. TIRICZ ${ }^{2}$, B. MORVAI ${ }^{3}$}

Investigations on the vitality, resistance and diversity of metal-adapted and non-adapted Rhizobium strains

${ }^{1}$ Research Institute for Soil Science and Agricultural Chemistry of the Hungarian Academy of Sciences

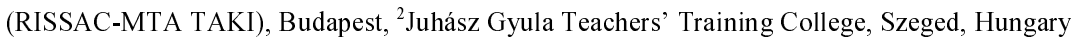

Waste disposal of the sewage sludge in the arable lands is a common agricultural practice throughout the world. After the long-term applications, however, some diverse effect of the accumulated heavy metals can be detected on some soilbiological groups and parameters. Among them the bacterial and fungal (Rhizobium 
and AMF) microsymbionts are sensitive enough to use them as potential, appropriate eco-toxicological biosensors (Balla et al. 1998).

Growth-rate and metal-tolerance of adapted and non-adapted Rhizobium leguminosarum bv. trifolii isolates were tested in vitro. Strains were originating from a heavily polluted soil, where various rates of communal sewage sludge were used regularly for more than ten years (in Hungary). Five concentrations $(0.1,1,10,100$ and $1000 \mathrm{mg} \mathrm{l}^{-1}$ ) of some heavy metal salts ( $\mathrm{Zn}, \mathrm{Cu}, \mathrm{Co}$ and $\mathrm{Ni}$, as sulphates and chlorides) were used in a micro-fermentor, where the cell number of the tested strains was estimated after 14 hours of incubation. Starting ratio of the rhizobium cells was set to $10^{6} \mathrm{CFU} \mathrm{ml}^{-1}$ in liquid YEM, yeast-extract mannitol-media (inoculated by about 100 $\mu 1 /$ tube after a Thoma-chamber counting and calculation). After 14 hours of growth (at $\left.28{ }^{\circ} \mathrm{C}\right)$ in a rotary shaker, optical density $(\mathrm{OD}=640 \mathrm{~nm})$ of the suspensions were measured and compared to the metal-free control. Modified plate count method was also used to assess the abundance of the culturable cells (Angerer et al. 1998). Plasmide profile analysis (PPA), as phenotypic community characteristic, was used to indicate the microbial diversity of the rhizobia in the sewage sludge treated plots. Data were analysed statistically.

Adapted Rhizobium strains, which were selected after 10 years of regular sewage-sludge treatments, were found to be almost uniformly tolerant to all of the applied heavy metal rates. Strains, originating from an unpolluted soil, however, were generally sensitive to as low, as $10 \mathrm{mg} \cdot \mathrm{kg}^{-1}$ concentrations of the metals. The lowest doses of some microelements (at about 0.1 and $1 \mathrm{mg} \cdot \mathrm{kg}^{-1}$ ) stimulated the growth, depending on the metals and the strains, as it was found in an earlier study (Kecskés et al. 1997).

Cell number of adapted rhizobia was found to be less by about twofold compared the untreated and non-adapted controls. Vitality and growth of the metaltolerant strains decreased by about $60 \%$ at all of the treatments after a 15 -years of metal contamination. Maximal genetical- (plasmide profile) diversity was present at the nonpolluted soils, whereas the communal sewage sludge application has decreased it as a function of the long-term effect, the soil-physical-chemical characteristics and the usage of the lands.

Sponsored by the Hungarian Research Fund (OTKA): T 023543 and T 030941.

1. Angerer, I. et al.: Agrokem Talajt 47, 297-305 (1998). 2. Birb, B.: Gyakorlati Agroforum (X) 9, 4-6 (1999). (in Hungarian) 3. Kecskés, M.: Acta Aliment 26, 313-315 (1997). 4. Balla, I. et al.: Plant Cell Tissue Org Cult 52, 113-116 (1998). 


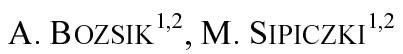

The cytological and genetical study of the dimorphic yeast Schizosaccharomyces japonicus

${ }^{1}$ Department of Genetics, Kossuth Lajos University, Egyetem tér 1, H-4010 Debrecen,

${ }^{2}$ DEOEC Human Genetical Institute, Nagyerdei krt. 98, H-4012 Debrecen, Hungary

S. japonicus is a unicellular haploid fission yeast. Life cycle has dimorphism: young colonies consist of cylindrical single cells and after 8-10 days on solid medium they develop hyphae characteristic of real fungi. We put emphasis on studying this dimorphism. We highlighted the differences between single cells and hyphae in cytological aspects: with respect of mitosis and the pattern of cytoskeletal elements the two forms shared the same morphology with a slight difference due to the shape of the cells. We generated auxotrophic mutants from the wild type strain.

We divided the isolated mutants into complementation groups; the exact spot of some of these groups were determined in the respective biosynthetic pathway. We performed protoplasts fusion. The segregation of alleles originating from azygotic asci turned to be mendelic. We isolated several hyphae-producing mutants and mutants that show sensitivity or resistance to hyphael growth-blocking toxins. Studying their genetical background we found important genes participating in metamorphosis. During the fluorescent paint of the nucleus we noticed three chromosomes in the cell. With pulsed field electrophoresis (CHEF) only two bands could be detected on the gele. Perhaps two chromosomes have the same size. Transformation was difficult: $S$. japonicus cannot apply the ARS of $S$. pombe. We generated $S$. japonicus library in pJK148 integrative plasmid and searched for specific ARS. With the help of this gene we elaborated an effective transformation system for $S$. japonicus. We are able to transform metamorphosis mutants and get more details about the genes regulating this phenomenon.

\section{A. BRÜCKNER, CS. BALLA, I. KISS}

\section{Effect of map on spoilage microorganism of cut vegetable}

Department of Refrigeration and Livestock Products Technology, Szent István University, Budapest, Hungary

In consequence of new consumer demands of the last decades fresh-like vegetable and fruit products with a shelf-life of few days appeared on the market.

Acta Microbiologica et Immunologica Hungarica 48, 2001 
Changes in quality - during modified atmosphere storage at $5{ }^{\circ} \mathrm{C}$ - of cut carrots and Chinese cabbage were examined. These quality changes were followed by the growth of spoilage microorganism populations (total counts of mesophil aerobe bacteria, Pseudomonas, lactic acid bacteria). Modified atmosphere in the sample packages was established by packaging into materials of different permeability to gases and by added $\mathrm{CO}_{2}$ or $\mathrm{O}_{2}$. So the atmosphere in the packages was normal (air), rich in $\mathrm{CO}_{2}$ - poor in $\mathrm{O}_{2}$ or rich in $\mathrm{O}_{2}$. To analyse the growth curves of microorganism populations the Baranyi-model was used.

High $\mathrm{CO}_{2}$ concentration restricted the growth of mesophil aerobe microorganism and Pseudomonas bacteria, but it had a beneficial effect on lactic acid bacteria, which were present in the starting microflora in more order lower numbers than mesophil aerobe microorganisms. High $\mathrm{O}_{2}$ level had restrictive effect on mesophil aerobe microorganisms in case of Chinese cabbage. Growth of microorganism in carrot samples did not show the same trend.

Each product needs different gas composition to achieve beneficial influence on the quality of different vegetables. Beside microbiological changes also other factors like plant respiration, sensorial changes have to be taken into consideration in case of planning a new product or choosing a technology.

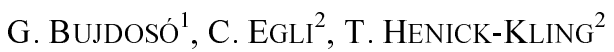

\section{Fast method for the identification and differentiation of species and strains belonging to genera Hanseniasporal Kloeckera by traditional and molecular biological methods}

\footnotetext{
${ }^{1}$ Department of Microbiology, Faculty of Food Science, Szent István University, Budapest, Hungary, ${ }^{2}$ Department of Food Science and Technology, Cornell University, New York State Agricultural Experiment Station, USA
}

The conversion of grape juice into wine is a complex process that is carried out by successive of various yeasts [1,2]. The fermentation of must or juice is often initiated by the strains of Hanseniasporal Kloeckera predominantly what can cause lot of concerns to winemakers regarding the off-flavors, e.g., acetic acid, acetaldehyde, ethyl acetate, these yeasts produce during their proliferation [3, 4]. Others although consider them as positive determinants what can contribute to wine with characteristic flavors by producing acetoin, 2,3-butanediol, glycerol and other higher alcohols [5, 6]. To know more about their biology, it is important to establish an easy and fast method for the identification and differentiation of the species within the genera of 
Hanseniasporal Kloeckera. Yeasts from different places around the world were examined to evolve an identification scheme for these genera. Physiological methods and molecular biological techniques, e.g., ITS-PCR, RAPD-PCR, Microsatellite-PCR and RFLP, were used to the assay. By the invented method strains belonging to these genera were identified and differentiated accurately. This procedure allows a fast and reliable methodology for the classification of strains of Hanseniasporal Kloeckera.

1. Fleet, G. H.: J Wine Res 1, 211-223 (1990). 2. Henick-Kling, T. et al.: J Appl Microbiol 84, 865876 (1998). 3. Schutz, M., Gafner, J.: J Appl Bacteriol 75, 551-558 (1993). 4. Velazquez, J. B. et al.: J Microbiol Biotechnol 7, 485-489 (1991). 5. Romano, P. et al.: J Appl Microbiol 82, 615-618 (1997). 6. Mateo, J. J. et al.: J Food Microbiol 14, 153-160 (1991).

\section{G. CSITÁRI, G. KEREKES, K. LÁSZLÓ}

\section{Effect of zineb on microbial activity in different soils}

Georgikon Faculty of Agronomy, University of Veszprém, Keszthely, Hungary

Zineb (zink-ethylene-1,2-bis-dithiocarbamate) is a dithiocarbamate type fungicid with broad-range specificity. It is commonly used as a folar fungicid, but it is also allowed for partial soil sterilization in some culture. Effect of pesticides containing zineb as active ingredient on soil microbial activity was evaluated. The soils used in the experiments differed from each other in humus and clay content (1.15-6.35 percent humus, 28-55 soil plasticity index $/ \mathrm{K}_{\mathrm{A}} /$ ). Measurements of microbial activity were based upon microbial biomass and three soil enzyme (dehydrogenase, phosphatase and invertase) activities. These enzymes differed from each other not only in substrate specificities but in their stability, too. Dehydrogenase activities bind to the intact, living cells, phosphatase activities maintain their activities after releasing from cells in the soil solution for weeks, invertase can be immobilised to soil colloids and remains active for years.

We concluded that soil type and fungicide treatment had significant effects on all variables measured (microbial biomass and enzyme activities) at 0.05 probability level. The correlations between the variables were determined by statistical methods. Correlation coefficients between the microbial biomass and enzyme activities were 0.435, 0.677 and 0.902 (dehydrogenase, phosphatase and invertase), respectively: The coefficients increased with the increasing stability of enzymes. There is a similar relationship between the microbial variables and soil properties (clay and humus content, $\mathrm{pH}$ and water holding capacity /WHC/): invertase activity and microbial 
biomass showed the strongest, dehydrogenase activity showed the weakest correlations. The correlations were positive in case of humus percent, clay content and WHC, they were negative in case of $\mathrm{pH}$.

The efficiency of fungicide treatments also changed in significant manner in different soils. The correlation between the soil properties and the efficiency, however, was weak.

\section{K. CZAKÓ-VÉR, Zs. KoÓSZ, M. PESTI}

\section{Classical genetic analysis of the Schizosaccharomyces pombe chromium(VI)-sensitive and tolerant mutants} Department of General and Environmental Microbiology, University of Pécs, P.O. Box 266,
H-7601 Pécs, Hungary

Hexavalent chromium(Cr(VI))-sensitive and tolerant mutants were isolated from Schizosaccharomyces pombe strains, with different auxotrophy and mating type. The following mutants were selected: wild-type mutant $\left(\mathrm{CW}-6, \mathrm{lys}^{-}, \mathrm{h}^{+}\right)$, a chromium sensitive (CS-6.51) and a tolerant one (CT-6.66) and other wilde-type strain (CW-9, leu $\left.{ }^{-}, h^{-}\right)$and its tolerant mutant (CT-9.204). For the crosses two wild-type strains with uracil auxotrophy were used (CW-189, ura ${ }^{-} \mathrm{h}^{+}$and $\left.\mathrm{CW}-190, \mathrm{ura}^{-}, \mathrm{h}^{-}\right)$.

The aim of this work was to determine and characterize the gene/genes involved in chromium tolerance and sensitivity. The classical genetical analysis was started with the ploidity test and mating type control, after the control of the spore-forming ability, tetrad analysis was done.

The sporaclones were tested for chromium tolerance and auxotrophy.

(i) CS- $6.51 \times$ CW-9 crosses: analysing 113 tetrads, only $17 \%$ of the sporaclones were viable, one complete tetrad were got, so for the determination of the genetic background this cross was not useful

(ii) CT-6.66 $\times$ CW-9: analysing 40 tetrads in 17 case were 2:2 segregation, 74 wild-type, 51 tolerant and 34 sensitive clones out of 160 clones were got

(iii) CT-6.66 $\times \mathrm{CW}-190$ : 11 out of 27 tetrads were 2:2 segregation, out of 108 sporaclones 42 wild-type, 48 tolerant, 18 not detectable

(iv) CT-9.204 $\times$ CW-189 9 tetrads out of 15 were 2:2 segregation, the clones were all parental ditype

For the transformation 5 clones, with chromium tolerant phenotype and uracil auxotrophy were selected. 


\section{Optimization of the green fluorescent protein (GFP) - blue fluorescent protein (BFP) dual tagging system in plants}

Agricultural Biotechnology Center, P.O.Box 411, H-2101 Gödöllö, Hungary

The green fluorescent protein (GFP) gene from Aequorea victoria has rapidly become of extensive use as a versatile vital marker in various organisms. Its fluorescence can be detected conveniently with non-invasive methods. Applications of fluorescent proteins have expanded greatly due to the availability of GFP mutants with altered spectral properties. One of these is the blue fluorescent protein (BFP) with an emission maximum shifted to shorter wavelength range. While GFP is routinely used in higher plants, there are only few data concerning the use of BFP. These proteins together are used for dual colour tagging experiments in other biological systems, however the benefits of this technique in plants have not been exploited yet.

In this study, our aim was to optimize the GFP-BFP double labelling method in plants. Such system has the capacity for use in virological experiments where the exact localisation of viral components and the kinetics of their expression could be studied. Distinct Nicotiana species were infected by plant virus vectors carrying the GFP or the Y66H type BFP gene. Fluorescence in the epidermal cells was detected with epifluorescence microscopy. While GFP expression level was high in every infected species, the level of BFP expression varied in wide range between the different Nicotiana species. Possible explanations for this phenomenon will also be discussed.

$$
\text { CS. DOBOLYI }{ }^{1} \text {, I. KERESZTÉNYI }{ }^{2} \text {, L. SIMOR JR. }{ }^{2}
$$

Can complementary biological oxidation be applied for treatment of toxic acid tar waste? - A biodegradation test

\footnotetext{
${ }^{1}$ Department of Microbiology, Szent István University, Gödöllö, ${ }^{2}$ Hungarian Oil and Gas Co., Research and Development, Százhalombatta, Hungary
}

The development of the wastewater treatment is one of the most important steps in the course of the modernisation of the Hungarian Oil and Gas Co. (MOL Rt.) Danube Refinery. A lot of wastewater treatment methods should be introduced in order to decrease the level of solved organic materials in the extremely polluted outlet waters of the works. Our goal was to investigate the applicability of the complementary 
biological oxidation that follows the chemical pretreatment of the highly acidic industrial wastewater.

The acid tar is a by-product of paraffin-refinement. It consists of sulphuric acid, sulphonated hydrocarbon fractions and carboxyl acid derivatives. The chemical oxygen demand (COD) of the fluid phase was $30000 \mathrm{mg} / \mathrm{l}$. The chemical treatment was an oxidation with hydrogen peroxide followed by neutralisation. The COD of the fluid phase was reduced to $8800 \mathrm{mg} / \mathrm{l}$ and the total organic carbon (TOC) became $3500 \mathrm{mg} / \mathrm{l}$.

Biological oxidation examination was performed from 2 and 10 times diluted samples of the pretreated water. The inoculum was activated sludge derived from the biological wastewater treatment system of the plant. The degree of biodegradation was determined by measuring COD and TOC.

On the basis of both COD and TOC data substantial differences were found in the extent of degradation by use of the two dilutions. A reduction of $360 \mathrm{mg} / 1 \mathrm{COD}$ (8\%) was found for the 2 times diluted samples, and the reduction of $430 \mathrm{mg} / 1$ (47\%) was found for 10 times diluted samples. The examination of the inhibitory action and the activity of the activated sludge demonstrate that the easily utilisable carbon and energy sources (glucose, acetate) are metabolised by the activated sludge at a high rate, however, their degradation decreased with an increase of a ratio of wastewater.

Processes in the degrading culture were also checked by the measurement of the inorganic carbon content (IC), too. The initial relatively homogenous IC level was reduced except in dishes containing higher amount of wastewater. It means that the possible biological oxidation had already been largely occurred. Provided that the COD is mainly caused by organic compounds the COD/TOC ratio could suggest the biological oxidation of the organic compounds. At the beginning of the experiment the ratio was usually higher than 24 hours later. One day later the biggest change in this ratio was in samples not containing wastewater. However, ratio was hardly reduced when wastewater was present in high volumes, moreover, a slight increase was sometimes found suggesting inhibitory action of wastewater on biological oxidation.

When the dilution was increased the ratios were reduced in greater extent meaning that the biological degrading process can be successful only with the application of at least $10 \times$ dilution. The wastewater system of the refinery possess substantial buffer capacity (even $100 \times$ dilution), thus we think that acid tar wastewater pretreated with chemical oxidation can reach a degree when its toxicity is eliminated. 


\section{T. EMRI ${ }^{1}$, É. LEITER ${ }^{1}$, E. FARKAS ${ }^{2}$, I. PÓCSI ${ }^{1}$}

Effect of the phenoxyacetic acid, phenylacetic acid and their derivatives on the glutathione metabolism and antibiotic production of Penicillium chrysogenum

\footnotetext{
${ }^{1}$ Department of Microbiology and Biotechnology, ${ }^{2}$ Department of Inorganic and Analytical Chemistry, Faculty of Sciences, University of Debrecen, Debrecen, Hungary
}

Although penicillin $\mathrm{G}$ and $\mathrm{V}$ are among the first known antibiotics we still have, surprisingly few data on the metabolism of their side-chain precursors, phenylacetic acid (PA) and phenoxyacetic acid (POA) are available. In this work we studied the effect of PA, POA and their hydroxyl derivatives (2-hydroxy-PA, 3-hydroxy-PA, 4hydroxy-PA, homogentisic acid, protocatechuic acid, 2-hydroxy-POA and 4-hydroxyPOA) on the glutathione (GSH) metabolism and penicillin production of an industrial strain of Penicillium chrysogenum. We also determined their minimal inhibitory concentrations (MIC) and their dissociation constants (pK). The following results were obtained:

1. PA and POA proved to be the most toxic compounds (MIC values $0.36 \%$ and 0.72, respectively). 2-Hydroxy-PA and 2-hydroxy-POA were also toxic (MIC values 0.74 and $0.92 \%$, respectively) but all the others showed only negligible toxicity (MIC values higher than $1.8 \%$ ).

2. Although these compounds are known to be transported into the cells by passive diffusion which depend on their acidity, we did not find any correlation between their toxicity (MIC) and their first dissociation constants. The $\mathrm{pK}_{1}$ values of PA and all the PA derivatives were between 4.08 and 4.25 while in case of POA and its derivatives between 2.77 and 2.93 .

3. The toxic compounds e.g. PA $(0.25 \%)$, POA $(0.5 \%)$ as well as 2-hydroxy-PA $(0.7 \%)$ and 2-hidroxy-POA $(0.7 \%)$ decreased the intracellular level of GSH which is an effective inhibitor of penicillin biosynthetic enzymes. They also induced both glutathione S-transferase and $\gamma$-glutamyl-transpeptidase, the first two enzymes of the GSH-dependent detoxification of xenobiotics. All the other compounds had no any effect on the GSH metabolism at $1 \%$ concentration.

4. Penicillin production did not correlate with either the toxicity of the potential side-chain precursors or their effect on the glutathione metabolism. The highest antibiotic productions were found in the presence of PA (3.8 mol $/ \mathrm{kg}$ protein) and POA ( $3 \mathrm{~mol} / \mathrm{kg}$ protein). Relatively high values were measured with 4 -hydroxy-PA and 4hydroxy-POA as well $(0.9$ and $1 \mathrm{~mol} / \mathrm{kg}$ protein, respectively). With all the other compounds the penicillin productions were less then $0.5 \mathrm{~mol} / \mathrm{kg}$ protein. 
Inhibition of nodulation induced by Rhizobium leguminosarum bv. phaseoli on the root of bean (Phaseolus vulgaris L.) in vivo

Agricultural-, Environmental Microbiology and Soil Biotechnology Ph.D. Subprogram, Szent István University, Budapest, Hungary

Inhibition of nodulation induced by Rhizobium leguminosarum bv. phaseoli strain was examined on the root hair of bean (Phaseolus vulgaris L.).

The seedlings were pretreated with promethazine or trimipramine in different concentrations. The effect of promethazine on the formation of bean root nodules and root hairs were examined in vivo. Promethazine was toxic for the seedlings at 40 $\mu \mathrm{g} / \mathrm{mL}(140 \mu \mathrm{M})$ and trimipramine at $60 \mu \mathrm{g} / \mathrm{mL}(204 \mu \mathrm{M})$.

The dry weight of the root hairs and the number of root nodules $(>5 \mathrm{~mm}$ or 3-5 $\mathrm{mm})$ were decreased significantly. The results demonstrated that the seedlings were more sensitive to the effect of promethazine and trimipramine than the symbiont $\mathrm{N}_{2}$ fixing strain. The Rhizobium-leguminous symbiotic systems may be suitable for testing the pollution of the environment.

$$
\text { Cs. FEKETE }{ }^{1}, \text { K. POSTA }{ }^{2} \text {, L. HORNOK }{ }^{1,2}
$$

\section{Isolation and characterization of a ribosomal protein gene, trp39} from Trichoderma hamatum

\footnotetext{
${ }^{1}$ Agricultural Biotechnology Center, Gödöllö, ${ }^{2}$ Department of Microbiology, Szent István University, Gödöllö, Hungary
}

The antagonistic activity of Trichoderma spp. is attributed to a synergistic combination of mycoparasitism, antibiosis and competition. The saprophytic competitive capability of fungal antagonists plays an important role in the colonization of the ecological niche, suppressing thus the pathogen microorganisms. Despite its importance, the mechanisms responsible for the competitive growth of Trichoderma spp. are not well understood.

The aim of the present study was to identify Trichoderma hamatum genes whose transcription could be induced by nutritional changes. By differential hybridization we created a set of clones and one of them was subjected for further characterization. This clone contained a gene (named trp39) encoding a $60 \mathrm{~S}$ cytoplasmatic ribosomal protein. Sequencing of both a genomic and a cDNA clone 
predicted a 105-aa polypeptide, interrupted by two introns. The deduced TRP39 protein showed high overall identity (55-62\%) to other ribosomal protein genes from $S$. cerevisiae L39 (RPL36) and mammals, including humans. High-stringency Southern analysis confirmed that trp39 is a single copy gene. Sequence analysis of the promoter region of $\operatorname{trp} 39$ revealed the presence of general promoter elements, as well as additional consensus motifs for specific functions, such as RPG-box, T-rich sequence and STRE element. The trp39 gene showed a low level of constitutive expression when glycerol or sorbitol was used as carbon source. It was completely repressed by carbon and nitrogen starvation, by shifting up or down the temperature, as well as after the addition of 2-deoxyglucose to the cultures. In contrast, the level of $\operatorname{trp} 39$ transcripts increased three to fivefold when glucose was added as a sole carbon source. The expression of trp39 was also elevated by adding cycloheximide, 3-isobutyl-1methylxanthine (IBMX) or a cAMP analogue, $\mathrm{N}^{6}, 2^{\prime}-\mathrm{O}-3^{\prime}, 5^{\prime}$-cyclic adenosine monophosphate to the cultures. A similar increase of the gene expression was observed during mycoparasitic interaction, in dual culture tests.

\title{
K. FORGÁCS, B. LENKEY
}

\section{Morphological and physiological changes accompanying the phenomenon of induced fluconazole resistance in Candida albicans}

\author{
Department of Microbiology and Biotechnology, Faculty of Natural Sciences, University of Debrecen, \\ Debrecen, Hungary
}

We investigated a fluconazole-sensitive $\left(\mathrm{MIC}_{\text {fluconazole }} 5 \mu \mathrm{g} / \mathrm{ml}\right)$ clinical isolate (FS) and a fluconazole-resistant ( $\mathrm{MIC}_{\text {fluconazole }}>80 \mu \mathrm{g} / \mathrm{ml}$ ) laboratory mutant Candida albicans strain (FR) developed from the sensitive one. We studied putative virulence factors including germination, adherence ability to either buccal epithelial cells or acrylate surface, the secreted aspartic proteinase (EAP), and the extracellular phospholipase (EP) activity of the two strains as well as their growth. The fluconazoleresistant strain proved to be superior in all the virulence traits tested than the original strain. The higher virulence of the fluconazole-resistant strain was also supported by mouse model. These results suggest that the development of fluconazole resistance can be accompanied by serious morphological and physiological changes: several putative virulence traits, moreover the in vivo virulence can increase simultaneously.

The inducible $\alpha$-glucosidase is usually considered as a potential virulence factor of $C$. albicans but this opinion is not generally accepted. We measured the intracellular and intact-cellular oc-glucosidase activities of the FS and FR strains grown on different 
carbohydrate sources. The expression of two putative virulence factors (EAP and EP) in 20 clinical isolates of $C$. albicans in addition to the intracellular $\alpha$-glucosidase activities was also investigated. Neither the physiological and enzymological studies on the $\alpha$-glucosidases of the FR and FS strain nor the correlation studies between the $\alpha$ glucosidase, EAP and EP activities of clinical isolates of $C$. albicans supported the view that the inducible $\alpha$-glucosidase might be associated with the virulence of $C$. albicans.

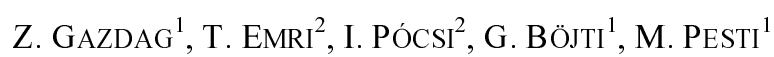

\section{Effect of altered glutathione and glutathione metabolism enzymes activities on chromate and cadmium sensitivity and tolerance of Schizosaccharomyces pombe}

\footnotetext{
${ }^{1}$ Department of General and Environmental Microbiology, University of Pécs, P.O.Box 266, H-7601 Pécs, Hungary, ${ }^{2}$ Department of Microbiology and Biotechnology, Kossuth Lajos University, Debrecen, Hungary
}

A Cr(VI) sensitive mutant CS-6.51 and a tolerant mutant CT-6.66 was obtained from wild-type strain CW-6 of Schizosaccharomyces pombe by induced mutagenesis.

The pretreatment of strains with subinhibitory concentrations of $\mathrm{Cr}(\mathrm{VI})$ did not raise the survival rate of cells after treatment with higher concentrations of $\mathrm{Cr}(\mathrm{VI})$, in fact it was decreased in the cases of wild-type strain CW-6, sensitive CS-6.51 and tolerant CT-6.66 mutants.

The glutathione (GSH) reducing effect of $\mathrm{Cd}^{2+}$ is well known. The $\mathrm{CdCl}_{2}$ pretreatment with subinhibitory concentration lowered the destructive effects of $\mathrm{Cr}(\mathrm{VI})$ at 100,250 and $500 \mu \mathrm{M}$ concentrations.

The above-mentioned three strains exhibit different sensitivity to the same $\mathrm{CdCl}_{2}$ concentration and it can be attributed to the different GSH concentrations. The tolerant mutant CT-6.66 containing the lowest amount of GSH is the most sensitive to $\mathrm{Cd}^{2+}$ stress.

The significantly higher GR, G6PD enzyme activities and NADPH concentration in the sensitive CS-6.51 mutant together result in an effective $\mathrm{Cr}(\mathrm{VI})$ reduction compared to the wild-type strain $\mathrm{CW}-6$; and contribute to an increased generation of ' $\mathrm{OH}$.

The low GR level of the tolerant mutant CT-6.66 compared to the wild-type strain CW-6 can be explained by the low level of GSH.

The changed sensitivity that we are going to study further can be explained by the changed elements of oxido-reductive homeostasis as well as by the reactive oxygen radicals. 


\section{Z. GAZDAG ${ }^{1}$, T. EMRI ${ }^{2}$, ZS. FEKETE ${ }^{1}$, I. PÓCSI ${ }^{2}$, M. PESTI $^{1}$}

Effect of altered antioxidant enzymes activities and reactive oxygen species production on stress tolerance of fission yeast

${ }^{1}$ Department of General and Environmental Microbiology, University of Pécs, P.O. Box 266, H-7601

Pécs, Hungary, ${ }^{2}$ Department of Microbiology and Biotechnology, Kossuth Lajos University, Debrecen,

Hungary

In our experiments, Cr(VI) sensitive CS-6.51 and tolerant mutant CT-6.66 of Schizosaccharomyces pombe obtained by means of mutagenesis were used.

Results of the sensitive CS-6.51 and the tolerant mutants CT-6.66 are compared to that of the original parent wild-type strain CW-6. The $\mathrm{CrO}_{4}$-isotope uptake is significantly higher in the sensitive mutant CS-6.51 than in the $\mathrm{Cr}(\mathrm{VI})$ tolerant mutant CT-6.66 and wild-type strain CW-6, where the uptake of $\mathrm{CrO}_{4}$ isotope is approximately the same.

The high level of superoxide radical $\left(\mathrm{O}_{2}{ }^{\prime}\right)$ of the tolerant mutant CT-6.66 can be explained by a significantly lower mitochondrial MnSOD activity.

The unchanged activity of catalase and SOD in case of high $\mathrm{H}_{2} \mathrm{O}_{2}$ and superoxide concentration in sensitive mutant CS-6.51 can be explained by the downregulation of these enzymes.

The response of sensitive mutants to outer oxidative stress is almost the same as that of the wild strain.

The $\mathrm{H}_{2} \mathrm{O}_{2}$ concentration and the catalase activity in tolerant mutant CT-6.66 exhibited no significant difference from those of the wild-type strain CW-6, however, the tolerant mutant showed extreme sensitivity to outer treatment with $\mathrm{H}_{2} \mathrm{O}_{2}$ and menadione.

The measurement of $\mathrm{OH}$ generation with $\mathrm{EPR}$ is in progress.

\section{A. GÁCSER, I. PFEIFFER, J. KUCSERA}

\section{Organisation of the its region in isolates of Cryptococcus hungaricus}

Department of Microbiology, University of Szeged, Szeged, Hungary

Basidiomycetes yeasts are important sources for bioactive compounds, i.e. pigments, antioxidants and lipids. The anamorphic Cryptococcus hungaricus described by Zsolt (1957) has reddish colonies due to carotenoid pigments of unknown constitution. 
We previously reported that $C$. hungaricus strains derived from various geographic area were polymorphic evidenced by studies based on physiological, biochemical and RFLP analysis (Gácser et al. 1999).

In the present study the ITS region of the ribosomal DNA in the strains CBS 4214, CBS 5124, CBS 6324, CBS 6569, CBS 6576, CBS 6953 were amplified by PCR. ITS 4 (5'-TCCTCCGCTTATTGATATGC-3') and ITS 1 (5'TCCGTAGGTGAACCTGCGG-3') were used as primers. The PCR products were subjected to restriction enzyme digestions (EcoRI, HhaI, HaeIII, and double digestion with EcoRI-HhaI). The size of the ITS regions proved to be 527 bp for CBS 4214, 559 bp for CBS 5124, 594 bp for CBS 6324, 645 bp for CBS 6569, 595 bp for CBS 6576 and 579 bp for CBS 6953. The DNA patterns of this region in CBS 6324 and CBS 6576 were identical all enzymes CBS 6569 exhibited different RFLP patterns, and significant differences in size (645 bp). The amplified ITS region of strain CBS 4214 was the smallest (527 bp), but its RFLP patterns were similar to CBS 5124, CBS 6324, CBS 6576 and CBS 6953. The nucleotide sequences of the amplified ITS regions are determined. The present study confirmed previous results, that all the strains differed from the type strains although CBS 6324 and CBS 6576 were closely related.

This work was financially supported by OTKA grant T025849 and FKFP 0218/97.

1. Zsolt, J.: A new yeast Dioszegia hungarica nov gen et sp. Botanikai Közl 47, 6-66 (1957). 2. Gácser, A., Pfeiffer, I., Kucsera, J.: Molecular and phenotypic characterization of Cryptococcus hungaricus isolates. Acta Microbiol Hung 46, 133 (1999).

$$
\text { G. GICZEY }{ }^{1} \text {, Z. KERÉNYI }{ }^{1} \text {, L. FÜLÖP }{ }^{2} \text {, L. HORNOK }{ }^{1,2}
$$

\section{The expression pattern of $c m g 1$, an exo- $\beta-1,3-$ glucanase gene of the mycoparasite, Coniothyrium minitans}

\footnotetext{
${ }^{1}$ Agricultural Biotechnology Center, Gödöllö, ${ }^{2}$ Szent István University, Gödöllö, Hungary
}

Coniothyrium minitans is a sclerotial mycoparasite of a number of plant pathogenic fungi. Due to this capability, the fungus is used in biological plant disease control. Information on the molecular mechanisms responsible for its parasitic activity is, however rather limited. During parasitism, the fungus penetrates through the sclerotial wall that contains $\beta-1,3$-glucan as a major constituent. The production of extracellular cell wall degrading enzymes, such as chitinases and glucanases appears to 
be an important factor for mycoparasitic fungi to facilitate penetration through host structures.

In the present work a PCR based strategy was applied to clone a $\beta$-1,3-glucanase encoding gene from $C$. minitans. Using degenerate oligonucleotide primers constructed on the basis of conserved regions of known fungal glucanases we isolated a full length cDNA copy of a putative glucanase gene, named $\mathrm{cmg} 1$. The nucleotide sequence of this gene and its deduced amino acid sequence was found to show high levels of similarity to fungal exo- $\beta-1,3$-glucanases. The $\mathrm{cmgl}$ gene codes for a protein of 782 amino acids. A signal peptid cleavage site is predicted between residues 24 and 25 by the SignalP program. The calculated molecular mass of the secreted protein is $82,346 \mathrm{Da}$ and its estimated pI point is 4.73 . The INVSc1 strain of Saccharomyces cerevisiae, used as heterologous expression host for $\mathrm{cmgl}$, secreted a $\sim 100 \mathrm{kDa} \beta$-1,3-glucanase enzyme (as determined by SDS-PAGE) into the culture medium. Temperature and $\mathrm{pH}$ optima of the recombinant enzyme purified from the yeast culture supernatant by ion exchange chromatography were $50{ }^{\circ} \mathrm{C}$ and $\mathrm{pH} 5.2$, respectively. Substrate specificity and hydrolysis product analyses revealed that the enzyme is an exo-acting glucanase with high specificity to $(1 \rightarrow 3)$ - $\beta$-glycosyl linkages.

The $\mathrm{cmgl}$ gene which is present in the genome of C. minitans in a single copy showed a low level of constitutive expression in in vitro shaken cultures. It is slightly repressed by glucose and induced by carbon starvation, sorbitol, as well as ground or intact sclerotia of Sclerotinia sclerotiorum to a similar extent. A moderate increase in the expression of cmgl was observed during the parasitic interaction with $S$. sclerotiorum suggesting the role of this gene in mycoparasitism.

\section{Zs. HAMARI, Á. JUHÁSZ, F. KEVEI}

\section{Incompatibility influences the effectivity of mitochondrial transmissions}

Department of Microbiology, Faculty of Sciences, University of Szeged, P.O. Box 533, H-6701 Szeged, Hungary

The mitochondrial genomes of the strains $A$. japonicus belonging to the imperfect black Aspergilli exhibit highly variable RFLP patterns. Transmissions of mitochondria were carried out between fully incompatible mitochondrial oligomycin resistant mutant (oliR) strain as donor and sensitive recipient strains carrying mtDNAs with different RFLP patterns by using protoplast fusion technique. These transfer experiments resulted in oliR progeny with recombinant and/or unchanged donor (substituted) mtDNA in each case of intraspecific combinations, but it failed when the 
closely related $A$. aculeatus was the recipient partner. Transmissions can be classified into three groups: (i) progeny with recombinant type of mitochondria only, (ii) progeny with exclusively substituted mitochondria, (iii) both types of progeny, predominantly the substituted one can be recovered. In the last case, the strains carrying substituted mitochondria display reduced fitness with appearance of decreased capacity of conidial formation. During subsequent cultivation of these oliR substituted strains a segregation process could be following resulted in morphologically stable strains with recovered fitness. These well-growing strains possess recombinant mtDNAs. With full knowledge of size differences of the donor and recombinant mtDNAs it can be concluded that intron loss itself can generate the recombinant characters. Our results might reflect the compatibility relations between strains involved in a mitochondrial transmission.

This work was financially supported by OTKA grant T025849 and FKFP 0218/97.

\section{Hegedüs ${ }^{1}$, M. KÖRSCHENS ${ }^{2}$, E. M. KLIMANEK ${ }^{3}$, N. NARUlA ${ }^{4}$, W. MERBACH${ }^{4}$, B. TóTH ${ }^{1}$}

\section{Soil microbiological effects in long-term experiments of Keszthely and Bad Lauchstädt}

\footnotetext{
${ }^{1}$ University of Veszprém, Georgikon Faculty of Agronomy, Chemical and Microbiological Department, Deák F. u. 16, H-8360 Keszthely, Hungary, ${ }^{2}$ UFZ-Centre for Environmental Research Leipzig-Halle GmbH, Hallesche Str. 44, 06246 Bad Lauchstadt, Germany, ${ }^{3}$ UFZ-Centre for Environmental Research Leipzig-Halle GmbH, Theodor-Lieser-Str. 4, 06120 Halle/Saale, Germany, ${ }^{4}$ Martin-Luther-Universität, Halle-Wittenberg, Landwirtschaftliche Fakultät Institut für Bodenkunde und Pflanzenernahrung, Adam-Kuckhoff-Str. 17b, 06108 Halle/Saale, Germany
}

In two long-term field trials in which farmyard manure (FYM) and artificial fertilizers were compared, we analysed soil microbial biomass, respiration, organic carbon $\left(\mathrm{C}_{\mathrm{o}}\right)$ content, total microbiological count and microbial activity (enzymatic activities for example: protease, alkaline phosphatase, $\beta$-glucosidase). The treatments included: 1. unmanured controls (O), 2. manured (FYM), 3. artificial fertilizers (NPK), 4. FYM + NPK together and different fallows (1. mechanical bare fallow, 2. bare fallow with herbicides, 3. mechanical bare fallow + herbicides and 4. green fallow).

Used methods: for enzymatic activities, for soil microbial biomass and respiration by K. Alef and P. Nannipieri (1995), for total microbiological count by R. Gahlot and N. Narula (1996), for organic carbon content by "Deutsche Einheitsverfahren zur Wasser-, Abwasser- und Schlamm-Untersuchung" (1998). 
The long-term experimental plots were set on in 1902 in case of Bad Lauchstädt (Germany, $11^{\circ} 53^{\prime}$ East, 51 24 ' North, $113 \mathrm{~m}$ above SL) and in 1963 in case of Keszthely (Hungary, $17^{\circ} 15^{\prime}$ East, $46^{\circ} 47^{\prime}$ North, $112 \mathrm{~m}$ above SL). Both of the longterm experimental fields are used for studying the interrelation between soil, plant, microbiological flora, atmosphere and water with regard to sustainable development. The running long-term field experiments are an ideal experimental basis for this research.

Soil samples were collected in March 2000 in case of the two long-term experiments from $30 \mathrm{~cm}$ soil depth.

Biological and chemical measurements were made in laboratories of UFZUmweltforschungszentrum Leipzig-Halle GmbH, Sektion Bodenforschung, microbiological measurements in laboratory of Martin-Luther-Universität, HalleWittenberg, Landwirtschaftliche Fakultät Institut für Bodenkunde und Pflanzenernahrung (Germany).

Our results indicate a strong correlation among the various properties. Organic carbon has positive influence on microbiological flora of various samples from the long-term experiments of both sites. Soil enzymes determined quantitatively represent various metabolic activities in combination with other properties in long-term fertilized soils and further studies will clearly show an understanding of cultivation practices, agrochemical and environmental effects in these soils.

1. Alef, K., Nannipieri, P.: Methods in Applied Soil Microbiology and Biochemistry. Academic Press London, 1995. p. 313, 338, 351, 397. 2. Gahlot, R., Narula, N.: Degradation of 2,4-Dichlorophenoxy Acetic Acid by Resistant Strains of Azotobacter Chroococcum, in Indian Journal of Microbiology Vol 36, September 1996, pp 141-143 (1996). 3. Deutsche Einheitsverfahren zur Wasser-, Abwasser- und SchlammUntersuchung. Wiley-VCH GmbH, Band III. H3. 1998.

\section{HORNOK}

\section{Research challenges for the development of genetically modified biocontrol microorganisms} Department of Microbiology, Agricultural Biotechnology Center and Szent István University, Gödöllö,
Hungary

Biological control could be an environmentally feasible alternative of chemical plant protection used nowadays almost exclusively in large-scale agricultural practice. However, biological control methods should be improved in efficiency and reliability. One of the means by which the effectiveness of biological control could be increased is 
the construction of genetically improved antagonistic-hyperparasitic microorganisms. In the past few years, efficient strain-breeding strategies suitable for improving plant growth promoting rhizobacteria were developed. Antagonistic and symbiotic properties were successfully combined into a single organism. Genetically engineered strains were produced to eliminate the gene drift hazards or to improve the aggressiveness of fungal hyperparasites. Although perspectives of the practical application of genetically modified biocontrol microorganisms are still uncertain, at least in Europe, a better understanding of the molecular background of the hyperparasitic way of living could help to manage and utilize the natural antagonist populations.

\title{
R. IZADPANAH ${ }^{1,4}$, Á. DÁN ${ }^{2,3}$, M. BENKÖ ${ }^{2}$, M. RUSVAI ${ }^{1}$, L. FODOR ${ }^{1}$, B. HARRACH ${ }^{2}$ \\ DNA sequence of a small, unidentified plasmid isolated from a Haemophilus somnus strain
}

\author{
${ }^{1}$ Department of Microbiology and Infectious Diseases, Faculty of Veterinary Science, Szent István \\ University, Budapest, ${ }^{2}$ Veterinary Medical Research Institute, Hungarian Academy of Sciences, \\ Budapest, ${ }^{3}$ Central Veterinary Institute, Budapest, Hungary, ${ }^{4}$ RAZI Vaccine and Serum Research \\ Institute, Teheran, Iran
}

One of the plasmids present in a Haemophilus somnus (H. somnus) strain isolated from nasal discharge of a cattle with respiratory disease symptoms was purified and cloned for DNA sequencing. The copy number of the plasmid was enough to use alkaline lysis method for DNA plasmid purification, which is widely used for high-copy-number cloning vectors of E. coli. The plasmid was found to be 1065 base pairs long and with $39.2 \% \mathrm{G}+\mathrm{C}$ content. Homology search failed to find any similar DNA in the nucleic sequence data bases. The longest putative open reading frame was 261 pairs long. Based on the location of possible translation initiation codons, there is a theoretical possibility on this plasmid to code for a protein of 43 amino acids. The homology search, however, showed no significant similarity with the presently available protein data.

Presence of plasmids in H. somnus was detected by some authors (Fussing and Wegener, 1993; Appuhamy et al., 1998) but this is the first report on the sequencing and DNA analysis of one of the plasmids.

This work was supported by Hungarian Scientific Research Fund grants OTKA T026604, T021060, M027651. 


\section{P. JAMNIK, M. BATIČ, P. RASPOR}

\section{Model for determination of yeast viability/mortality in the presence of chromium(VI) compounds}

Biotechnical Faculty, University of Ljubljana, Jamnikarjeva 101, 1001 Ljubljana, Slovenia

The viability vs. mortality of yeasts Saccharomyces cerevisiae - ZIM 321 and Schwanniomyces occidentalis - ZIM 763 in the presence of $\mathrm{K}_{2} \mathrm{Cr}_{2} \mathrm{O}_{7}$ was studied. After cultivating in malth broth the yeasts were exposed to the $\mathrm{Cr}(\mathrm{VI})$ in concentrations of 1 , 10,100 in $1000 \mu \mathrm{mol} / 1$ for 24 hours at $28{ }^{\circ} \mathrm{C}$. The survival of living cells depends on their ability to sense changes in the environment and to appropriately respond to the newly emerged conditions [1]. Stress response mechanisms aim to protect cells against the potentially detrimental effects of stress challenges and to repair any molecular damage [1]. Determination of yeast viability vs. mortality in the presence of specific effector $\mathrm{Cr}(\mathrm{VI})$ was followed in each particular step of the analytical procedure and a mathematical model-a set of equations was developed with the intention to establish a rational tool for analysing the impact of the effector. The model was built with parameters as follows: Population Condition (PC), Cell Viability in the Buffer (VB), Cell Viability in the Buffer supplemented with the Effector (VEB), Specific Cell Viability (Vs), Cell Mortality in the Buffer (MB), Cell Mortality in the Buffer supplemented with the Effector (MEB) and Specific Cell Mortality (Ms) [2]. The model was shown to be useful. It enabled to determine the difference in yeast tolerance to $\mathrm{Cr}(\mathrm{VI})$. The results showed that Sacch. cerevisiae - ZIM 321 is more tolerant to $\mathrm{K}_{2} \mathrm{Cr}_{2} \mathrm{O}_{7}$ than Schwann. occidentalis - ZIM 763.

1. Hohmann, S., Mager, W. H.: Yeast Stress Responses. Springer Verlag, Heidelberg. 1997. pp. 1-3, 176, 183. 2. Raspor, P., Batitt, M., Jamnik, P.: Food Technology and Biotechnology 37(2), 81-86 (1999). 


\section{JEVCSÁK ${ }^{1}$, L. KÖDÖBÖCZ ${ }^{1}$, M. KECSKÉS ${ }^{1}$, T. SZILI-KOVÁCS ${ }^{2}$, B. BIRÓ \\ Microbial characteristics of pea rhizosphere affected by sewage sludge doses in some Hungarian soil types}

${ }^{1}$ Szent István University, Gödöllő, Ph.D. Subprogram, Budapest, ${ }^{2}$ Research Institute for Soil Science and Agricultural Chemistry of the Hungarian Academy of Sciences, Budapest, Hungary

Municipal sludge of the Gödöllö community (Hungary) with a high Zn content was used in a long-term pot experiment to study some microbiological characteristics of the pea (Pisum sativum L.) rhizosphere.

Four Hungarian soil types were selected (carboneaceous chernozem Nagyhörcsök, carbonaceous sandy soil - Örbottyán, slightly acidic silty soil of Gyöngyös and acidic sandy soil of Nyírlugos). Colony forming units (CFU ml ${ }^{-1}$ ) of some most important microbiological groups (such as Pseudomonas, Rhizobium or the total countable number) were assessed by a modified plate counting method of Angerer et al. (1998) by using Congo-red YEM, King B and Nutrient media. Biochemical characterization of the pea rhizosphere was done by chloroform fumigation procedure of biomass-C measurements (Vance et al. 1998). Metal $\left(\mathrm{Zn}\left(\mathrm{NO}_{3}\right)_{2}\right.$ and $\left.\mathrm{ZnSO}_{4}\right)$ tolerance of some Pseudomonas strains were also tested in vitro by using $25,50,100$, $200,300 \mu \mathrm{M} \mathrm{l}^{-1}$ salts in three replications.

Influence of the increasing doses of communal sewage sludge on the microbiological and biochemical characteristics was highly depending on the physical and chemical properties of the soil-types investigated. There was a positive correlation between the application rates of the sludge and the total microbial counts or the microbial biomass parameters, especially in case of the nutrient poor sandy soils. There was no much relation, however, between the number of the total countable microbes and the microbial biomass measurements, due to the high dependence on the mediumcomponents ( $\mathrm{C}$ and $\mathrm{N}$ sources) in connection with the culturability.

Pseudomonas bacteria originating from the highest doses of $\mathrm{Zn}$ pollution showed a better in vitro resistance to the investigated $\mathrm{Zn}$-salts, compared those strains from the unpolluted pots (in accordance with the preliminary results of Kecskés et al. 1997).

Although the total $\mathrm{Zn}$ concentration at the highest sewage sludge rates was still well below the international permissible standards, there was an adverse effect recorded on the selection pressure and adaptability of some beneficial microbial groups.

Financial support of the Hungarian Research Fund is highly acknowledged (TO 30941).

1 Vance, E. D. et al.: Soil Biology and Biochemistry 19, 703-707 (1987). 2 Angerer, I. et al: Agrokém Talajt 47, 297-305 (1998). 3 Kecskés, M. et al.: Acta Aliment 26, 313-315 (1997). 


\section{Interaction between mitochondria in black Aspergilli}

Department of Microbiology, Faculty of Sciences, University of Szeged, P.O. Box 533, H-6701 Szeged, Hungary

In contrast to the nuclear genome the mtDNA does not undergo recombination process during sexual cycle owing to uniparental inheritance of extrachromosomal elements.

In case of asexual black Aspergillus strains bearing mitochondria with different molecular and resistance markers (such as mtDNA RFLPs and oligomycin resistance) a mixed population of extrachromosomal elements could be established under experimental conditions. Since black Aspergilli exhibit high degree of vegetative incompatibility their mitochondria were transferred by protoplast fusion, applying donor strains with oligomycin resistant mitochondria and sensitive recipient partner. The results of intraspecific mitochondrial transmission between $A$. niger strains, and $A$. japonicus isolates, as well as interspecific transfer between $A$. niger and $A$. tubingensis strains will be discussed. Selecting for the drug resistance and the recipient nuclear phenotype oligomycin resistant progenies were recovered. These strains basically inherited the mitochondrial DNA of the donor strain, which might remain unchanged (so-called substituted progeny) or might be modified by specific sequences of the recipient mtDNAs named recombinant mitochondria. The sequences originated from the recipient proved to be mobile introns. Substituted progeny would be either stable wild type like strain as a result of compatible co-operation between donor mitochondria and recipient nuclei, or occurred as slow growing non-conidiating strains. The latter type was probably due to the less compatible communication between two genetic systems originating from different parents. These progenies were able to undergo some segregation process during subsequent cultivation resulting in a stable wild phenotype which possessed new mtDNA type resembling to the acceptor parents. Different mobile elements characteristic for recipient parents were exclusively responsible for development of the feature of recombinant mtDNAs.

This work was financially supported by OTKA grant T025849 and FKFP 0218/97. 


\section{G. KISKÓ ${ }^{1}$, K. KAFFKA ${ }^{2}$, H. DAOOD ${ }^{3}$ \\ Investigation for mould contamination of tomato purée by NIR spectroscopy}

${ }^{1}$ Department of Microbiology and Biotechnology, ${ }^{2}$ Department of Refrigeration and Livestock Products Technology, Faculty of Food Science, Szent István University, Budapest, ${ }^{3}$ Department of Lipid Chemistry, Central Food Research Institute, Budapest, Hungary

In the industrial practice Howard mould count (1911) is used for the estimation of mould contamination of foods. It was developed originally for investigation of tomato products. It is also used nowadays for quality control purposes. Recently this constitutes the basis of the acceptance of the finished products in international trade. This technique demands experts with a lot of practice and morphological proficiency. Variation coefficient of the method is $15 \%$ or even higher.

The possibility of the determination of mould contamination of tomato puree was investigated aiming at exchanging the Howard method. The NIR technique - as a rapid, non-destructive, reagentless and accurate method - was anticipated as a suitable method for the purpose mentioned. Canned tomato puree had been allowed to become mouldy than the sample was blended with non mouldy samples in different ratio, so a series of tomato-purees containing known amounts of mouldy puree was prepared. Howard mould counts and ergosterol content - another mould contamination relating value - were used as reference values for NIR calibration.

At quantitative investigation better results were obtained using ergosterol values. The best correlation coefficient $(\mathrm{R}=0.94)$ and the smallest standard error of calibration ( $\mathrm{SEC}=0.076 \mathrm{mg} / \mathrm{g}$ ergosterol) was achieved with triangular smoothing of the spectra. The standard error of prediction ( $\mathrm{SEP}=0.10 \mathrm{mg} / \mathrm{g}$ ergosterol) was acceptable. At qualitative investigation Polar Qualification System (PQS) was used. Clusters between samples with low and high ergosterol levels could be separated.

\section{K. KISS ${ }^{1}, \mathrm{~K} . \mathrm{LÁSZLÓ}^{2}$}

\section{Effect of municipal sewage sludge on the phosphatase and catalase} activity of Raman-type brown forest soil

${ }^{1}$ BIOGEN, Tapolca, ${ }^{2}$ Georgikon Faculty of Agronomy, University of Veszprém, Keszthely, Hungary

In the agricultural practice municipal sewage sludge is frequently used as a soil fertilizer. It improves the physical and chemical properties of the through the addition 
of organic matter and essential nutrients, but it may cause serious ecological and hygienic problems because of its elevated concentrations of pollutants including heavy metals. The measurement of metabolic activity of microbial communities - like the measurement of enzyme activity - gives an immediate indication of the effects of perturbations on the community.

The purpose of our study was to check the effect of different concentrations of sewage sludge on the phosphatase and catalase activity of microbial communities in the soil, and to compare how can these two enzyme activities characterize the changes.

Municipal sewage sludge was obtained from the Regional Wastewater Treatment Plant, Keszthely. A subsample was digested and analysed for the total chemical content. The results: $\mathrm{pH}: 5.8$, total solids: $0.10 \mathrm{~kg} / \mathrm{kg}, \mathrm{N}: 29400, \mathrm{P}: 6810, \mathrm{~K}$ : 3470, Pb: 61, Cd 2.9, Zn: 1319, Cu: 147, Mn: 349, Cr: 30 mg/kg dry weight.

The Raman type brown forest soil was treated with different quantities of wet sewage sludge which were equal to the level of $0 ; 2.5 ; 5 ; 10 ; 20$; and 40 t/ha dry sewage sludge. In small pots the samples were incubated at $25^{\circ} \mathrm{C}$ for $1,3,8,12$ and 20 days, and the phosphatase and catalase activity were measured by photometry and titrimetry. The results were analysed mathematically.

During the whole experimental time there were significant differences at $95 \%$ confidence level in all phosphatase activity among the soils for all sludge amounts added. Expressed as percentages of control activity, the phosphatase activity ranged from 153 to $310 \%$ as for the highest concentration. Therefore the municipal sewage sludge proved to be absolutely innocuous. The results showed that the sewage sludge improved the microbial processes because of its own population and the nutrient contents.

The measure of catalase activity didn't prove to be a sensitive method for characterizing the microbial processes. There was no connection between the concentration of municipal sewage sludge and catalase activity.

\section{T. KLEFFLER, A. MARÁZ}

\section{Monitoring diversity of yeast biota from vineyard to wine}

Department of Microbiology and Biotechnology, Faculty of Food Science, Szent István University, Budapest, Hungary

In the oenological microbiology, several publications surveyed the composition of yeast biota occurring in different vineyards and grape-processing equipments. We have a lot of information about the change of the yeast diversity at species level and the 
process of their succession from must to wine. Diversity of yeasts is also big in vineyards but it is changing from field to field and from year to year. There are few results, however, about the origin of yeasts and how much they represent the yeast biota of a vineyard or cellar. One of the reasons is that the traditional identification, using morphological, biochemical and physiological tests is not suitable for characterisation at strain level. Molecular typing methods are excellent, however, for such purposes.

The aims of our research were to survey and characterize yeast biota in vineyard Etyek from the beginning of grape ripening; the study of the origin and dynamics of yeasts starting and implementing must fermentation; and to examine the interaction of the starter yeast culture and spontaneous yeast biota.

The origin of the isolates was the vineyard and pre-processing equipments in Etyek and wine factory in Budafok, using active dry Saccharomyces cerevisiae starter cultures. We collected samples before and after vintage, and followed the spontaneous and inoculated fermentations. Our isolates were identified at species level by traditional identification methods. The similarity of the strains and typing at species level were examined by molecular genotyping methods, such as RAPD-PCR, pulsed field gel electrophoresis and RFLP of rDNA sequences.

Several yeasts were found in the cleaned equipments before vintage, which probably survived there. The basidiomycetes Cryptococcus laurentii and Sporidiobolus salmonicolor were dominant.

The number of yeast cells increased by about two-three order of magnitude during vintage but the wide biodiversity still remained. Sp. salmonicolor still occurred among them, but the ascomycetes Debariomyces, Hanseniaspora and Saccharomyces genera became dominant.

In the grape juice Hanseniaspora uvarum was the dominating species and we found several Saccharomyces ludwigii and Candida apicola isolates, too. At the beginning of fermentation, Torulaspora occurred in the highest ratio, beside the dominant Saccharomyces sensu stricto species. In the middle and last fermentation phase, we found Saccharomyces sensu stricto species only.

With the application of molecular typing methods, we determined the similarity of strains belonging to a given species, and detected yeasts strains, which survived in the processing equipments. These methods proved very useful in monitoring the succession of yeasts during spontaneous and inoculated fermentations.

This work was supported by MKM FKFP No.1121/1997 Hungarian project. 


\title{
L. KÖDÖBÖCZ ${ }^{1}$, I. JEVCSÁK ${ }^{1}$, B. BIRÓ ${ }^{2}$, H.E.A.F. BAYOUMI ${ }^{1}$, M. KECSKÉS ${ }^{1}$ \\ Comparison of the antibiotic-sensitivity of lupine rhizobia originating from different agrotechnical systems
}

\author{
${ }^{1}$ Szent István University, Ph.D. Subprogram, Budapest, ${ }^{2}$ Research Institute for Soil Science \\ and Agricultural Chemistry of the Hungarian Academy of Sciences, Budapest, Hungary
}

Various agrotechnical conditions (such as organic and conventional) may influence the functioning and stress-tolerance ability of the different soil-plant systems. Among the main environmental factors the antibiotic sensitivity may reflect the interactions of the microbial populations.

30 Bradyrhizobium sp. strains, originating from the root-nodules of sweet lupine (Lupinus albus L.) were investigated for their antibiotic sensitivity in in vitro conditions. 19 strains were isolated from the traditional crop-rotation experiment of Westsik, started in 1929 on the slightly acidic sandy soil of Nyírség (Lazányi, 1994). Other strains were originating from the same hosts, grown in an intensive agricultural system (with the originally high amounts of agrochemicals and fertilizers). Yeastmannitol-agar (YMA) plates were used to study the sensitivity of seeded lupine rhizobia (100 $\mu \mathrm{l}$ of $10^{6} \mathrm{CFU} \mathrm{ml}^{-1}$ ) against 10 different antibiotics (RESISTEST discs) in 3 replicates. After 24 hours of incubation at $28{ }^{\circ} \mathrm{C}$, the inhibition zones were registered (Vincent 1970). Results were subjected to two ways of ANOVA investigations.

A much higher availability and dimension of antibiotic sensitivity was found with the 19 Bradyrhizobium strains of the Westsik organic crop-rotation systems. This phenomenon was highly influenced by the different organic treatments of the XV plots, which has resulted a great variation of the general soil conditions, as a consequence. Biomass production, symbiotic characteristics and nitrogen-fixing effectiveness produced the same diversity of data in an earlier study (Ködöböcz et al. 1999).

In the intensive agrotechnical systems, therefore, the isolated lupine rhizobia were found to be identical for the general antibiotic sensitivity, which reflects a reduced diversity of the population and the selection of antibiotic-resistant lines. Westsik organic treatments, however have preserved the natural genetical balance of the lupine rhizobia. Interrelations between the antibiotic sensitivity and the nodulation and nitrogen-fixation ability is further discussed.

Relevance of the organic systems to preserve the natural biodiversity of beneficial microbes (nitrogen-fixing rhizobia) is highlighted from this study.

Financial support of the Hungarian Research Fund (OTKA) is acknowledged (T0 23543). 
1. Biró, B.: Ph. D. dissertation and thesis. GATE, Gödöllő (1980). 2. Lazányi, J.: Productivity of the crop-rotation systems in a slightly acidic sandy soil. (in hungarian). DATE, K.K., Nyíregyháza, (1994). 3. Vincent, J. M.: A manual for the practical study of root nodule bacteria. IBP Handbook, Oxford, (1970). 4. Ködöböcz, L. et al., In Sikolya, L. (ed.): 8. Annual Meeting of the SZ. SZ. B. M. T. T. Rim Nyomda, Nyíregyháza. 1999.

\section{KREDICs ${ }^{1}$, I. DÓCZI ${ }^{1}, Z_{\text {S. ANTAL }}^{2}$, L. MANCZINGER ${ }^{1}$ \\ Influence of heavy metals on mycelial growth and in vitro enzyme activities of mycoparasitic Trichoderma strains}

\footnotetext{
${ }^{1}$ Department of Microbiology, Faculty of Sciences, University of Szeged, ${ }^{2}$ Research Group for Microbiology, Hungarian Academy of Sciences and University of Szeged, Szeged, Hungary
}

The effect of ten heavy metals (aluminium, copper, nickel, cobalt, cadmium, zinc, manganese, lead, mercury and iron) on the linear mycelial growth, and on the in vitro activities of extracellular enzymes involved in antagonism against plant pathogenic fungi ( $\beta$-glucosidase, cellobiohydrolase, endocellulase, $\beta$-xylosidase, endoxylanase, $\beta$-1,4-N-acetylglucosaminidase, trypsin-like protease, chymotrypsin-like protease, and $\beta$-1,3-glucanase) was studied in case of six Trichoderma strains belonging to species groups T. harzianum, T. viride and T. aureoviride. Each particular heavy metal inhibited mycelial growth in all six strains to a similar extent, significant variation of $\mathrm{IC}_{50}$ concentrations between the strains was found only in case of iron. In a concentration of $1 \mathrm{mmol}$, only mercury showed high inhibitory effects on the in vitro activities of the investigated enzymes, the inhibition of enzyme activities by the other heavy metals was not so expressed. However, the slight inhibition of trypsin- and chymotrypsin-like activities by aluminium, copper, and lead should be mentioned. Extracellular enzymes seem to remain active even at heavy metal concentrations, where mycelial growth is already strongly inhibited. This suggests the possibility of breeding for heavy metal resistant Trichoderma strains for biocontrol purposes in soils with heavy metal contamination or for combined application with heavy-metal containing pesticides.

This work was supported financially by grant T025849 of the Hungarian Scientific Research Fund and FKFP-0218/97 of the Hungarian Ministry of Education. 


\section{J. KROMMER ${ }^{1}$, G. SZABÓ ${ }^{1}$, I. KISS ${ }^{2}$}

\section{Effect of nisin on the microbial stability of sausages}

${ }^{1}$ Hungarian Meat Research Institute, ${ }^{2}$ Department of Refrigeration and Livestock Product Technology, Faculty of Food Science, Szent István University, Budapest, Hungary

The antimicrobial effect of nisin produced by Lactococcus lactis is well known. Nisin is the only bacteriocin that has been accepted as a preservative in some foods. Since consumers are oriented to natural food products, preserved with less or no chemicals, the use of natural preservatives is in the centre of interest.

The antimicrobial effect of nisin in different meat products was studied. Nisin was added to meat product (Bologna-type sausage emulsion) and experiments were performed to determine the effect of nisin for the microbial stability and sensory characteristics.

According to the results we concluded that nisin in 100 and $200 \mathrm{IU} \mathrm{g}^{-1}$ concentration extended the shelf life of these products, without nisin the total viable cell count and enterococci were high after 30 days of storage. By use of these concentrations off-flavour of the samples were noted. The use of nisin in lower concentration (50 IU g $\mathrm{g}^{-1}$ ) also resulted a low microbial viable cell count and without any off-flavour.

\section{J. KUCSERA ${ }^{1,2}$, K. YARITA ${ }^{1}$, K. TAKEO ${ }^{1}$, A. GÁCSER $^{2}$, Zs. HAMARI $^{2}$, F. KEVEI $^{2}$ \\ Colony variation of the human pathogenic yeast Cryptococcus hungaricus on Phloxin B medium}

\footnotetext{
${ }^{1}$ Research Center for Pathogenic Fungi and Microbial Toxicoses, Chiba University, Japan,

${ }^{2}$ Department of Microbiology, Faculty of Sciences, University of Szeged, Szeged, Hungary
}

Cryptococcus neoformans is an encapsulated opportunistic human pathogenic yeast, which can cause meningitic, pulmonary or systemic infections. It can occur in immunocompetent patients but it is more frequent and cause more severe symptoms in patients with acquired immunodeficiency syndrome (AIDS) or other conditions associated with immunosuppression. Cultivation of $C$. neoformans isolates on complete medium containing $10 \mu \mathrm{M}$ Phloxin B resulted in different coloured colonies (pink, red and sectors of both pink and red). Colony-colour variants were detected in two laboratory strains (IFM 5844, 5845) but not in 20 other strains derived from AIDS patients. Segregants were isolated from the red $(\alpha \mathrm{R})$ and pink $(\alpha \mathrm{P})$ sectors of one 
colony from IFM 5844. Beside these original isolates an additional slow growing colony was isolated from a subculture of $\alpha \mathrm{R}(\alpha \mathrm{Rs})$. These three isolates were analysed for physiological and molecular peculiarities. The segregants differed in the size of capsule and also in growth rate and temperature tolerance. Karyotyping by CHEF demonstrated that there were no chromosomal polymorphisms among them. However minor genetic polymorphisms were evident in the DNA fingerprints obtained by RAPD PCR among the three segregants. The process by which red (hypocapsulated) and pink (highly capsulated) colour variants arose could be attributed to phenotypic switching as it was shown by reversion frequency analysis. The plausible explanation for temperature sensitive variant was random spontaneous mutation, as reversion to growth at $37^{\circ} \mathrm{C}$ was not observed among cells of the temperature sensitive segregant $\alpha$ Rs. The reason for colour changes was also investigated and attributed to the differential ability of the cells to accumulate the xanthene dye Phloxin B either into their capsules or into their cells. The cultivation method described here is potentially applicable for detection of strain heterogenity and varying degree of encapsulation in both clinical and basic microbiology laboratories.

\author{
J. KUKOLYA ${ }^{1}$, E. BÉKI ${ }^{2}$, L. HORNOK ${ }^{1,2}$
}

\title{
Cloning and heterologous expression of cell wall degrading enzyme encoding genes of Thermobifida fusca
}

\author{
${ }^{1}$ Department of Microbiology, Szent István University, Gödöllő, ${ }^{2}$ Agricultural Biotechnology Center, \\ Gödöllő, Hungary
}

Twelve thermophilic actinomycete isolates were screened for cell wall degradation activity. Among them Thermobifida fusca strain TM51 proved to be the most active cellulase and xylanase producer. Streptomyces lividans strain TK24 was used for the expression of the T. fusca hydrolase genes. This closely related host possesses the appropriate protein folding, glycosylation and secretion system for the heterologous enzymes. A genomic library was constructed by using the plasmid pIJ699. Genomic DNA fragments with an average size of $15 \mathrm{kbp}$ were ligated into pIJ699. The transformation frequency approximated $90 \%$ and altogether 1700 thiostreptone positive colonies were isolated. This amounts to a $93 \%$ representation of the complete gene bank.

S. lividans strains harbouring the recombinant plasmids were grown on liquid LB medium, which prevents the induction of the host's own polysaccharide degrading enzymes. After $48 \mathrm{~h}$ micro-fermentation period the individual transformants were 
screened for enzyme activity by means of a fluorogenic substrate-mix containing methylumbelliferyl- $\beta$-D-glucoside, -mannoside, -cellobioside and -xyloside. Endoglucanase and endoxylanase activities were measured by the Congo-red staining method. Crude enzyme preparations were obtained from the positive transformants and subjected to SDS-PAGE zymogram analysis. Screening of the expression library yielded a number of $T$. fusca hydrolases, including five different endoglucanases (their molecular weights ranged between 45 and $110 \mathrm{kDa})$, two endoxylanases (48, $53 \mathrm{kDa})$, one $\beta$-mannosidase (75 kDa), a cellobiohydrolase $(62 \mathrm{kDa})$ and a $\beta$-xylosidase (130 $\mathrm{kDa})$. This latter proved to be a dimeric enzyme, as after heat shock treatment it was dissociated to two equal, $66 \mathrm{kDa}$ monomers resulting in the total loss of enzyme activity.

The extreme heat stability and detergent tolerance of the two endoglucanases are worthy of mentioning. These enzymes retained their activity after 5 minutes boiling in loading buffer containing $1 \%$ SDS and $100 \mathrm{mM}$ mercaptoethanol, indicating their potential utility for industrial application.

\section{J. Kukolya ${ }^{1}$, M. LÁDAY ${ }^{2}$, A. Halbritter ${ }^{3}$, O. ORAVECZ ${ }^{3}$, K. MÁRIAligeti ${ }^{3}$, L. HORNOK ${ }^{1,4}$}

\section{Thermobifida cellulolytica sp. nov., a new lignocellulose decomposing member of the genus Thermobifida}

\footnotetext{
${ }^{1}$ Department of Microbiology, Szent István University, Gödöllö, ${ }^{2}$ Plant Protection Institute, Hungarian Academy of Sciences, Budapest, ${ }^{3}$ Department of Microbiology, Eötvös Loránd University of Sciences, Budapest, ${ }^{4}$ Agricultural Biotechnology Center, Gödöllö, Hungary
}

Five actinomycete strains, K21, K52, TB100, TB108 and TB110, were isolated from the overheated region of manure compost. The isolates were assigned to the genus Thermobifida on the basis of morphological, physiological and biochemical characteristics. All investigated strains produced single, ovoid $(11.4 \mu \mathrm{m})$, heat sensitive (wet heat, $80^{\circ} \mathrm{C}, 15 \mathrm{~min}$ ) spores on dichotomically branched aerial hyphae, as revealed by scanning electron microscopy. The temperature range of growth was $35-45^{\circ} \mathrm{C}$ for the thermotolerant strains, $\mathrm{K} 21$ and $\mathrm{K} 52$, whereas this value ranged between $42-65{ }^{\circ} \mathrm{C}$ for the thermophilic isolates, TB 100, TB 108 and TB 110. All the strains were capable of degrading starch, xylan, as well as soluble and crystalline cellulose; they showed lignocellulose solubilization on straw powder. They tolerated erythromycin at concentrations of 5-50 $\mu \mathrm{g} \mathrm{ml}^{-1}$, whereas Thermobifida fusca strains were sensitive to this antibiotic. The partial 16S rDNA sequence similarity among these newly isolated 
strains reached $99.8-100 \%$, whereas the almost complete $16 \mathrm{~S}$ rDNA sequence of TB100, the representative strain of this collection, showed only 97.4 and 97.8 similarity to the corresponding rDNA sequences of the type strains of $T$. fusca, and $T$. alba, respectively. The $70-71 \mathrm{~mol} \% \mathrm{G}+\mathrm{C}$ content of the DNA of these isolates significantly differed from the $66.5 \mathrm{~mol} \% \mathrm{G}+\mathrm{C}$ value determined for the type strain of T. fusca. The chemotaxonomic features of these isolates were similar to that of the well documented species of the genus Thermobifida. Cell wall analysis revealed the presence of meso-diaminopimelic acid, but no other characteristic amino acids or sugars in the mureine (cell wall type III). According to polar lipid analysis all strains showed PLII type phospholipid composition; phosphatidylethanolamine was detected together with some unidentified phospholipids. The cellular fatty acid and isoprenoid quinon composition of the new isolates characteristically differed from that of the other two Thermobifida species. Based on both phenotypic and genotypic data we suggest that these strains should be assigned to a new species within the genus Thermobifida under the name Thermobifida cellulolytica sp. nov. The type strain is TB100.

\title{
L. Majoros, C. MiszTI, G. Kardos, I. ANDiRKÓ, B. SZABÓ
}

\section{Fungal sepsis in newborns and childhood}

\author{
Department of Microbiology, Medical School, University of Debrecen, Debrecen, Hungary
}

We have studied Candida albicans sepsis of two stillborns (below 1000 gram) and of a 3-years-old child. Invasion of C. albicans into cerebrospinal fluid (CSF) was observed in case of two newborns. The culture from blood and CSF of the boy patient gave positive result in 3 cases. The samples from the respiratory tube proved to be positive for the presence of $C$. albicans in 3 cases and in 1 case this fungus was isolated from the purulent arthritis as well.

The ineffective fluconazole therapy was replaced by liposomal amphotericin-B treatment for 3 weeks. This appropriate therapy resulted in complete healing of arthritis as well.

The granulomatoid meningitis of the newborn girl was fatal. In addition to positive CSF culture before the death the hyphal form of $C$. albicans was also demonstrated from the brain after autopsy.

The pulse-field electrophoresis revealed the same karyotype pattern of $7 \mathrm{C}$. albicans isolates of the newborn boy indicating the generalization of the infection. Similarly, the CSF and blood C. albicans isolates of the newborn girl were also identical. 
The C. albicans sepsis of a 3-years-old girl after operation a Fallot-tetralogy was of a better outcome. Three days after the operation C. albicans was cultured from the pleural fluid. This finding was followed by 12 additional identical isolations of $C$. albicans (hemocultures, respiratory tube, wound). infection.

The adequate amphotericin-B therapy completely eradicated the fungal

In vitro and in vivo studies are going on in our laboratory to investigate the potential neurovirulent nature of our C. albicans isolates.

\section{Majoros, C. MiszTI, G. KARDOS, I. ANDIRKÓ, B. SZABÓ}

\section{Repeated positive Candida cultures from male urine samples}

Department of Microbiology, Medical School, University of Debrecen, Debrecen, Hungary

During a 29 month period the Laboratory for Bacteriological Diagnostics of University of Debrecen tested about 70 thousand specimens. Five hundred seventy-one samples proved to be positive for the presence of yeasts from 11062 urine specimens. The etiological connection between candidurias and kidney lesions requires support by repeated cultivation of Candidas mainly in females but in males as well. Because of the anatomical differences the possibility of contamination is significantly lower in males, thus the subject of the present study was the male candiduria. In 33 cases two or more urine samples were positive for the presence of Candidas during repeated sampling.

We have obtained the repeated urine samples from four different groups of patients. In the first group of 6 renal transplant patients $C$. albicans was cultured from blood or ascites fluid as well. In the second group of 6 patients from Department of Urology we isolated from one patient $C$. glabrata 12 times. We have isolated repeatedly Candidas from urine of young children ( 7 boys). The hospitalized, burned patients represented the fourth group of our patients who received antibiotic treatment for a long time. Repeated positive cultures were also registered in this group.

In our study groups the invasive instrumental procedures, the catheters, the anatomical situations, the immunosuppressive therapies and/or conditions make plausible the etiological relationship between candiduria and the disease.

The pulse-field electrophoresis method was useful for determination of karyotype profile of the Candida strains. In case of identical karyotype of the repeatedly isolated. Candida strains the above discussed etiological connection seems to be much more plausible. 


\title{
Species diversity of bacteria participating in the biodegradation of reed rhizomes
}

Department of Microbiology, Eötvös Loránd University, Budapest, Hungary

Traditional cultivating procedure was used to study the bacterial community structure developing on the surface of the degrading reed rhizomes. The rhizomes were exposed to biodegradation in net begs on the water surface of their natural environment, a sodic steppe lake. For the isolation and cultivation of bacterial strains cellulose containing oligotrophic, complex and alkaline media were applied.

The bacterial strains based on their phenotypic characteristics were grouped into different phena from which representatives were chosen to ARDRA. The members of each ARDRA groups were subjected to partial sequencing of 16S rDNA.

The strains which were isolated from cellulose containing synthetic medium and possessed cellulolytic activity were identified as: Paenibacillus illioniensis (97.2\%), Bacillus benzoevorans (96.4\%), Cellulomonas favigena (96.2\%), Methylobacterium organophilum (94.9\%), Rahnella aquatilis (99.8\%), Rhodopseudomonas acidophila (93\%), Pseudomonas citronellolis (96.0\%) and Agrobacterium tumefaciens (96.7\%).

The results of the partial sequencing of 7 bacterial strains originated from the cellulose containing alkaline media were as follows: Exiguobacterium aurantiacum (98.6\%), Dietzia sp. (99.7\%), Bacillus alcalophilus (97\%), Nesterenkonia halobila (95.4\%), Halomonas venusta (96.8\%), Pseudomonas oleovorans (93.0\%) and Stappia stellulata $(93.7 \%)$.

\section{MIKLÓs, M. SIPICZKI}

\section{Suppression of a cytokinesis defect in a Schizosaccharomyces pombe mutant strain}

\author{
Department of Genetics and Molecular Biology, University of Debrecen, Egyetem tér 1, H-4010
} Debrecen, Hungary

Study of cell cycle is a favourite topic of cell biology as different defects of cell division can cause for example cancer.

We are interested in cytokinesis (separation of mother and daughter cells), which is the last step of cell division. The fission yeast $S$. pombe was used for the experiments, which is a genetically tractable model system. Since it is a unicellular 
microorganism, the failure of cell separation causes the formation of threads, which contain several cells.

Lots of strains defective in cytokinesis were isolated. One of them was referred to as spl1-1 (sep-like Sipiczki et al. J Cell Sci 1993).

Investigation of the $s p l 1-1$ strain shows that mutation in the $s p l 1^{+}$gene confers a pleiotropic phenotype to the cells:

- longer, slow growing cells even at $30{ }^{\circ} \mathrm{C}$,

- mycelial bent cells, which cannot separate from each other at the restrictive temperature $\left(35^{\circ} \mathrm{C}\right)$,

- temperature sensitivity, as the cells stop growing with diffuse nuclei and $2 \mathrm{C}$ DNA content at restrictive temperature,

- the cells are sensitive to $\mathrm{CaCl}_{2}$ and caffeine.

To determine the precise role of the $s p l 1^{+}$gene, we started to clone the gene. Up to the present we have managed to find just a suppressor, which is a proline t-RNA gene.

Further experiments to find the genomic spll gene are under way. The mutant strain was transformed with a wild-type genomic library. One positive clone has been found and it is being sequenced.

\author{
CS. MOHÁCSI-FARKAS ${ }^{1}$, L. MÉSZÁROS ${ }^{2}$, J. FARKAS $^{2}$, G. KISKÓ $^{1}$
}

\title{
Non-thermal pasteurization of tomato juice by high hydrostatic pressure treatment
}

\footnotetext{
${ }^{1}$ Department of Microbiology and Biotechnology, ${ }^{2}$ Department of Refrigeration and Lifestock Products Technology, Faculty of Food Science, Szent István University, Budapest, Hungary
}

In the frame of an INCO/COPERNICUS EU ("Plantchem") project antimicrobial activity of essential oils of medicinal and aromatic plants and their potential application as biopreservatives were tested. In addition, the novel non-thermal pasteurization treatment, the high hydrostatic pressure and their combinations were investigated.

Freshly prepared tomato juices were treated in several experimental series with addition of essential oils and/or by high hydrostatic pressure. High hydrostatic pressure ("HP") treatments were performed by a Stansted (U.K.) "FoodLab-9000" high hydrostatic pressure equipment. The samples were stored at $15{ }^{\circ} \mathrm{C}$, and periodical microbiological testings were performed during storage. 
Both pressure treatment of $400 \mathrm{MPa}$ for $20 \mathrm{~min}$ and addition of $0.5 \%$ oregano or thyme oil were able to result in a microbiologically stabile product for at least a few weeks.

Significant retardation of lactic acid spoilage was obtained even by $0.05 \%$ level of oregano oils whereas a full microbiological stability of the tomato juice was achieved by the higher pressure for a shorter time $(400 \mathrm{MPa}, 5$ or $10 \mathrm{~min}) \mathrm{HP}-$ treatment.

Addition of $0.05 \%$ essential oils (thyme and dill seed) had only little effect on the microbiological growth when applied alone and the efficiency of the relatively mild, $200 \mathrm{MPa}, 10 \mathrm{~min}$ pressure treatment could not be increased by this low level of essential oils, resulting only in a temporary delay of spoilage.

The microbiological shelf-life of the tomato juice was extended and the efficiency of the $200 \mathrm{MPa}, 10 \mathrm{~min}$ pressure treatment was increased considerably by the addition of $0.1 \%$ thyme oil resulting in a microbiologically stable product for at least 3 weeks of storage at ambient temperature investigated. Thus, combining the two non-thermal preservative methods makes it possible to reduce the concentration requirement of essential oils and/or the requirement (pressure or duration) of the high hydrostatic pressure treatment.

\title{
Z. NAÁR ${ }^{1}$, F. ROMÁN $^{2}$, M. KECSKÉS ${ }^{2}$
}

\section{Long-term effect of heavy metals on the species composition of Trichoderma population in a chernozem soil}

\author{
${ }^{1}$ Department of Botany, Eszterházy Károly College, Eger, ${ }^{2}$ Environmental Microbiological Research \\ Group of the Hungarian Academy of Sciences, Budapest, Hungary
}

Indigenous species of the Trichoderma population was studied in a long-term field experiment, where calcareous chernozem soil was artificially polluted with heavy metals 7 years prior the assessment. Three doses $\left(30,90,270 \mathrm{mg} \mathrm{kg}^{-1}\right.$ dry soil) of the $\mathrm{Cd}$, Ni and $\mathrm{Zn}$ salts (as sulphates) were studied on the species composition of Trichoderma fungi in parallel with the estimation of arbuscular mycorrhizal colonizations (Vörös et al., 1998). A Trichoderma selective medium (Askew and Laing, 1993) was used for the artificial cultivation of small soil particles for 1 week at $28{ }^{\circ} \mathrm{C}$. Abundance of the various species was estimated by microscopical identification of isolates according to Rifai (1969), Bissett (1991a-c, 1992). Correlation-regression analysis was used to estimate the statistical interrelationships between the available heavy metal content and the diversity and abundance of Trichoderma population. 
Six Trichoderma species (T. atroviride, T. harzianum, T. pubescens, $T$ tomentosum, $T$. virens and $T$. viride) were isolated from the untreated, control soil at various frequencies. Heavy metal pollution in general has resulted in significant loss both in the diversity and in the abundance of Trichoderma population. All heavy metal treatments have decreased the Shannon's diversity index. In case of $\mathrm{Cd}$, however, there was a slightly increased diversity found at the $\mathrm{Cd}-90 \mathrm{~kg} \mathrm{ha}^{-1}$ rate, preceding the total loss of the Trichoderma population at the highest dose. There was such a tendency published by Bíró et al. (1999) in case of As and Se toxic metals in the same long-term experiment. The highest number of Trichoderma propagules was found at the 270 $\mathrm{mgkg}^{-1}$ doses of $\mathrm{Ni}$ and $\mathrm{Zn}$ heavy metals.

A reduced correlation is concluded for the species composition of the Trichoderma fungi at the lower doses of heavy metal salts. Simultaneously with the toxicity, however the role of heavy metal salts are increasing. Correlation regression analysis proved to be a suitable tool for estimating the interrelations between the Trichoderma species.

Financial support of the Hungarian Research Fund (OTKA) is highly acknowledged (F025924).

1. Vörös, I. et al.: Agrokem Talajt 47, 277-288 (1998). 2. Askew, D. J., Laing, M. D.: Plant Pathol 42, 686-690 (1993). 3. Rifai, M. A.: Papers, Commonw Mycol Inst Kew, Surrey, England. 116, 1-56 (1969). 4. Bissett, J.: Can J Bot 69, 2357-2372 (1991a). 5. Bissett, J.: Can J Bot 69, 2373-2417 (1991b). 6. Bissett, J.: Can J Bot 69, 2418-2420 (1991c). 7. Bisset, J.: Can J Bot 70, 639-641 (1992). 8. Bíró, B. et al:: In Wenzel, W. (ed.): Proc of 5th ICOBTE Conference. Vienna, 1999. pp. 178-179.

\section{Á. NAGY ${ }^{1}, Z^{\prime}$. PALÁGYI ${ }^{2}$, T. PAPP ${ }^{2}$, L. FERENCZY ${ }^{2}$, CS. VÁGVÖLGYI ${ }^{1}$}

\section{Pulsed field electrophoresis of Mortierella (Micromucor) chromosomal DNA}

\footnotetext{
${ }^{1}$ Department of Microbiology, Faculty of Sciences, University of Szeged, ${ }^{2} \mathrm{HAS}$ Microbiological Research Group, Department of Microbiology University of Szeged, Szeged, Hungary
}

Many members of Mortierella genus are potent producers of long chain polyunsaturated fatty acids (e.g. arachidonic and dihomo- $\gamma$-linolenic acids). These compounds are important both nutritionally and pharmacologically. In spite of their biotechnological importance, the organization of the nuclear genome has not been described so far.

Electrophoretic karyotype analysis using different approaches of pulsed field gel electrophoresis has led to a significant progress in fungal genetics. In the present study, 
contour-clamped homogeneous field pulsed-field electrophoresis (CHEF) was applied to obtain information on the organization and intragenetic variability of the nuclear genome in three Mortierella (Micromucor) strains from different species (M. isabellina and $M$. ramanniana). None of the strains gave the same electrophoretic pattern; 12 (for M. isabellina) and 11 or 14 (for M. ramanniana) chromosomal mobility groups were resolved. The relative intensities of the separated bands suggest the presence of several comigrating chromosomal DNAs, resulting in comparable genome sizes (about $24 \mathrm{Mb}$ ) for Mortierella, which are larger than those reported for other yeast genomes, but smaller than those observed for the majority of the filamentous fungi. Gene assignment experiments with cloned heterologous gene probes were also carried out.

This study was supported in part by OTKA grants T032738 and D29113.

\section{Z. NAGY ${ }^{1}$, A. SZENTIRMAI ${ }^{1}$, S. BIRÓ ${ }^{1,2}$ \\ Carbon catabolite repression of $\beta$-galactosidase biosynthesis by Penicillium chrysogenum}

\footnotetext{
${ }^{1}$ Department of Microbiology and Biotechnology, Faculty of Natural Sciences, University of Debrecen,

${ }^{2}$ Department of Human Genetics, Health and Medical Sciences Center, Medical School, University of Debrecen, Debrecen, Hungary
}

Industrial production of penicillin by Penicillium chrysogenum is carried out with lactose as the carbon source by feeding subrepressing doses of glucose since the production of penicillin appears to be favoured by suboptimal growth conditions. Carbon source regulation seems to act at several points of the penicillin biosynthesis. Carbon catabolite regulation of penicillin biosynthesis is exerted by glucose and other easily utilizable carbon sources but not by lactose. Investigating the carbon catabolite repression in Penicillium chrysogenum, a similar phenomenon was observed in case of $\beta$-galactosidase biosynthesis. Using lactose as the only carbon source in shaken cultures of Penicillium chrysogenum the $\beta$-galactosidase activity is the highest. Addition of glucose to the culture reduced the biosynthesis of the enzyme. Other repressing carbon sources such as sucrose, galactose and glycerol also have a negative effect on $\beta$-galactosidase production. Lactose induced the biosynthesis of $\beta$ galactosidase, glucose and other easily utilizable carbon sources repressed it. Glucose grown cultures had no $\beta$-galactosidase activity but after consuming of the glucose enzyme activity increased. This phenomenon is due to the derepression of enzyme synthesis. Adding caffein to lactose+glucose grown cultures had no effect on enzyme synthesis but significantly decreased the growth of the cultures. This can be explained 
if the increased intracellular cAMP concentration had no effect on catabolite repression, but reduced glucose utilization.

QuANG D. NGuYEN, J. M. REZESSY-SZABÓ, Á. HoschKE

\section{Improvement of amylolytic production by changing the components of fermentation medium}

Department of Brewing and Distilling, Szent István University, Budapest, Hungary

One of most important point of view in fermentation industry is to apply the suitable medium components. In this way, not only the amount of the final product can be increased, but it is also possible to reduce the expenses of fermentation medium. The effects of carbon- and nitrogen-sources and the initial $\mathrm{pH}$ of medium on the amylolytic activities of Thermomyces lanuginosus was investigated in this study.

According to previous reports the amylolytic enzymes are stable at $\mathrm{pH}$ ranging from 4.0 to 8.0 , the optimum $\mathrm{pH}$ is between 4.6 and 6.5. Based on preliminary experimental results we confirmed that the $\mathrm{pH}$ of the ferment broth reached very high values $(\mathrm{pH}=8.0-9.5)$ at the end of the fermentation, which may cause the inactivation of the enzymes. The effects of initial $\mathrm{pH}$ of media were examined by preparing them with $100 \mathrm{mM}$ citrate buffer of different $\mathrm{pH}$. The analysis of the changes of $\mathrm{pH}$ values during fermentation showed that the $\mathrm{pH}$ in the reference trial increases to a great extent. The application of a buffer system could restrict the increase of $\mathrm{pH}$. The results revealed that the $\mathrm{pH}$ has strong influence on amylolytic activities. When the initial $\mathrm{pH}$ of the media was adjusted to 4.9 with citrate buffer, the glucoamylase activity was 3.5 times and the $\alpha$-amylase activity 1.7 times higher than that of the reference trial. In case of buffered conditions the profile of the dry mass and amylolytic activities showed inverse function with the initial $\mathrm{pH}$ of the medium. In this way it was possible to repress the mycelium growth and favour the enzyme production. If the $\mathrm{pH}$ of the medium was lower than 4.0 both amylolytic activities decreased drastically. It should be noticed that if the initial $\mathrm{pH} \leq 3$ no growth was observed.

The effects of various carbon-sources (starch, glucose, maltose, maltodextrin, amylopectin, amylose, dextran and dextrin) on the production of amylolytic enzymes were investigated. Starch is generally accepted as nutritional component for induction of amylolytic enzymes. In our study this was applied as reference. Growing fungus on glucose, maltose, maltodextrin, amylopectin, dextran and dextrin the amylolytic activities were higher than on starch. In case of $\alpha$-amylase the maltodextrin was found to be the best carbon source. Applying maltodextrin as a sole carbon source the $\alpha$ - 
amylase activity was approximately $25 \%$ higher than that of the control one. In case of glucoamylase the dextrin proved to be the best, giving twices higher activity than starch.

In the investigation of the effects of various nitrogen-sources (L-asparagine, yeast extract, $\mathrm{CH}_{3} \mathrm{COONH}_{4}, \mathrm{NH}_{4} \mathrm{NO}_{3}, \mathrm{NaNO}_{3},\left(\mathrm{NH}_{4}\right)_{2} \mathrm{SO}_{4}$ and $\left.\mathrm{NH}_{4} \mathrm{H}_{2} \mathrm{PO}_{4}\right)$ on amylolytic enzyme production, L-asparagine was found to be the most promising one. In case of $\alpha$-amylase activity yeast extract seemed to be suitable as well, but in case of glucoamylase the enzyme productivity was only half of that, which was produced on Lasparagine. When inorganic nitrogen-sources were used, the fungus grew excellently, but very poor enzyme activities were achieved.

This work was supported by National Scientific Research Fund Project No. OTKA T-029882.

\section{T. PAPP ${ }^{1}$, I. NYILASI ${ }^{2}$, K. ÁCS ${ }^{2}$, M. VASTAG ${ }^{2}$, Cs. VÁGVÖLGYI ${ }^{2}$}

Taxonomic position of Gilbertella persicaria based on glyceraldehide-3phosphate dehydrogenase gene and nuclear ribosomal-DNA sequence data

${ }^{1}$ Department of Microbiology, HAS Microbiological Research Group, ${ }^{2}$ Department of Microbiology, Faculty of Sciences, University of Szeged, P.O. Box 533, H-6701, Szeged, Hungary

Gilbertella persicaria (a member of the Mucorales) is known to be as a storagerot microorganism primarily of peaches. This species was originally described as Choanephora persicaria and was included in the Choanephoraceae on the basis of the morphology of the sporangia and sporangiospores. Later, the genus Gilbertella was introduced and placed into the Mucoraceae, because this fungus forms Mucor-type zygospores. Finally, this genus (and G. persicaria) was removed to a newly-created monogeneric family (Gilbertellaceae). The first objective of this study was to reveal the phylogenetic relationships between fungi belonging to Gilbertellaceae, Choanephoraceae and Mucoraceae. Two strains of G. persicaria, 7 strains belonging to the Mucoraceae (Actinomucor elegans, Mucor piriformis, M. rouxii, M. circinelloides, Rhizomucor miehei, R. pusillus and R. tauricus) and 4 strains of the Choanephoraceae (Blakeslea trispora (+), B. trispora (-), Choanephora conjuncta and Poitrasia circinans) were involved in these experiments. The complete ITS (internal transcribed spacer) region coding the ITS1, the ITS2 and the 5.8S rDNA and a fragment of the glyceraldehyde-3-phosphate dehydrogenase gene ( $g p d$ ) consisting of 240 base pairs were amplified by polymerase chain reaction. Sequences of the amplified DNA 
fragments were determined and analysed. The congruency of the sequence data obtained by the analysis of the ITS region and the gpd gene was also evaluated. The results support the "intermediate" position of G. persicaria between Choanephoraceae and Mucoraceae.

This study was supported by OTKA grant T032738.

M. PAŠ, P. JAMNIK, S. PRAH, M. BATIČ, P. RASPOR

\section{The influence of chromium compounds on yeast viability}

Biotechnical Faculty, University of Ljubljana, Jamnikarjeva 101, 1001 Ljubljana, Slovenia

The intrinsic, biochemical, structural and genetic properties of the yeast cell along with environmental conditions are crucial for its survival when exposed to toxic metals (1). The ability of yeasts to tolerate higher concentrations of chromium, which plays an important role in their metabolism (2), depends on the concentration and form of the chromium compound. The effect of chromium(VI) compounds $\left(\mathrm{K}_{2} \mathrm{CrO}_{4}\right.$, $\mathrm{K}_{2} \mathrm{Cr}_{2} \mathrm{O}_{7}, \mathrm{Na}_{2} \mathrm{Cr}_{2} \mathrm{O}_{7} \times 2 \mathrm{H}_{2} \mathrm{O}$ ) in concentrations of $\mathrm{Cr}(\mathrm{VI}) 0.001,0.01,0.1,1 \mathrm{mM}$ and chromium(III) compounds $\left(\mathrm{CrCl}_{3} \times 6 \mathrm{H}_{2} \mathrm{O}, \mathrm{Cr}\left(\mathrm{CH}_{3} \mathrm{COO}\right)_{3}, \quad \mathrm{KCr}\left(\mathrm{C}_{2} \mathrm{O}_{4}\right)_{2} \times 3 \mathrm{H}_{2} \mathrm{O}\right)$ in concentrations of $\mathrm{Cr}$ (III) $0.1,1,10,100,200 \mathrm{mM}$ on the viability of yeast Saccharomyces cerevisiae ZIM 753 was studied. After cultivation in malt broth the biomass was harvested in the early stationary phase, washed and resuspended in MES buffer $(\mathrm{pH}=4.0)$ and adjusted to dry mass concentration of $0.05 \mathrm{mg} / \mathrm{ml}$. The effect of chromium compounds on the yeasts was lasting 24 hours in the MES buffer at $28{ }^{\circ} \mathrm{C}$. The yeast viability was determined as CFU on agar plates. The results showed that different chromium compounds exhibit different toxicity to the yeast Saccharomyces cerevisiae. Yeasts tolerated $\mathrm{Cr}(\mathrm{III})$ compounds more efficient than $\mathrm{Cr}(\mathrm{VI})$ compounds (3), furthermore, there were also differences in toxicity among all compounds. The highest toxicity was observed in case of $\mathrm{CrCl}_{3} \times 6 \mathrm{H}_{2} \mathrm{O}$ among $\mathrm{Cr}$ (III) and in case of $\mathrm{K}_{2} \mathrm{Cr}_{2} \mathrm{O}_{7}$ among $\mathrm{Cr}(\mathrm{VI})$ compounds. However, the highest tolerance was found in the presence of $\mathrm{K}_{2} \mathrm{CrO}_{4}$ for $\mathrm{Cr}(\mathrm{VI})$ and $\mathrm{KCr}\left(\mathrm{C}_{2} \mathrm{O}_{4}\right)_{2} \times 3 \mathrm{H}_{2} \mathrm{O}$ for $\mathrm{Cr}(\mathrm{III})$.

1. Blackwell, K. J., Singleton, I., Tobin, J. M.: App Microbiol Biotechnol 43, 579-584 (1995). 2. Losi, M. E., Amrhein, C., Frankenberger, W. T.: Reviews of Environmental Contamination and Toxicology 136, 91-115 (1994). 3. Rapoport, A. I., Muter, O. A.: Process Biochemistry 30, 145-149 (1995). 4. Raspor, P., Batic, M., Jamnik, P.: Food Technology and Biotechnology, 37(2), 81-86 (1999). 


\section{A. PENGOV}

\section{Bovine mycotic mastitis}

Institute for microbiology, Veterinary faculty of Ljubljana, Gerbiceva, 1000 Ljubljana, Slovenia

Objectives: The objective of this study was to evaluate the prevalence of yeast udder infections among dairy cows.

Material and methods: The following study includes a total amount of 93 selected isolates obtained from culture of milk samples from dairy cows. During a sixmonth period milk samples of 1652 cows functional quarters were taken.

The above-mentioned 93 isolates were differentiated with the API $20 \mathrm{C}$ and API C AUX (Bio Merieux) systems.

Results: Besides bacterial udder pathogens 76 yeast strains and 17 prototheca were isolated from infected bovine mammary glands. The most prevalent species were:

Candida krusei, C. glabrata and C. albicans.

No relation was found between the different species in regard to the somatic cell count and the severity of clinical symptoms.

\section{PFEIFFER, J. KUCSERA}

\section{Organization of the mitochondrial genome in Phaffia rhodozyma CBS 5905}

Department of Microbiology, Faculty of Sciences, University of Szeged, Szeged, Hungary

While the structure of the mitochondrial genome seems to be circular in the majority of cases, some organisms have linear mitochondrial DNA. Independently of the structure one intact molecule specifies several proteins of the respiratory complexes, two ribosomal RNA and tRNAs characteristic of the species.

Phaffia rhodozyma is a red-pigmented heterobasidiomycetous yeast species [1]. The existence of its linear DNA plasmids was proved in 1987 [2]. Our study demonstrated that these plasmids or some of them represent the mitochondrial genome of this species. The type strain of Phaffia rhodozyma (CBS 5905) does not contain DNA plasmids. The molecular weight of its mtDNA was calculated by restriction enzyme analysis and proved to be approximately $13 \mathrm{~kb}$. Its structure was analysed by electron microscopy. Mitochondrial genes from different fungi do not hybridise to it, 
for this reason homologous gene probes were prepared by PCR techniques. The partial sequence of the coxI and ATPase9 was determined.

This strain gives small, "petite" colonies with low frequencies among the normally growing ones. These colonies fermented glucose in the presence of oxygen, were not able to grow on nonfermentable carbon sources and did not respond to inhibitors of respiration. Besides spontaneous occurrence, this mutation proved to be almost $100 \%$ inducible by low levels of ethidium bromide treatment, suggesting that it is mitochondrially inherited.

According to our results, Phaffia rhodozyma is the only known petite-positive basidiomycetous yeast and has the smallest mitochondrial genome among fungi.

This work was financially supported by OTKA grant T025849, F020870 and FKFP 0218/97.

1. Kucsera, J., Pfeiffer, I., Ferenczy, L.: Homothallic life cycle in the diploid red yeast Xanthophyllomyces dendrorhous (Phaffia rhodozyma). Antonie van Leeuwenhoek 73, 163-168, (1998). 2. Wilber, K. A., Proffitt, J. H.: Detection of linear plasmids in Phaffia rhodozyma. UCLA Yeast Symp. 1987. p. 106.

\title{
I. PÓCSI, T. EMRI, L. SÁMI, T. PUSZTAHELYI
}

\section{The glutathione metabolism of the filamentous fungus Penicillium chrysogenum}

\author{
Department of Microbiology and Biotechnology, Faculty of Sciences, University of Debrecen, \\ P.O. Box 63, H-4010 Debrecen, Hungary
}

Glutathione ( $\gamma$-L-glutamyl-L-cysteinyl-glycine; GSH) is structurally analogous to $\delta$-(L- $\alpha$-aminoadipyl)-L-cysteinyl-D-valine (ACV), which is an important intermediate of the $\beta$-lactam biosynthesis, and, as a result, GSH suppresses the penicillin production by inhibiting ACV synthase and isopenicillin $\mathrm{N}$ synthetase (IPS) activities in $P$. chrysogenum. Detailed physiological studies on $P$. chrysogenum revealed that

1. The $P$. chrysogenum tolerated the oxidative stress caused by high concentrations of peroxides (up to $700 \mathrm{mM} \mathrm{H}_{2} \mathrm{O}_{2}$ or $2.0 \mathrm{mM}$ tert-BOOH) exceptionally well. This resistance was explained by the high intracellular glutathione peroxidase and catalase activities.

2. An idealistic culture media for $\beta$-lactam production by $P$. chrysogenum would contain lactose, glutamate and cysteine as carbon, nitrogen and sulphur sources, 
respectively. Nevertheless, all of these additives would increase the intracellular GSH concentrations too and, hence, should decrease the penicillin yields.

3. Nevertheless, under $\beta$-lactam producing conditions the intracellular GSH pool can be decreased considerably via the GSH-dependent detoxification of the highly toxic, protonophore penicillin side chain precursors phenoxyacetic (POA) and phenylacetic (PA) acids. So, in an indirect way, the side chain precursors themselves could release the penicillin biosynthetic machinery from the inhibitory effect of GSH.

In addition, possible connections between the acidity, toxicity, GSH-dependent detoxification and $\beta$-lactam production of POA, PA and their hydroxylated derivatives were also thoroughly investigated. The toxicity of the side chain precursors correlated with GSH-dependent detoxification but did not correlate well with acidity and $\beta$-lactam production. Thus, penicillin production does not seem to be an alternative of the GSHdependent detoxification. Moreover, reactive, epoxide intermediates of the hydroxylation reactions are thought to contribute profoundly to the toxicity of the side chain precursors in addition to their protonophoric character. These intermediates are the most probable targets for the GSH-dependent detoxification.

The senescence in ageing $P$. chrysogenum cultures can be characterized with fragmentation, the release of hydrolytic enzymes, autolysis and, at last, the onset of a new equilibrium between cell dying and cryptic growth. From these processes, fragmentation and cryptic growth can be hindered using the pseudotrisaccharide allosamidin, one of the most potent and specific inhibitors of chitinases. On the other hand, neither the specific GSH concentrations nor the GSH/GSSG redox balances of the $P$. chrysogenum cells were disturbed by either ageing or the inclusion of allosamidin into the culture media. Hence, any causal connection between the observed morphological changes and the redox status of the cells seems to be unlikely.

M. RECEK, P. JAMNIK, P. RASPOR

\section{Yeast biomass enriched with chromium}

Biotechnical Faculty, University of Ljubljana, Jamnikarjeva 101, 1001 Ljubljana, Slovenia

Chromium, in trace amounts, is an essential component of human nutrition and it has been determined to be required for normal carbohydrate and fat metabolism. Beside foods naturally rich in chromium, brewer' $s$ yeast is the good natural source, but chromium concentration is quite low $\left(0.2-5 \mu \mathrm{g} \mathrm{g}^{-1}\right.$ dry biomass). The aim of our study was to prepare yeast biomass enriched with chromium. It is known that microorganisms are able to accumulate toxic metal ions such as hexavalent chromium. 
The screening method according to tolerance to $\mathrm{Cr}(\mathrm{VI})$ among nine yeast strains was performed. The most tolerant yeast was Candida intermedia ZIM 156, which was further cultivated with chromium chloride hexahidrate compound. It was established that this yeast could accumulate $\mathrm{Cr}(\mathrm{III})$, which is desirable from the nutritional aspect. Investigation of some ecological parameters with intention to reach high accumulation of chromium in the yeast biomass was done. Beside addition of chromium at different phases of yeast growth two physicochemical parameters, like concentration and temperature on chromium accumulation, were investigated. In case of concentration (3, $5,10 \mathrm{mM} \mathrm{Cr}^{3+}$ ) the results showed that yeast growth at higher chromium concentration was more inhibited but accumulation of total chromium was higher, which corresponded to 670,960 and $2400 \mu \mathrm{g} g-1$ dry biomass, respectively. Addition of chromium $\left(5 \mathrm{mM} \mathrm{Cr}^{3+}\right)$ in the middle of the exponential phase did not show the inhibitory effect on yeast growth, but accumulation was lower $\left(610 \mu \mathrm{g} \mathrm{g}^{-1}\right.$ dry biomass). Increase of temperature in the deceleration phase had an additional effect on chromium accumulation, which was $920 \mu \mathrm{g} \mathrm{g}^{-1}$ dry biomass.

\title{
M. RECEK, M. SKRT, P. RASPOR
}

\section{Accumulation of chromium(III) in yeast Candida intermedia}

\author{
Food Science and Technology Department, Biotechnical Faculty, University of Ljubljana, \\ Chair of Biotechnology, Jamnikarjeva 101, 1111 Ljubljana, Slovenia
}

Chromium is an essential microelement for mammals and probably for microorganisms and it is most notably associated with glucose metabolism. Inorganic chromium salts are not as readily absorbed or biologically active as organic forms of chromium. Under certain ecological conditions yeasts are able to accumulate chromium and other trace elements and incorporate them into organic compounds. Effect of elevated chromium concentration of 3,5, 10 and $20 \mathrm{mM} \mathrm{Cr}^{3+}$ (chromium chloride hexahidrate), and time of addition to the medium on yeast growth and accumulation of total chromium in yeast biomass were evaluated. Chromium was added in chemically defined medium in the beginning of the bioprocess $\left(3,5\right.$ and $\left.10 \mathrm{mM} \mathrm{Cr}^{3+}\right)$ and in the middle of exponential growth $\left(3,5,1.0\right.$ and $\left.20 \mathrm{mM} \mathrm{Cr}^{3+}\right)$ of yeast Candida intermedia ZIM 156. Yeast were cultivated in batch mode in 3.51 stirred bioreactor $(\mathrm{Ve}=2.51,200$ rpm, $1 \mathrm{vvm}, 28^{\circ} \mathrm{C}, 10 \%$ inoculum). Parameters $\mathrm{pH}, \mathrm{pO}_{2}$ and yeast growth were on-line measured, while accumulation of total chromium in yeast biomass was determined in different periods of time. The results showed that the level of chromium accumulation was dependent on both ambient concentration and time of chromium addition into the 
medium. It was found that elevated concentration of $\mathrm{Cr}(\mathrm{III})$ in the environment caused a reduction of growth rate and biomass production but increased total chromium accumulation in yeast biomass. Chromium addition in the middle of the exponential growth phase had no notably effect on yeast growth, which was comparable with yeast cultivation without chromium addition.

\section{J. REZESSY-SZABÓ, I. SinKÓ, E. BuJNA, QUANG D. NGUYEN}

\section{Enhancement of productivity of $\alpha$-galactosidase by optimization of medium composition}

Department of Brewing and Distilling, Szent István University, Budapest, Hungary

One promising methodology for improvement in fermentation technology is the optimization of media composition to enhance productivity or reduce expenses. Thermomyces lanuginosus is a thermophilic fungus, which produces numerous extracellular enzymes such as amylases, xylanases, invertase, lipase, proteases and galactosidases etc. We studied the production of $\alpha$-galactosidase enzyme of Thermomyces lanuginosus CBS $395.62 / \mathrm{b}$ strain. We aimed to increase the $\alpha$ galactosidase activity by optimization of medium composition. The effects of the carbon and nitrogen sources were investigated. The function between the enzyme activity and the concentration of raffinose as sole carbon source, moreover the effect of nitrogen source as a quality factor was examined. The used nitrogen substrates were yeast extract and L-asparagine. Their quantities were defined according to the equal nitrogen content. Application of different organic nitrogen sources did not show any significant influence on $\alpha$-galactosidase activity, but the increase of raffinose concentration from $1.5(\mathrm{w} / \mathrm{v}) \%$ to $2.5(\mathrm{w} / \mathrm{v}) \%$ gave about 2 times higher activity. Taking into consideration that raffinose is an expensive carbohydrate we did not want to increase its concentration above $2.5(\mathrm{w} / \mathrm{v}) \%$. Seven different compounds as possible nitrogen source were tested. The highest $\alpha$-galactosidase activity was detected when cultivation was carried out on ammonium-acetate. To search a cheaper carbon source, fermentation was made applying various carbohydrates. The produced $\alpha$-galactosidase activity was the same on raffinose and sucrose. This value was $50 \mathrm{IU} / \mathrm{ml}$. To enhance the productivity of $\alpha$-galactosidase from Thermomyces lanuginosus two-level factorial experiment design was carried out. Variables were sucrose $[1(\mathrm{w} / \mathrm{v}) \% ; 3(\mathrm{w} / \mathrm{v}) \%]$ and ammonium-acetate $[0.3(\mathrm{w} / \mathrm{v}) \%$ and $0.6(\mathrm{w} / \mathrm{v}) \%]$. For the evaluation of the results $\mathrm{Y}=\mathrm{a}_{0}+\mathrm{a}_{1} \mathrm{x}_{1}+\mathrm{a}_{2} \mathrm{x}_{2}+\mathrm{a}_{12} \mathrm{x}_{1} \mathrm{x}_{2}$ equation was used, where $\mathrm{Y}$ is the $\alpha$-galactosidase activity, $\mathrm{x}_{1}=$ sucrose concentration, $\mathrm{x}_{2}=$ the concentration of ammonium-acetate, $\mathrm{a}_{0}, \ldots, \mathrm{a}_{12}$ are the 
constants of the function. The results were processed by means of SPSS for Windows software. The increase of both sucrose and ammonium-acetate led to the improvement of the productivity of $\alpha$-galactosidase. In this way $100 \mathrm{IU} / \mathrm{ml}$ activity was reached. Further enhancement of the productivity can be predicted by increase of both carbon and nitrogen sources.

On the base of our results it is possible to establish an industrially acceptable fermentation, where molasses can serve as main carbon source.

The research was supported by National Scientific Research Fund Project No. OTKA T-029882.

\section{K. RigÓ, B. TÓTH, J. VARGA}

\section{Analysis of genetic variability within the Aspergillus viridinutans species}

Department of Microbiology, Faculty of Sciences, University of Szeged, Szeged, Hungary

The intraspecific variability of the Aspergillus viridinutans species was examined using various techniques including morphological examinations, carbon source utilization tests, restriction enzyme analysis of the mitochondrial and nuclear DNA, and sequence analysis of part of the $\beta$-tubulin gene. Although the genetic distances between the isolates were higher than between e.g. A. fumigatus and Neosartorya fischeri, most A. viridinutans isolates together with $N$. aureola and $N$. udagawae strains were found to belong to a single cluster based on sequence data. Strain FRR 1266, which was earlier classified as a highly divergent A. fumigatus isolate, was found to belong to the $A$. viridinutans species. The ochratoxin A producing $A$. viridinutans strain IMI 306135 was most closely related to an asexual isolate. These two latter strains were more closely related to A. fumigatus and $N$. fischeri than to any A. viridinutans strains, and possibly represent a new species in Aspergillus section Fumigati. The dendrogram based on carbon source utilization data and results of restriction analysis of the mitochondrial and nuclear DNA of the strains supported most of the evolutionary relationships observed based on sequence data. The results indicate that the presence or absence of nodding conidial heads is not an unequivocal morphological character for the identification of species within Aspergillus section Fumigati.

This work was financially supported by Hungarian Scientific Research Fund (OTKA) grant \#F023062. J. Varga was in receipt of a Bolyai Research Fellowship grant. 


\section{Evolutionary relationships within Aspergillus section Circumdati}

Department of Microbiology, Faculty of Sciences, University of Szeged, Szeged, Hungary

Sequences of the intergenic transcribed spacer regions and the 5.8 S rRNA gene of type or neotype strains of species currently assigned to Aspergillus section Circumdati were analysed. Parsimony analysis of sequence data indicated that Aspergillus section Circumdati is non-monophyletic. Aspergillus campestris, A. lanosus, and $A$. dimorphicus with $A$. sepultus were found to be more closely related to Aspergillus sections Candidi, Flavi and Cremei, respectively These results were also supported by phenotypic data. A. robustus and A. ochraceoroseus were found not to be related to any of the species examined. Species of the proposed revised Aspergillus section Circumdati formed two main clades, which could also be distinguished based on phenotypic methods. Ochratoxin producing species were scattered on the cladogram indicating that ochratoxin producing ability of the strains was lost (or gained), several times during the evolution of Aspergillus section Circumdati. Ochratoxin producing abilities of the isolates examined did not correlate with their taxonomic relationships based on sequence data, although a clade found not to produce ochratoxins during an earlier study of genetic variability of $A$. ochraceus could also be identified in this study.

This work was financially supported by Hungarian Scientific Research Fund (OTKA) grant \#F023062. J. Varga was in receipt of a Bolyai Research Fellowship grant.

$$
\text { F. ROMÁN }{ }^{1}, Z^{2} \text { NAÁR }{ }^{2}, \text { B. BIRÓ }{ }^{3}, \text { M. KECSKÉS }{ }^{1}
$$

\section{Heavy metal tolerance of Trichoderma fungi isolated at different adaptation periods in a long-term field-experiment}

\footnotetext{
${ }^{1}$ Environmental Microbiological Research Group of the Hungarian Academy of Sciences, Budapest, ${ }^{2}$ Department of Botany, Eszterházy Károly College, Eger, ${ }^{3}$ Research Institute for Soil Science and Agricultural Chemistry of the Hungarian Academy of Sciences, Budapest, Hungary
}

The anthropogenic heavy metal pollution of soil (e.g. field application of sewage sludge) may alter the composition of soil microbiota (Biró 1999, Kecskés et al. 1997), resulting in a reduced natural biocontrol of the soil-borne plant pathogens. Trichoderma fungi are world-widely spread common soil microorganisms, which play an important role in the biocontrol processes (Cook 1993). Heavy metal tolerance of 
some Trichoderma isolates were studied in vitro for the spore germination and the mycelial growth in liquid and solid medium. Strains were originating from a long-term field-experiment, where the calcareous chernozem soil was artificially contaminated by 13 heavy metal salts in four levels $\left(0,30,90\right.$ and $\left.270 \mathrm{mg} \mathrm{kg}^{-1}\right)$. Samples of the $\mathrm{Cd}, \mathrm{Ni}$ and $\mathrm{Zn}$ were selected after 3 and 5 years of pollution, respectively.

Regarding the heavy metal sensitivity significant differences were found among the Trichoderma isolates obtained in the same year from different treatments (application rates and types of the metals). Much less differences were observed, however among the isolates, which were originating from the same metal treatments at two consecutive, different isolation periods.

Less significant changes in the sensitivity are concluded (within a two-yearadaptation periods), comparing to the high variability of metals and their application rates. The effect of heavy metal salts among the natural environmental conditions is especially complex and influenced by several biotic and abiotic environmental factors. Long-term field experiment with the separated rates of several toxic elements (in Nagyhörcsök, Hungary) serve as a model background for studying the main soilbiological processes and microbial interactions (Kádár 1995).

Financial support of the Hungarian Research Foundation (OTKA: T0 23543 and T0 30941) is highly acknowledged.

1. Biró, B.: Gyakorlati Agrofórum (X) 9, 4-6 (1999). 2. Kecskés, M. et al:: Acta Alimentaria 26, 313-315 (1997). 3. Cook, R. J.: Annu Rev Phytopathol 31, 53-80 (1993). 4. Kádár, I.: Toxic elements in the Soil-plant-human systems in Hungary. Akaprint, Budapest, 1995.

\section{SÁmi, T. EMRI, Z. VARECZA, T. PUSZTAhElYI, I. PÓCSI}

\section{Fragmentation, autolysis and cryptic growth in ageing Penicillium chrysogenum cultures}

Department of Microbiology and Biotechnology, Faculty of Life Sciences, University of Debrecen, P.O. Box 63, H-4010 Debrecen, Hungary

The pseudotrisaccharide allosamidin, which is known to be one of the most specific and effective inhibitors of chitinases, retarded significantly the fragmentation of hyphae in ageing carbon-depleted cultures of an industrial $\beta$-lactam-producing Penicillium chrysogenum strain, especially between 60 and $80 \mathrm{~h}$ incubation times. Under antibiotic producing conditions, allosamidin did not have any effect on either the growth or the penicillin yields. At $115 \mathrm{~h}$ cultivation, fragmentation was complete, even 
with allosamidin treatment, giving a very similar morphology comparing to control cultures, with the dominance of yeast-like surviving forms usually consisting of two cells. Not only the number and germinating ability of these cells, but the extracellular autolytic enzyme, e.g. hexosaminidase and chitinase activities were the same. Moreover, the intracellular gluthatione level, which is an indicator of the physiological state of the cells, was not disturbed by allosamidin either. These results suggest that the rate of autolysis, although shifted in time, could be very similar in the cultures.

Allosamidin also hindered, even after addition of an extra dose of glucose, the outgrowth of new tips from the surviving hyphal fragments. In spite of this, only a slight difference between the glucose utilisation rates of allosamidin-treated and control cultures was found, which means that the treated cells still had considerable metabolic activity. Moreover, after transferring the cells into fresh, glucose-containing and allosamidin-free culture medium, the treated cells regained their ability to produce new tips, showing the same outgrowth as the control cells did.

In addition to morphological changes, allosamidin also had a significant effect on the dry weight of the cells, which increased about $25 \%$. This suggests significant changes in the structure and chemical composition of the cell wall. According to nitrogen elemental analysis of alkali insoluble wall residues, the chitin content of the wall increased considerably.

The most active extracellular chitinases, determined by SDS-PAGE were found to be 21 and $33 \mathrm{kDa}$. The properties of these enzymes are now examined.

To sum it up, the morphological effects of allosamidin on ageing $P$. chrysogenum gave a clear evidence of the involvement of extracellular chitinases in the age-related fragmentation of the fungus. Moreover, allosamidin-sensitive chitinase(s) have also been shown to play a crucial role in the outgrowth of new hyphal tips from dormant hyphal fragments, which may therefore contribute to the maintenance of the cryptic growth observed under carbon starvation. On the other hand, allosamidin did not influence the process of autolysis of this Penicillium strain during the examined cultivation time. 


\title{
E. SÁNDOR ${ }^{1}$, L. KARAFFA ${ }^{1}$, G. C. PAUL ${ }^{2}$, C. R. THOMAS ${ }^{2}$, A. SZENTIRMAI ${ }^{1}$ \\ Analysis of the morphology of Acremonium chrysogenum under producing circumstances
}

\author{
${ }^{1}$ Department of Microbiology and Biotechnology, Faculty of Science, University of Debrecen, \\ Debrecen, Hungary, ${ }^{2}$ School of Chemical Engineering, The University of Birmingham, Birmingham, \\ United Kingdom
}

Growth of mycelial microorganisms and their interactions with the environment in the fermenter are complex. Morphology and differentiation are very important reflections of the organism physiology, which change during the course of fermentations as well as with operating conditions. Computer-driven image analysis is a vital tool to gather data on these aspects of physiology, and to relate them to fermentation conditions.

For the classification of mycelial morphology by image analysis, cells are considered as either dispersed forms or pellets. Dispersed forms are further divided into two groups, namely freely dispersed forms and mycelial clumps. The latter ones are loose aggregates of hyphae, which are not sufficiently tightly packed to be described as pellets, but which do not show a simple mycelial tree shape. Rate of conversion of the clumps onto freely dispersed forms is a good indicator of the fragmentation of mycelia.

The cephalosporin C producer Acremonium chrysogenum ATCC 46117 did not exhibit pellets during the course of fermentation. Proportion of clumps, roughly $60 \%$ after inoculation, stayed on this level during the first 24 hours of cultivation, then started to decline steadily, reaching a value of less than $10 \%$ of all mycelia and indicating a considerable rate of fragmentation. In contrast, the average number of hyphal tips increased from 4.5 to 6 in the first day of cultivation, followed by a heavy decline which resulted in an average tip number of 3 . Similar time-course pattern was found over the average total hyphal length of the freely dispersed forms. By the 48th hour of cultivation, almost all the carbon sources had been consumed, resulting in a cease in the biomass and $\mathrm{CO}_{2}$ production rates.

Addition of glucose quickly restored biomass and $\mathrm{CO}_{2}$ production, and resulted in a sharp increase in the proportion of clumps, up to the starter value of $60 \%$ of all mycelia. Average hyphal area, average hyphal length and the average number of tips also increased considerably. However, as the additional carbon source was exhausted, all these changes turned into negative in a surprisingly short period of time. A renewed addition of glucose resulted in changes of the same pattern. 
However, addition of soybean oil, considered as an "unregulated" and hence beneficial carbon source with respect to cephalosporin $\mathrm{C}$ production, failed to stimulate the above-detailed changes in morphology. Ratio of clumps to all mycelial forms decreased to low level, together with the average hyphal area, average hyphal length and the average number of hyphal tips, as well as the biomass production rate. Nevertheless, cephalosporin $\mathrm{C}$ production rate, negligible upon glucose addition, was boosted.

Our results clearly indicate that morphological parameters obtained by image analysis are consistent primarily with the growth pattern of the fungus. It can also be concluded, that the ratio of mycelial clumps to the total hyphal pool is the most sensitive indicator of the fragmentation process during fermentation.

\section{T. SIMONICS, A. MARÁZ}

\section{High frequency electro-transformation for Schizosaccharomyces pombe}

Department of Microbiology and Biotechnology, Faculty of Food Science, Szent István University, Budapest, Hungary

High frequency transformation is a prerequisite for efficient transformation of cells with a genomic library. In the yeast Schizosaccharomyces pombe, the alkali cation method is considered as a simple and effective transformation method (Okazaki et al. 1991). We could not, however, adapt this method for our strain (S 18-82), which originated from the crossing and meiotic segregation of a transformable (D 18) and a selenate-resistant auxotrophic strain (0-82).

The aim of our experiments was to develop an efficient, high frequency electroporation method for transformation of S 18-82 ura4 strain with genomic bank based on pUR $18 \mathrm{~N}$ vector.

We applied treatment of cells before electroporation (Gene Pulser, BioRad) with disulphide reducing agents 2-mercapto-ethanol or dithiothreitol and partly digested the cell wall with lysing enzyme (Sigma). Different parameters for the electroporation were used (voltage, capacitance and resistance) and the effect of osmotic stabilization of cells after electric pulse was also tested. By the use of optimum electroporation parameters, $10^{3}$ and $10^{4}$ transformants/ $\mu$ g DNA was achieved for S 18-82 and D 18, respectively.

This work was supported by Hungarian grant OTKA T 022744

1. Okazaki, K. et al.: Nucl Acid Res 18, 6485-6489 (1991). 


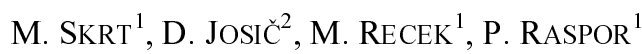 \\ Isolation of low-molecular-weight chromium species from yeast Candida intermedia
}

\author{
${ }^{1}$ Biotechnical Faculty, University of Ljubljana, Jamnikarjeva 101, 1001 Ljubljana, Slovenia, ${ }^{2}$ Research
} and Development Department, Octapharma, Vienna, Austria

In 1988 chromium was recognized as an essential element for humans (IPCS, 1988) and adequate daily dietary intake (ESADDI) was established by the FOOD and Nutrition Board of the National Academy of Science (Food and Nutrient Board, 1989). The chromium story began in 1959 though, when Schwarz and Mertz found that chromium-rich brewer's yeast was the most efficient regulator of glucose tolerance in rats compared to inorganic chromium(III) compounds. Chromium species was named as Glucose Tolerance Factor (GTF) and Cr(III) was recognized as biologically active component of the substance GTF (Schwarz and Mertz, 1959). Ever since researchers tried to isolate the chromium GTF from yeast Saccharomyces cerevisiae, since it was proved that $S$. cerevisiae yields the largest quantity of naturally occurring chromium (Toepfer et al., 1973). Today, the enigma of isolated chromium binding compounds from yeasts is characterization of chromium ligands. The hypothesis is that chromium is coordinated to amino acids such as glycin, glutamic acid, cystein or maybe to nicotinic acid which was later seriously questioned (Sumrall and Vincent, 1997). The first partially characterization of LMWCr compound was done by Yamamoto (Yamamoto et al., 1987), who isolated LMWCr from the rabbit liver (later also from other mammals) and it is believed to be naturally-occurring, biologically active, chromium-containing oligopeptide of ca 1500 daltons in mammals (Davis and Vincent, 1997). In order to contribute to chromium story, we isolated LMWCr species from chromium(III) chloride enriched yeasts Candida intermedia in phase of exponential growth. Biomass was harvested from two different bioprocesses, in one chromium(III) (in form of chromium(III) chloride hexahydrate) supplementation was $5 \mathrm{mM}$ and in the other $20 \mathrm{mM}$. LMWCr species from yeast Candida intermedia were isolated as ethanol precipitates from cytoplasm. In comparison $\mathrm{LMWCr}$ species were isolated from biomass Candida intermedia, which was not enriched with chromium(III) chloride. The following comparison of all three LMWCr species from Candida intermedia was made by ion-exchange chromatography on Pharmacia Biotech DEAE-Sepharose fast flow support and on BIA CIM-DEAE disks. Electrothermal atomic absorption spectrometry (EAATS) and FAAS were employed for detection of isolated and separated LMWCr species. Results revealed that although total chromium content was highest in LMWCr species isolated from biomass Candida intermedia enriched with $20 \mathrm{mM} \mathrm{Cr}(\mathrm{III})$, total 
LMWCr species amount was lower compared to the total amount of LMWCr species from $5 \mathrm{mM} \mathrm{Cr}(\mathrm{III})$ enriched biomass Candida intermedia. IR spectroscopy was employed to detect $\mathrm{Cr}$-species in each isolation step. Size-exclusion chromatography on Pharmacia Biotech Superdex support revealed that all LMWCr species have molecular weight below 10000 .

1. Davis, C. M., Vincent, J. B.: Arch Biochem Biophys 339, 335-343 (1997). 2. Food and Nutrient Board: 10th ed. National Academy Press, Washington, 1989. 3. DC. IPCS International Programme on Chemical Safety, WHO, Geneva, Switzerland, 1988. 4. Schwarz, K., Mertz, W.: Arch Biochim Biophys 85, 292 (1959). 5. Sumrall, K. H., Vincent, J. B.: Polyhedron 16, 4171-4177 (1997). 6. Toepfer, E. W., Mertz, W., Roginski, E. E., Polansky, M. M.: J Agr Food Chem 21, 69-73 (1973). 7. Yamamoto, A., Wada, O., Ono, T.: Eur J Biochem 165, 627-631 (1987).

\section{A. SZABÓ}

\section{A comparative study of alkaline ponds in the Hortobágy and Kiskunság National Parks}

Department of Microbiology and Soil Sciences, Agricultural Centre, Debrecen University, Debrecen, Hungary

Protozoological research of small alkaline bodies may arouse interest because these biotopes are unique in Europe, or all over the world.

Small alkaline ponds (Zab-szék, Fehér-szék, Kelemen-szék, Bödi-szék) near Szeged and Kecskemét (KNP - Kiskunság National Park) evolved on sodic "solonchak" soils with alkaline upper A-layer. Therefore their water is very alkaline (pH: 9.2-9.5) all the year round, the conductivity is high $(1000-9700 \mu \mathrm{S} / \mathrm{cm})$ with a $\mathrm{Na}-\mathrm{HCO}_{3}-\mathrm{Cl}$ character. These water, have a stable ion content and are usually opalescent. Their depth is $20-50 \mathrm{~cm}$.

Small water bodies of Zám-puszta (south of Faluvéghalom, HNP - Hortobágy National Park) accumulating in the microgeomorphologically deeper, barren areas are found on different subtypes of "solonetz" soils with acidic A-layer, thus their water is usually neutral or slightly alkaline $(\mathrm{pH}$ : 7.3-8.6). Conductivity values are relatively low (470-900 $\mu \mathrm{S} / \mathrm{cm}$ ), becoming only higher (tip to $2000-5800 \mu \mathrm{S} / \mathrm{cm}$ ) during the concentration process. These waters are opalescent, their depth is $10-25 \mathrm{~cm}$. The water character is mainly $\mathrm{Na}-\mathrm{Cl}-\mathrm{HCO}_{3}$, sometimes $\mathrm{Na}-\mathrm{HCO}_{3}-\mathrm{Cl}$.

As a consequence of these facts there are significant differences in the Ciliata fauna of the two studied areas. This can be essentially explained by the influence of the different chemical character of the waters and their effect on the species diversity. 
As it has been proven by earlier studies $30-32 \%$ of Ciliata species in the small water bodies of the KNP were preferring alkaline environment while this figure in the case of the HNP ponds was found to be only $18-20 \%$.

There are many cosmopolitan species of wide ecological tolerance spectrum in both areas. The number of species is low in the small alkaline ponds of the two parks (4-6 species as an average), but especially low in those of the KNP. It is remarkable that Astylozoon vagans, Epistylis digitalis, Marituja pelagica, Hypotrichidium tisiae, Pseudochilodonopsis algivora was found exclusively in the HNP ponds, while Mycterotrix ovata, Pseudochilodonopsis piscatoris, Prorodon marinus and Coleps minor only in the KNP ones.

As a result of our studies a number of species preferring definitely the alkaline, sodic environment were found even in small water bodies of $\mathrm{Cl}^{-}$character, like Epistylis halophila, Epistylis microdiscum, Uronema marinum; Monodinium sp., Hemiophrys fusidens, Oxitricha sirnilis, Vorticella difficilis, Hastatella radians, Astylozoon fallax, Astylozoon vagans, Frontonia leucas, Frontonia atra.

\section{Zs. SZILÁGYi ${ }^{1}$ Á. GRALLERT ${ }^{1}$, E. ZILAHI ${ }^{1}$, M. SIPICZKI ${ }^{1,2}$}

\section{The Schizosaccharomyces pombe sep10 gene encodes a conservative protein that presumably plays a role in transcription of a subset of genes}

\footnotetext{
${ }^{1}$ Department of Genetics and Molecular Biology, University of Debrecen, Debrecen, ${ }^{2}$ Research Group for Microbial Developmental Genetics, Hungarian Academy of Sciences, University of Debrecen, Debrecen, Hungary
}

Regulation of gene expression is remarkably important for unicellular and multicellular eukaryotes.

Based on scientific achievements of recent years, it is accepted that eukaryotic gene expression is an extremely sophisticated and highly organized event, which requires a large number of gene products assembled in different transcription complexes. These complexes have to communicate with activators and repressors to regulate transcription of a single gene, and consist of RNA polymerase II, mediators and co-factors, general and specific transcription factors. Therefore these factors and mediators play an important role in regulating transcription of a subset of genes, and influence numerous cell functions in context with there specificity.

Yeast is a widely used model for understanding cell processes, so that a number of putative mediator and transcription factor genes were identified from Saccharomyces cerevisiae, but little is known about their function. In many aspects, the fission yeast 
Schizosaccharomyces pombe is more similar to higher eukaryotes and provides a powerful model, but genes have not been isolated.

By using the fission yeast, sep mutants with complex defects (including cell separation and mitotic abnormalities) were isolated, and eleven novel sep genes were identified. Three of them were cloned. sep 9 encodes a homologue of SPT8, a protein involved in the SAGA complex existing in baker's yeast, and play a role in chromatin remodelling prior to transcription. The sep 15 gene product is a homologue of the $S$. cerevisiae MED8, a protein required to mediate transcription.

The sep10 protein shows high homology to the SOHI protein and to its homologues from Drosophila melanogaster, C. elegans and Homo sapiens. The SOHI gene is a suppressor of HPRI, which product is a member of a transcription complex, and is believed to act as an effector of several external stimuli.

The lecture will cover mainly the results of studies with the sep 10 gene, and the probable function of the protein in cell separation and differentiation will be discussed.

\author{
GY. SZÜCS ${ }^{1}$, G. REUTER ${ }^{1,2}$, K. BÁNYAI $^{1}$, F. JAKAB ${ }^{1}$, M. ÚJ ${ }^{1}$ \\ Importance, detection, and taxonomic classification of human \\ caliciviruses
}

\footnotetext{
${ }^{1}$ Regional Laboratory of Virology, Baranya County Institute of the State Public Health Sevice, Pécs,

${ }^{2}$ Department of Medical Microbiology and Immunology, Medical Faculty, Pécs University, Pécs, Hungary
}

Human caliciviruses (HuCVs), members of the family Caliciviridae, are the major cause of acute viral gastroenteritis cases and epidemics in all age-groups worldwide. In countries where investigations for the detection of HuCVs have been done, they were found in 30 to $40 \%$ of gastroenteritis cases. These viruses spread by feco-oral route (via contaminated food, water or direct contact) without predominant seasonality, however, a small peak in the number of cases can be observed in winter and spring months under the temperate climate. In addition to sporadic cases, the outbreaks occurring mainly in semi-closed populations, such as nurseries, schools, summer-camps, hospitals, barracks, hotels, restaurants, etc., have special epidemiological importance.

Up to now nobody has been able to propagate HuCVs either in experimental animals or tissue cultures and the infections can be verified only by molecular methods on genomic level. In addition to the reverse transcription-polymerase chain reaction (RT-PCR) using fecal samples (less frequently water and food), sequencing and 
subsequent phylogenetic analysis revealed the circulation of high number of strains and proved their heterogeneity, as well.

Due to the limited data of antigen-based investigations, the taxonomic classification is based on the genom (polymerase and/or capsid region) analysis. Currently, HuCVs are subdivided into two generas as Norwalk-like viruses and Sapporo-like viruses, including two (GI, GII) and one (GIII) genotypes, respectively. Within the genotypes several clades or clusters are described according to the results of comparative investigations of the individual viruses found in different geographical locations.

Because CVs, considering their importance, are still less known in our country, the aim of this presentation - as an introduction of the following accompanying lecture on the first Hungarian HuCV investigations - was to review the increasing epidemiological importance and research of these viruses, and provide information about the diagnostic development for the detection of HuCV infections in Hungary.

\title{
P. G. TORNAI-LEHOCZKI
}

\section{Importance of "CHROMagar Candida" medium in differentiation of foodborne, food spoilage and opportunistic pathogenic yeasts}

\author{
National Collection of Agricultural and Industrial Microorganisms, Szent István University, Somlói út \\ 14-16, H-1118 Budapest, Hungary
}

CHROMagar Candida medium is a differential culture medium, which was originally developed for selective isolation and presumptive identification of some clinically important yeast species. On CHROMagar Candida medium Candida albicans forms green colonies, C. tropicalis blue-gray colonies with dark brownish purple halo, C. krusei, (Issatchenkia orientalis) pink colonies with white edge, C. glabrata deep pink or purple colonies. Together with the differences in colony surface this medium is capable for presumptive identification of the yeast species most commonly isolated from clinical material (Odds and Bernaerts, 1994). The reliability of CHROMagar for the above-mentioned purposes was confirmed by other authors as well (e.g. Freydiere and Gille, 1994a and 1994b).

The purpose of our work was to study the capacity of this medium for visual discrimination of yeast species frequently isolated from different kinds of foodstuffs and some opportunistic pathogenic yeast species associated with food. 190 strains, including 72 type strains, were investigated. The performance of the medium was 
studied by streaking the strains on CHROMagar Candida medium. After 48-72 $\mathrm{h}$ incubation at $30^{\circ} \mathrm{C}$, the morphology and colour of the colonies were noted.

The investigated strains gave green, blue, blue-green, pink, deep violet, claret coloured, yellow, beige, brownish and white coloured colonies. In agreement with the earlier findings (Freydiere and Gille, 1994a) the appearance of the colonies of the investigated Trichosporon cutaneum strains were blue-green, but on the basis of their different colony morphology it was possible to distinguish them from Candida albicans and $C$. tropicalis strains. However the broadening of the spectrum of the investigated species resulted in the detection of other green or blue-green colony colours, e.g. in case of Candida zeylanoides, C. sake, Debaryomyces polymorphus, D. maramus and some Cryptococcus species. The colour of the colonies of the different strains representing the same species was the same or very similar, indicating that the medium is suitable for typing the strains of non clinical yeasts. In some cases the medium proved to be useful in rapid differentiation of related species pairs belonging to the same genera as well. CHROMagar Candida medium provides a fast possibility to separate Zygosaccharomyces bailii from $Z$. rouxii, Debaryomyces hanseni from $D$. polymorphus as well as Rhodotorula glutinis from R. mucilaginosa.

\section{S. TÓTH ${ }^{1}$, B. FILIPIČ ${ }^{2}$, F. SOMOGYVÁRI ${ }^{3}$, K. KOVÁCs ${ }^{1}$, R. KOREN ${ }^{2}$}

\section{Inhibition of cell culture growth by short impulses of ionic current, electric and magnetic fields}

\footnotetext{
${ }^{1}$ Department of Biotechnology, University of Sciences, Szeged, Hungary, ${ }^{2}$ Institute of Microbiology and Immunology, Medical Faculty, Ljubljana, Slovenia, ${ }^{3}$ Pándy Kálmán Hospital, Gyula, Hungary
}

Adherent cell cultures of different species origin were treated with short (10 ms) impulses of direct ionic current, were submitted to electric field or to magnetic field for the same period. The field force was $100 \mathrm{~V} / \mathrm{cm}$ for the ionic current, $1000 \mathrm{~V} / \mathrm{cm}$ for the electric field and $10 \mathrm{mT}$ for the magnetic field. The energy densities were $1.8 \times 10^{5}$ $\mathrm{J} / \mathrm{m}^{3}, 1.1 \mathrm{~J} / \mathrm{m}^{3}$ and $6 \mathrm{~J} / \mathrm{m}^{3}$, respectively. All cultures showed a marked growth inhibition upon three consecutive impulses applied before seeding of the cells. Although cumulative population doubling curves run parallel - indicating a single modulation event - the effect could be observed at least for 72 hours. The greatest inhibition was observed when electric field was used. Although the culture conditions would greatly influence the growth responses of the tested cell lines to the electromagnetic stimuli, it was proven that the responses could be attributed to the cells and not to the 
environmental conditions. It is also apparent that the effectivities of the three stimulus types were markedly different. The extremely high efficiency of electric and magnetic fields in comparison to direct current underlines the importance of careful assessment of the environmental risk of the electromagnetic pollution.

\author{
E. VARGA ${ }^{1}$, A. MARÁZ ${ }^{2}$, G. MĂRCuș ${ }^{1}$, L. HeCsER $^{1}$, K. CSEDÖ $^{1}$
}

\title{
Effects of different ointments with Saccharomyces cerevisiae in regeneration of epidermis
}

${ }^{1}$ University of Medicine and Pharmacy, Marosvásárhely, Romania, ${ }^{2}$ Faculty of Food Science, Szent István University, Budapest, Hungary

We studied the effect of inactivated baker's yeast for external use on rabbits. We eliminated the epidermis from exterior members of the legs, making 4 lesions with 1 $\mathrm{cm}$ diameters after depilation. We prepared three ointments with inactivated baker's yeast and we treated the rabbits divided in to three groups.

All animals had 4 lesions. The first lesion from left anterior leg was not treated. It was the control lesion. The second lesion from left posterior leg was treated with 5\% inactivated yeast incorporated in one of the base material of ointments. The third lesion from right anterior leg was treated with one of the base material of ointments and the fourth with inactivated powder of yeast. We treated the rabbits with these preparations one hour after the epidermis elimination.

The first group of rabbits was treated with 5\% inactivated baker's yeast incorporated in unguentum simplex, with unguentum simplex and with powder of inactivated yeast. The second group of rabbits was treated with 5\% inactivated baker's yeast incorporated in Carbopol gel, with Carbopol gel and with powder of inactivated yeast. The third group of animals was treated with 5\% inactivated baker's yeast incorporated in unguentum emulsificans, with unguentum emulsificans and with powder of inactivated yeast.

After 2 days of treatments the epitelisation process was faster on lesions treated with inactivated yeast powder and with $5 \%$ inactivated yeast incorporated in Carbopol gel. After 4 days in this regions the lesions was softer and smaller. After 6 days this sloughs was very small and very soft.

The scar process was faster on lesions treated with inactivated yeast powder, followed by lesions treated with 5\% inactivated yeast incorporated in Carbopol gel. When we used the 5\% inactivated yeast in base material of ointments in the first group of animals the wounds was normal and in the third group these were big and cracked. The lesions treated with base material of ointments healed later than the untreated lesions (control lesions). 


\title{
J. VARGA ${ }^{1}$, L. FERENCZY ${ }^{2}$
}

\section{Taxonomic position of the cyanobacterium causing toxic algal blooms in lake Balaton}

\author{
${ }^{1}$ Department of Microbiology, Faculty of Sciences, University of Szeged, Szeged, ${ }^{2}$ Microbiological \\ Research Group of the Hungarian Academy of Sciences, University of Szeged, P.O. Box 533, H-6701 \\ Szeged, Hungary
}

A filamentous cyanobacterium responsible for toxic algal blooms in Lake Balaton was isolated and cultivated in our laboratory. Morphological examination of the isolate led to the assumption that it belongs to the species Cylindrospemopsis raciborskii. To prove this hypothesis, nucleic acids were isolated from the isolate, and sequence analysis of the $16 \mathrm{~S}$ rRNA gene was carried out. A simple nucleic acid isolation protocol was developed for the isolation of high molecular weight DNA and RNA simultaneously from filamentous cyanobacteria. Plasmids or phage nucleic acids were not observed in the total nucleic acid preparations. A $1500 \mathrm{bp}$ fragment of the 16 S rRNA gene was amplified and sequenced using appropriate primers. Altogether 1423 nucleotides were involved in the phylogenetic analysis. Parsimony and neighbourjoining analyses of sequence data indicated that this isolate is most closely related to $C$. raciborskii strains, although the sequence of its $16 \mathrm{~S}$ rRNA gene differs significantly (3.85\%) from those of Australian C. raciborskii isolates. More C. raciborskii isolates of diverse origin should be examined to clarify the taxonomic identity of this strain.

This work was financially supported by an FKFP grant \#0216/1997, and OTKA grant \#F023062. J. Varga was in receipt of a Bolyai Research Fellowship grant.

\author{
J. VARGA ${ }^{1}$, B. TÓtH ${ }^{1}$, SZ. SZENCZ ${ }^{1}$, J. MOLNÁR $^{1}$, Cs. FEKETE $^{2}$, L. SZABÓ $^{2}$ \\ Mycoviruses in Aspergillus species \\ ${ }^{1}$ Department of Microbiology, Faculty of Sciences, University of Szeged, Szeged, ${ }^{2}$ Agricultural \\ Biotechnology Center, Gödöllő, Hungary
}

Mycoviruses with double-stranded RNA (dsRNA) genomes are frequently encountered in Aspergillus isolates. A detailed study of such dsRNA elements in black Aspergillus isolates collected worldwide was carried out, and the data were analysed. The results indicate that about $10 \%$ of black Aspergilli are infected. However, the geographic distribution of infected isolates exhibit large variations; $3-13 \%$ of the isolates collected from different continents were found to carry dsRNA elements. 
Hybridization experiments indicated that electrophoretic banding patterns are not reliable tools for estimating the diversity of these mycovirus genomes. Among strains representing other Aspergillus sections, dsRNA segments indicative of mycovirus infection were observed for the first time in 3 Aspergillus species (A. leporis, $A$. petrakii, A. primulina). The last species is able to reproduce sexually, its teleomorph is Neosartorya primulina. This is the second report on the detection of naturallyoccurring dsRNAs in sexually reproducing Aspergillus species. The presence of viruslike particles in these and other Aspergilli was also examined by electron microscopy. Most infected Aspergillus isolates examined were found to carry virus-like particles in the size range of $36-40 \mathrm{~mm}$.

This work was financially supported by Hungarian Scientific Research Fund (OTKA) grants \#F023062 and \#A334. J. Varga was in receipt of a Bolyai Research Fellowship grant.

\section{Cs. VÁGVÖLGYI, T. PAPP, H. HEINRICH, GY. LUKÁCS, L. FERENCZY}

\section{Genetic variability of Rhizopus strains assessed by random amplified polymorphic DNA analysis and carbon source utilization tests}

${ }^{1}$ HAS Microbiological Research Group, Department of Microbiology, University of Szeged, P.O. Box 533, H-6701, Szeged, ${ }^{2}$ Department of Microbiology, Faculty of Sciences, University of Szeged, P.O. Box 533, H-6701, Szeged, Hungary

RAPD analysis and carbon source utilization tests were carried out on 25 Rhizopus isolates. A high level of intra- and interspecific genetic variability was detected. However, 3 species groups (Rh. stolonifer, Rh. circinans and Rh. oryzae) could be identified unambiguously. The $R h$. circinans was originally described as an independent species, but the recent taxonomic revision of the genus (carried out on a morphological basis) did not distinguish it from $R h$. stolonifer. Our results do not support this approach, but clearly show the need to handle $R h$. circinans as a separate species. Strains of $R h$. oryzae form a relatively uniform group; both the patterns of the carbon source utilization and the RAPD amplification products were very similar even for isolates originating from widely-separated places (e.g. from different continents). These data disprove the view that $R h$. oryzae is a heterogeneous group in the Rhizopus genus. The mainly morphological characters, used in previous taxonomic works on this genus, exhibit too much variation to form the basis for a long-standing taxonomy and/or a safe species delimitation. Accordingly, in our work physiological and RAPD 
markers were determined which are suitable for identification of the isolates of the investigated Rhizopus species.

This study was supported by OTKA grant T032738.

\title{
P. VLADÁR ${ }^{1}$, A. BORSODI ${ }^{1}$, A. MICSINAI ${ }^{1}$, N. M. RESKÓNÉ ${ }^{2}$, G. KOVÁCS $^{1}$,
} O. ORAVECZ ${ }^{1}$, B. BESZTERI ${ }^{1}$, J. MAKK ${ }^{1}$, A. HALBRITTER ${ }^{1}$

\section{Sulphate-reducing bacteria from the healthy and the degrading reed rhizosphere of lake Velencei}

\author{
${ }^{1}$ Department of Microbiology, Eötvös Loránd University, Budapest, ${ }^{2}$ Central Danubian Environmental \\ Protection Agency, Székesfehérvár, Hungary
}

Rhizome of healthy and degrading reed stands and sediment samples from Lake Velencei were taken in June 1999. To estimate the CFU number of the sulphatereducing bacteria (SRB) in the rhizosphere and sediment the MPN technique was used. Cultivation of the SRB took place in an anaerobic cabinet using different SRB media and finally 7 pure cultures were obtained.

The 16S rRNA gene of these strains was subjected to ARDRA and two groups have been detected. The partial sequencing of the 16S rDNA of each group was carried out.

The Anaerobic BIOLOG identification system was applied to investigate the sole-carbon-source utilization patterns of the two sequenced bacterial strains.

The number of SRB in the rhizosphere was about two orders higher than in the sediment. This can be due to the increased amount of root exudates, organic matter from the biodegradation processes and fermentation products in the rhizosphere.

The bacterial strain isolated from the rhizosphere of the healthy reed stand proved to be Desulfovibrio alcoholivorans at a similarity value of $98.4 \%$. The other strain isolated from the degrading stand was closest to Desulfovibrio fructosivorans (95.6\%) based on partial sequencing, however, when the full sequence of the $16 \mathrm{~S}$ rDNA was analysed it was found to be nearly identical (99\%) with the sequence of an environmental Desulfovibrio clone obtained from a French wine distillery's anaerobic digestor. 


\section{T. ZAGORC ${ }^{1}$, M. RESNIK ${ }^{2}$, K. POVHE JEMEC ${ }^{1}$, M. KMETIC ${ }^{2}$, J. NEMANIC ${ }^{2}$, P. RASPOR ${ }^{1}$}

The influence of indigenous wine killer yeast on white wine fermentations - microbiological, chemical and sensorial evaluation

${ }^{1}$ Biotechnical Faculty, University of Ljubljana, Jamnikarjeva 101, 1001 Ljubljana, ${ }^{2}$ Slovenian Agricultural Institute, Hacquetova 17, Ljubljana, Slovenia

The problem of top quality wine production is tightly connected with wine yeast selection and strain improvement. Selected yeast strains can provide better control over the fermentation process. The use of a selected yeast strain can improve wine quality and stability in various dimensions. For these reasons, yeast selection is a common practice in winemaking industry. General problem of traditional selections is that they are often too much oriented in the selection of an universal wine yeast strain. Our research was focussed at the selection of indigenous wine killer yeast with beneficial properties for the product, which should keep the traditional local characteristics of wine. Primary selection was done on total wine yeast population of 462 isolates. We performed selection of potential starter culture among several indigenous wine killer yeast strains of Saccharomyces genus, which were characterized regarding killer activity and plasmid profiles. Four carefully selected strains were inoculated in the must of Malvazija, which was prepared according to traditional standardized technology. Fermentation process and its dynamic were followed microbiologically and chemically during the fermentation time course, and sensorically as well. With microbiological assays we trace killer character of isolated yeast generated from the starter culture in four consecutive sampling points from fermentors. Further the proportion of killer starter vs. natural flora was estimated by karyotyping. It was found that indigenous flora was really suppressed by killer inoculum. With numerous chemical assays we followed accumulation of amino acids, production of ethanol and higher alcohols, conversion of sugars, level of organic acids as well as tradition enological parameters what gave an excellent view on yeast from product point of view. Since chemical status of wine is not sufficient for final decision on its quality, a testing penal was performed as well. Must transformation to wine was followed sensorically with an expert, however after five months of maturation the produced wine was evaluated according to the official method of OIV with highly skilled persons. It is encouraging to conclude that one of the selected wine killer strains produced the most favourable wine compared to spontaneous fermentation process and some industrial starter cultures from the market tested in the same Malvazija must. 


\section{Antimycotic sensitivity/resistance of Candida albicans and nonalbicans species}

Mycological Department, “Johan Béla” National Center for Epidemiology, Budapest, Hungary

There are several mechanisms defending the human being against infections of yeasts colonizing the mucosa and skin surfaces of the human body or environmental vectors (equipment, food, ...), however, minor defect of the immunsystem is enough for infection caused by the most virulent $C$. albicans strains.

The higher lack of immundefense can lead to severe invasive mycoses and can give opportunity for infections by the other less virulent fungal species.

The spectrum of the pathogen yeasts has changed and extended because of the increased number of neutropenic patients, parenteral feeding, using of catheters, etc., and usage of the (sometimes excessive) azole antifungal therapy.

While in the 1970' and 1980' the consideration was focussed on the $C$. tropicalis and C. parapsilosis, in the 1990' the fluconazole resistant C. krusei and $C$. glabrata has become most important.

There are emerging new tasks in the mycological diagnostics for exact identification and determination of the antimycotic sensitivity/resistance of the isolated strains because of the changing of the spectrum of the pathogen species.

We have tested the antimycotic fluconazol (Flu), itraconazol (Itr), amphotericin B (AmB), ketoconazol (Ket), miconazol (Mic), nystatin (Nys)) sensitivity/resistance of the most common Candida albicans strains (296) and "nonalbicans" Candida strains (144): Candida colliculosa (1), C. glabrata (70), C. guilliermondii (I), C. inconspicua (5), C. kefyr (6), C. krusei (15), C. lipolytica (1), C. lusitaniae (7), C. magnoliae (1), C. norvegensis (10), C. parapsilosis (12), C. tropicalis (10), and Geotrichum candidum (1), G. sp. (1), Rhodotorula sp. (3), Saccharomyces cerevisiae (16), Trichosporon beigelii (4), T. capitatum (3), T. sp. (1) by Etest, Fungitest and disk diffusion in 19992000 (I-II quarter)

While the large amount of the Candida albicans strains was proved to be sensitive or intermediate sensitive to the tested antimycotics other yeast species (Candida glabrata, Candida krusei, Candida lusitaniae, Candida norvegensis, Candida parapsilosis, Candida tropicalis, Saccharomyces cerevisiae) seemed to be resistant in higher rate in case of some antimycotics (Flu, Itr, Ket, AmB). The development of resistance against nystatin, miconazole, however, was not found important. 
Summary:

1. A revision of the list of - mainly fluconazole - resistant Candida species must be made.

2. The identification and discrimination of the biochemically similar Candida species should be made very carefully, as test kits commercially available might cause some problems.

3. The problematics of monitoring, therapy and profilaxis should be reconsidered because of the increased number of Amphotericin B resistant isolates (mainly in case of C. krusei). 


\title{
BACTERIOLOGY AND VIROLOGY
}

\author{
S. G. B. AMYES \\ Genetic problems of penicillin-resistant pneumococci \\ Department of Medical Microbiology, The Medical School, University of Edinburgh, Teviot Place, \\ Edinburgh EH8 9AG, UK
}

Streptococcus pneumoniae is a common cause of severe community-acquired pneumonia. For many decades, this pathogen has been treated successfully with penicillin and until recently, has remained sensitive. However, within the last decade, there has been a steady increase in penicillin resistance; which has, in some areas, resulted in the more than $50 \%$ of isolates losing their sensitivity. This decrease in susceptibility is manifested by changes in the penicillin binding proteins, particularly by the formation of mosaic genes. The acquisition of penicillin-resistance is accompanied by a corresponding increase to most of the beta-lactam antibiotics, including the carbapenems. Interestingly, the proportional increase to cephalosporin resistance is higher raising the question whether their usage has promoted the selection of beta-lactam resistance. The bacteria that become resistant to beta-lactams are also likely to become resistant to the macrolides, suggesting that these strains have a predisposition towards the acquisition of resistance.

These bacteria do not, however, have an innate capability to become resistant to the fluoroquinolones. There are a number of new fluoroquinolones currently targeted at pneumococci. Resistance can emerge to them but at a relatively low frequency. There is some debate as to which is the main target of these new fluoroquinolones, and thus which mutations contribute most to resistance. The traditional view is that the main target is Topoisomerase IV, but there is increasing evidence to suggest that the Gyrase A subunit is, as it is in Gram-negative bacteria, the primary target of the fluoroquinolones and that mutations in this protein are the major cause of resistance.

A major difficulty in following the epidemiology of resistance has been in the typing of the bacteria. They are traditionally typed by serology; however, more recent genotyping techniques do show considerable variation within a single serotype suggesting that it may be difficult to identify clonal spread, and thus epidemic formation, if phenotyping is used alone. 


\title{
M. BAGDÁNY ${ }^{1}$, I. SZABÓ ${ }^{2}$, F. HERNÁDI $^{1}$, ZS. GÁL $^{1}$
}

\section{Oxacillinase activity in clinical isolates of borderline methicillin resistant Staphylococcus aureus}

\author{
${ }^{1}$ Department of Pharmacology, ${ }^{2}$ Department of Humangenetic, DEOEC, Debrecen, Hungary
}

Staphylococcus aureus is one of the most threatening Gram-positive clinical pathogen, which with increased $\beta$-lactam resistance can cause many therapeutical failures. At first the penicillin resistance, then soon after the introduction of methicillin the appearance of methicillin resistant was described. Methicillin resistance is termed intrinsic due to the production of an additional, low affinity penicillin-binding protein. Recently, S. aureus strains with borderline methicillin resistance have been identified. Borderline phenotype cannot be attributed solely to the classical penicillinase, since a second, methicillin hydrolysing enzyme (methicillinase) is produced.

The aim of our work was to search borderline methicillin resistance strains among clinical isolates of $S$. aureus in order to study the resistance mechanism.

We have worked with altogether 53 clinical isolates and according to their MIC values four were found to be borderline resistant. In the presence of $\beta$-lactamase inhibitors (clavulanic acid, sulbactam) their MIC values to oxacillin were reduced. To determine the enzyme activity, we used whole cells as enzyme sources. We measured the $\beta$-lactamase activity with and without methicillin induction. All the four strains produced inducible $\beta$-lactamases. The induction ratios (the ratios of the $\beta$-lactamase activities of the induced and uninduced cells) were between 12 and 24 . For typing $\beta$ lactamases we used $\beta$-lactamase reference strains. According to the activities of the cefazolin/cephaloridine and nitrocefin/cefazolin ratio, the $\beta$-lactamases produced by the four strains proved to be type A.

For the measurement of the hydrolysis of oxacillin we elaborated two different methods. In the first one, the hydrolysis of oxacillin was determined spectrophotometrically. Nitrocefin was applied as control compound. The oxacillin was hydrolysed by the cells in detectable extent. The whole-cell preparation contained both the extracellular and membrane-bound $\beta$-lactamases. To clarify whether the extracellular or the membrane-bound enzyme was responsible for the hydrolysis of oxacillin, we isolated extracellular enzymes and purified by affinity chromatography. These preparations did not hydrolyse oxacillin in detectable extent. In the second method, membranes were prepared in order to demonstrate that oxacillinase activity originated from the membrane fraction. The isolated membranes were preincubated with oxacillin solution, and the residual concentrations of oxacillin were measured by agar diffusion method using Bacillus subtilis test strain. The isolated membranes were 
able to split oxacillin. Our observations confirmed the findings that a membrane-bound oxacillinase is responsible for the borderline methicillin resistance in S. aureus strains.

\section{T. BAKONYI ${ }^{1}$, M. DOBOS-KOVÁCs ${ }^{2}$, M. RUSVAI ${ }^{1}$}

Nucleic acid investigations of the acute bee paralysis virus and development of a diagnostic PCR assay

\footnotetext{
${ }^{1}$ Department of Microbiology and Infectious Diseases, ${ }^{2}$ Department of Pathology and Forensic Veterinary Medicine, Faculty of Veterinary Science, Szent István University, Budapest, Hungary
}

An unusual adult bee and brood mortality was observed in some colonies of an apiary near Budapest. In healthy honey bee pupae infected by an injection of bacteria free extract of the diseased adult bees a virus was detected by electron microscopy, and the virus was later identified as acute paralysis virus (APV) by serological investigations.

The isolate was propagated by intra-abdominal injection of white- or light brown-eyed pupae from symptomless colonies. The pupae were maintained at $35{ }^{\circ} \mathrm{C}$ for three days and were homogenized afterwards. Viruses were purified from the suspension and concentrated by caesium-chloride gradient ultracentrifugation. The viral RNA was isolated and cDNA was synthetized by oligo (dT) primer method. The cDNA was amplified using virus-specific primers and primers designed under conserved sequences of related picornaviruses. The polymerase chain reaction (PCR) provided specific products. A PCR product was sequenced and aligned to other sequences available at genebank database. The highest consensus was found with a sequence fragment of an APV strain isolated in the United Kingdom. Now we are concerned with sequencing further parts of the genome.

Viral nucleic acid was detected directly by RT-PCR from some bee samples from apiaries of five counties of Hungary. We would like to survey the distribution of the acute paralysis virus in the Hungarian apiaries using RT-PCR. We would also like to proof the presence of other bee pathogen viruses by propagation in pupae and electron microscopic investigations.

Our research was supported by OTKA C077 and T030335 projects. 


\section{A. BAKOS, A. VÁRKONYI, J. MINÁROVITS, L. BÁTKAI}

\section{Effect of simulated microgravity on human lymphocytes}

Microbiological Research Group, “Johan Béla” National Center for Epidemiology, Budapest, Hungary

During space flight the function of the immune system changes significantly. This is partly due to microgravity condition itself. We wished to analyse mechanisms responsible for changing leukocyte functions in low gravity environment. For terrestrial simulation of microgravity we used a Rotary Cell Culture equipment developed by NASA.

We investigated the effect of simulated microgravity on separated human peripheral blood lymphocytes. Different cell populations were detected with the help of Flow Cytometer (Coulter EpicsXL) by antibodies conjugated to fluorescent dyes (anti CD4-PE, anti CD8-PE and anti CD19-PC5). Since the microgravity during space flight reduces the number of peripheral lymphocytes we supposed that apoptotic (programmed cell death) processes might be induced. This hypothesis was supported by our earlier result demonstrating that simulated microgravity increased the level of Tumor Necrosis Factor-alpha (a known apoptotic signal molecule) significantly.

For the detection of apoptosis we applied the Annexin-V propidium-iodide Assay which is based on the appearance of phosphatidil-serine (PS) in the outer leaflet of the membrane. PS is recognized by FITC conjugated Annexin-V protein. As propidium-iodide cannot penetrate through intact membranes, this DNA binding florescent dye discriminates between cells with apoptotic PS distribution and disrupted cells (caused by other mechanisms) with PS in the inner leaflet of membrane.

During a three days period of observation simulated microgravity did not affect the percentage of apoptotic cells in $\mathrm{T}$ helper $(\mathrm{CD} 4+)$ or cytotoxic $\mathrm{T}(\mathrm{CD} 8+)$ cell populations. On the contrary, the percentage of B cells (CD 19+) dying by programmed cell death showed a significant increase over control.

\section{B. BANIZS, CS. JENEY, O. DOBAY, E. ÁDÁM, I. NÁSZ}

\section{The effect of mutant Rab 5 endosomal proteins on adenoviral viropexis}

Institute of Medical Microbiology, Semmelweis University, Budapest, Hungary

The function and the material circulation of the early endosomal compartments that play an important role in adenoviral viropexis are affected by different protein 
containing systems. The function of these proteins is often essentially important. The examination of mutants of these proteins gives important details on the interaction between the virus and the host cell.

Our former investigations proved that the inactivated epsilon COP protein is able to partially inhibit the virus penetration to the cell. As Rab 5 proteins similarly play a basic role in the endosomal material circulation, in this study we examined the effect of these proteins on the adenoviral viropexis: Our data suggest that the mutant Rab 5 N133I with dominant negative effect surprisingly increases the viral entry, although it inhibits the fluid phase endocytosis in the other hand. We presume that the change in the dynamics of the endosomal material circulation stands in the background.

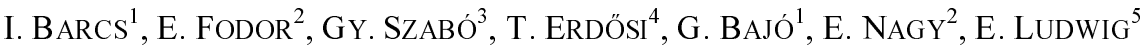

\section{Family-carriage of a Staphylococcus aureus strain examined by classical and molecular microbiology methods}

\author{
${ }^{1}$ Bajcsy-Zsilinszky Municipal Hospital, Budapest, ${ }^{2}$ Department of Clinical Microbiology, Medical \\ Faculty, University of Szeged, Szeged, ${ }^{3}$ Institute of the National Public Health and Medical Officer \\ Service, Budapest, ${ }^{4}$ National Centre for Epidemiology, Budapest, ${ }^{5}$ St. Leslie's Hospital, Budapest, \\ Hungary
}

Staphylococcus aureus strain isolated from a chronic recidival furuncle and its family spread was examined. The strain was isolated from furunculous wound of a 16year-old girl and also from nose or hand samples of her parents and of two sisters. Biotyping by STAPHYtest 16, BBL Crystal Gram positive ID and ATB ID Staph panels, antibiograms, phage patterns, pulsed field gel electrophoretograms and APPCR patterns suggest the presence of the same clone within the family. 


\section{K. BÁNYAI ${ }^{1,2}$, J. R. GENTSCH${ }^{2}$, D. D. GRIFFIN ${ }^{2}$, J. HOLMES $^{2}$, R. I. GLASs ${ }^{2}$, M. ÚJ $^{1}$, G. REUTER ${ }^{1,3}$, GY. SZÜCS ${ }^{1}$}

\section{Investigation of human rotavirus strains in six consecutive rotavirus seasons in Hungary}

\footnotetext{
${ }^{1}$ Regional Laboratory of Virology, Baranya County Institute of the State Public Health Service, Pécs ${ }^{2}$ Viral Gastroenteritis Section, Division of Viral and Rickettsial Diseases, Centers for Disease Control and Prevention, Atlanta (GA), USA, ${ }^{3}$ Department of Medical Microbiology and Immunology, Medical Faculty, Pécs University, Pécs, Hungary
}

Human rotaviruses are the major etiologic agents of viral acute gastroenteritis in childhood. Based on differences of the two surface antigens ( $G$ and $P$ antigens, respectively) many serotypes have been described. The authors aimed to provide data of strain diversity, temporal and geographical distribution of human rotaviruses circulating in two regions (Budapest including the metropolitan area and Baranya county) of Hungary. 1240 rotavirus positive stool samples collected in six consecutive seasons (1994/1995 to 1999/2000) were tested with MAb-EIA. The majority of the samples represented the four most common serotypes (G1 to G4) as follows: G1$61.3 \%$, G2- 14.5\%, G3- 1.5\%, G4- 1.9\%. Mixed infections were detected in $3.2 \%$ of the samples. $9.4 \%$ of the specimens were non-typeable, partly due to strong crossreactions. Furthermore, $8.2 \%$ of the samples showed reactivity with the VP7 specific common MAb (MAb 60), but not with any of the serotype specific MAbs. Some of these ( $0.9 \%$ of the total) displayed G6 specificity and represented the first isolation of this serotype in Hungary and its second detection in Europe. Results obtained with MAb-EIA were confirmed using RT-PCR (144 of 1240) and nucleic acid sequencing. These surveys were extended to the $\mathrm{P}$ antigen, as well. In addition to the most common strains (P[8]G1, P[4]G2, P[8]G3, P[8]G4) five additional genotype combinations were identified (P[6]G4, P[9]G3, P[8]G9, P[9]G6, P[14]G6). Although similar strain diversity has been previously demonstrated, those reports were mostly from tropical settings. 


\section{Induction of full replication cycle of human cytomegalovirus by the Tax protein in CD4+ T cells}

Institute of Microbiology, Medical Faculty, Medical and Health Science Center, University of Debrecen, Debrecen, Hungary

Human cytomegalovirus (HCMV) is one of the most frequent opportunistic agents causing severe illness in chronic human $\mathrm{T}$ cell leukemia-lymphoma type I (HTLV-I) infection. Our previous studies have shown that coinfection of macrophages with HCMV and HTLV-I significantly enhances HCMV replication. HCMV release from dually infected macrophages alone, however, could not account for symptomatic HCMV infection in patients suffering from adult T cell leukemia (ATL). HCMV has been shown in latently infect CD4+ T cells. We hypothesized that interaction between HCMV and HTLV-I in ATL cells was also critical to the dissemination of opportunistic HCMV infection. For this purpose, we studied HCMV replication in various T cell lines. In HUT-78 and H9 cells no replication of HCMV was observed. In contrast, HCMV infection of HTLV-I-carrying MT-2, MT-4 and C8166-45 cells resulted in release of infectious progeny virus. Since cellular transcription factors NF$\kappa B, C R E B$ and SRF play a crucial role in HCMV replication, presence of these Taxinducible proteins was investigated in the various $\mathrm{T}$ cell lines by electrophoretic mobility shift assay. Results showed high levels of NF- $\mathrm{B}$, CREB and SRF expression in MT-2, MT-4 and C8166-45 cells, whereas none of these transcription factors were found in HUT-78 and H9 cells. Using an inducible system. (JPX-9 cells), significant NF- $\kappa \mathrm{B}, \mathrm{CREB}$ and SRF expression as well as HCMV replication were observed. These data strongly suggest that the effect of Tax on HCMV replication in $T$ cells is accomplished through at least three host-related transcription factor pathways. 


\section{O. BENEDEK ${ }^{1,2}$, J. KNURR $^{1}$, C. L. TURNBOUGH JR. ${ }^{1}$}

\section{Characterization of tight-binder peptide ligands to Bacillus subtilis} spores

${ }^{1}$ Department of Microbiology, University of Alabama at Birmingham, Birmingham, AL 35294 USA,

${ }^{2}$ Department of Microbiology and Immunology, University of Pécs, Pécs, Hungary

Phage display is a novel method for analysing protein-protein interactions. Obviously, it might be also helpful to study the spore coat assembly in Bacillus subtilis, which relies on the proper interaction of several structural proteins and enzymes.

We used an M13 phage display library expressing random heptamer peptides to select ligands, which bind tightly to Bacillus subtilis spores. After several rounds of biopanning we enriched for heptamers containing an NHFLP consensus sequence at the $\mathrm{N}$-terminus of the peptides. We constructed two phages expressing the tetramer sequence NHFL and a pentamer sequence NHFLP. Using competitive biopannings we were able to show that NHFLP sequence is also a sufficient binder but not the tetramer NHFL sequence.

Doing sequence similarity search we found the NHFLP sequence close to the Nterminus of the $\mathrm{SpsC}$ protein. Its N-terminus is the following: MVKQRNHFLPYSLPL... SpsC protein is responsible for spore coat polysaccharide biosynthesis along with other proteins transcribed from the spsA-K gene cluster which knock-out makes the spore surface more hydrophobic. Based on the theory that with phage display we can mimic naturally occurring protein-protein-protein interactions we proposed that this protein is processed and needs the NHFLP sequence for binding to the spore surface. We constructed several phage expressing decamer sequences from the SpsC N-terminus: MVQKRNHFLP, RNHFLPYSLP and NHFLPYSLPL. We analysed phage binding to Bacillus subtilis spores with flow cytometry and only the NHFLPYSLPL phage gave a fluorescent shift. This result supports the protein processing theory. Expressing wild type and N-terminal deletion mutants of SpsC and doing further flow cytometry on Bacillus subtilis spores would completely confirm our proposal. 


\section{BOLE-HRIBOVŠEK, M. DROBNIČ-KOSOROK}

\section{Influence of chestnut tannins on growth of Clostridium perfringens and $E$. coli}

Veterinary Faculty, University of Ljubljana, Gerbiceva 60, 1000 Ljubljana, Slovenia

Introduction: Chestnut tannins are a mixture of hydrolysable and condensed tannins, known to react nonspecifically with proteins, forming insoluble complexes. The result of this interaction is an inactivation of the proteins' biological activity. Clostridium perfringens type $\mathrm{C}$ is the etiologic agent of haemorrhagic enterotoxaemia in piglets, lambs, calves, foals and sheep and necrotic enteritis in chickens. Escherichia coli causes different conditions affecting intestine, toxaemia and sepsis in many domestic animals and men.

Materials and methods: As a source of tannins we used Farmatan (Tanin, Sevnica), containing $70 \%$ of tannins. The influence of tannins on the growth of Clostridium perfringens type C (ATCC 51880) was tested in Brain heart infusion broth. After 12 hours anaerobic incubation at $37{ }^{\circ} \mathrm{C}$ tenfold dilutions were prepared from which cfus on blood agar plates incubated anaerobically for 24 hours were counted and numbers of $C$. perfringens calculated. In the preliminary test concentrations of $0.5 \%$ and $0.05 \%$ tannins were used. Twofold dilutions down to $0.0015 \%$ were used to determine MIC. E. coli $\mathrm{G} 491(0138 ; \mathrm{K} 81,88 \mathrm{ac})$ was tested with the concentrations of $2.5 \%, 0.5 \%$ and $0.05 \%$ of tannins in peptone water (PW), Brain Heart Infusion Broth (BHI) and Trypticase Soy Broth (TSB). The inoculum was $2.2 \times 10^{6} \mathrm{cfu} / \mathrm{ml}$. After an aerobic incubation of 8 hours at $37{ }^{\circ} \mathrm{C}$, cfus from twofold dilutions on blood agar were counted and numbers of $E$. coli calculated.

Results and discussion: Within 12 hours $0.05 \%$ tannin in BHI reduced an inoculum of $4.4 \times 10^{4} \mathrm{cfu} / \mathrm{ml}$ of $C$. perfringens more than 44 -fold (i.e. under detection limit), while the number in BHI increased 382-fold. Concentrations of $0.025 \%$ and $0.0125 \%$ reduced numbers of $C$. perfringens in inoculum of $5.4 \times 10^{4} \mathrm{cfu} / \mathrm{ml}$ of $\mathrm{HBI}$ more than 54 -fold, concentration of $0.006 \%$ allowed only a slight growth to $7.3 \times 10^{4}$, while concentrations of $0.0031 \%$ and $0.00625 \%$ reduced growth only 2.7 -fold and 1.7 fold, respectively, compared to $9.3 \times 10^{7} \mathrm{cfu} / \mathrm{ml}$ in BHI.

The best growth of $E$. coli was found in TSB with an 244-fold increase of inoculum, followed by 188 -fold in BHI and 98 -fold in PW. Only a small reduction of growth was observed in media with $0.05 \%$ of tannins. In media with $0.5 \%$ of tannins the inoculum increased only 2-fold in PW, 5-fold in BHI and 46-fold in TSB. The concentration of $2.5 \%$ of tannins reduced inoculum more than 2180 -fold (under detection limit) in PW, 436-fold in BHI and 218-fold in TSB. Comparing both bacteria 
C. perfringens proved to be much more sensitive to tannins than E. coli. In E. coli the sensitivity was greatly influenced by growth medium like BHI and PW versus TSB.

\author{
E. BUJNA ${ }^{1}$, A. MAYER ${ }^{1}$, T. BALOGH ${ }^{1}$, CS. BOGNÁR ${ }^{2}$
}

Evaluation of prebiotics in different microbial system

${ }^{1}$ Faculty of Food Sciences, Szent István University, ${ }^{2 *} \mathrm{~J}$ ohan Béla" National Centre of Epidemiology, Budapest, Hungary

In the past few years science has discovered the importance of intestinal microbiota and the role of functional food in maintaining its natural, healthy balance. Functional food contains pre-, pro- and symbiotics thus exerting positive effect on the human body.

Probiotic food additives consist of living bacterial culture (Bifidobacterium, Lactobacillus). When they get into the body they serve as substrates of the intestinal microbiota and have a positive influence on it. There are short chain fatty acids among the metabolic products of these bacteria that have an antibacterial effect by lowering the $\mathrm{pH}$ of the colon. They also improve the state of the immune system and help to reestablish the intestinal microbiota following an antibacterial treatment. Prebiotics serve as nutrients for probiotic bacteria. Prebiotics are non-living food components that go through the intestinal tract undigested and act as substrates for intestinal bacteria. Some oligosaccharides have prebiotic, bifidogenic effect. Human digesting enzymes cannot break down these oligosaccharides, thus blood sugar level does not rise, but they help digestion and the growth of beneficial intestinal bacteria.

The aim of the work was to investigate which commercially available prebiotic oligosaccharides are able to support the growth of bifidobacteria. Enteropathogenic bacteria were also taken into consideration as secondary selection factors. It was found that all commercially available prebiotics can serve as nutrients for bifidobacteria. The enteropathogenic bacteria utilise fructo-oligosaccharides and some of the isomaltooligosaccharides. The only exception was a product called Oligotime that does not support the growth of the investigated pathogens (Salmonella derby, Salmonella choleraesius, Shigella dysenteriae, Shigella flexneri, E. coli O55H6, E. coli, Proteus mirabilis and Yersinia enterocolitica). Oligotime is an isomalto-oligosaccharide in which $90 \%$ of the glycolitic bonds are $\alpha(1-6)$ ones.

As a result of our investigation it is possible to create a symbiotic functional product that contains bifidobacteria as probiotics, and prebiotics as well to sustain their viability while not supporting pathogenic bacteria. 
The author would like to thank the financial grant from Ministry of Agriculture (Project No. KF-76/7/99).

\author{
GY. CSERMELY ${ }^{1}$, R. KOISS ${ }^{1}$, L. UNGAR ${ }^{1}$, Z. MARCSEK ${ }^{2}$
}

Is there any importance of the detection of "high-risk" HPV types in Gynecological cervical screening program?

\footnotetext{
${ }^{1}$ Department of Obstetric-Gynecology and Gynecology Oncology, Szent István Hospital, Budapest, ${ }^{2}$ National Center for Public Health, Department of Experimental Pathology and Mutagenesis, Budapest, Hungary
}

Patients: 100 women were examined, who potentially suffer from "high-risk" HPV infection, the diagnosis was raised by the pathologist screening of the cervical smear, or by the gynaecologist screening the surface of the cervix by colposcopy

Methods: Samples were taken by Digene special kit from the surface and from the canal of the cervix, which contained epithelial cells. DNAs were isolated and using "high-risk" HPV specific primers (MP09-MP11 primer pair, Research Genetics) were amplified by PCR, high-risk-specific oligonucleotides were shown by agarose electrophoresis.

Results: The study shows that the possibility of "high-risk" HPV type infection is likely at women, whose cervical smear are suspect, or colposcopic atypia was detected. We directed our attention to those cases, where "high-risk" HPV infection was detected without cytological or colposcopical abnormality.

\title{
Zs. CSUKÁS ${ }^{1}$, M. BAusZ ${ }^{2}$, J. TÓTH ${ }^{2}$, I. SÜVEGES ${ }^{2}$, F. ROZGONYI ${ }^{1}$
}

\section{Bacterial and mycological examinations of the corneal discs removed with keratoplastica \\ ${ }^{1}$ Institute of Medical Microbiology, ${ }^{2} 1$ st Department of Ophthalmology, Semmelweis University, Budapest, Hungary}

At the 1st Department of Ophthalmology of Semmelweis University 73 corneae removed by keratoplastic surgery between 01 September 1999 and 30 April 2000 were investigated with histological, bacteriological and mycological methods.

Indications of keratoplastica most frequently included degeneration of corneal endothelium, dystrophy as well as ulcers of corneae. 
Out of 73 specimens tested 29 bacteria were isolated including 3 aerobic and 26 anaerobic strains. No fungi were isolated. Most frequent isolates included Proprionibacterium ances (11), Peptostreptococcus spp. (6), anaerobic Corynebacterium (3), Stomatococcus (3), Gemella (1) and Clostridium bifermentans (1).

Antibiotic susceptibility as well as their enzyme and toxin production associated with their pathogenic role were investigated in Proprionibacterium strains.

\section{A. Czeglédi, E. Ferenczi, E. Tóth, I. Mezey, Gy. Berencsi}

\section{Serosurvey of tick-borne encephalitis virus (TBEV) in Hungary}

"Johan Béla" National Center for Epidemiology, Budapest, Hungary

Sera of healthy individuals older than 20 years of age were tested for TBEV antibodies. All sera were tested by ELISA and those of borderline or slight positive result were confirmed by immunofluorescence (IFA) and haemagglutination inhibition test (HAI). Altogether 129 positive samples were identified of 2256 sera following verification $(5.72 \%)$.

These specific antibodies may be produced either following natural infection or due to active immunisation with one of the killed vaccines available.

The seropositivity of 107 serum samples could not be verified using the alternative techniques $(4.7 \%)$. The origin of false positivity could not be identified yet. Previous experiments suggested that the association of false-positivity and inappropriate collection or storage of serum samples was not significant. TBE seropositive persons were found to be present in all areas of Hungary. As determined earlier in connection with the diagnostic screening of clinical diseases the majority of the seropositive inhabitants are concentrated in 5 forested counties. The seroprevalence was found to be $13 \%$ in Baranya, $12 \%$ in Nógrád, $10 \%$ in Vas, $8 \%$ in Zala and only $6 \%$ in Somogy. $90 \%$ of the total number of seropositive individuals lived in the above 5 counties.

Based on our recent results and the earlier field trials in natural foci the Transdanubian region and the Northern central chain of mountains are endemic territories. The distribution of seropositive sera was: $36 \%$ in the Transdanubian ridge of hills, 22\% in the Plain in Northwestern Hungary including the Subalpine region, 19\% at the Northern central chain of mountains, $13 \%$ at the Transdanubian central chain of mountains, whilst only $10 \%$ in the inhabitants of the Great Hungarian Plain. The data 
of Budapest and Pest county were omitted, since these two administrative areas are located at the border of three different geographical regions.

The age group between 20 to 29 years possessed the highest seroprevalence. Thus they belong to the age group of highest risk and/or this population takes advantage of the vaccination.

The rate of antibody positive persons was found to decrease with the age. One can suppose that a significant proportion of seropositive samples originates from vaccination.

Significant deviation was found in comparison to the results of earlier investigations in the distribution of positive samples by gender. It was found earlier that men represent a higher proportion (70\%) of persons having antibodies against TBEV. According to the results of this study, the difference between the two genders was reduced from 70 to $54 \%$, but the dominance of men still exists. The shift is probably caused by the post-vaccination seropositivity of the population examined.

\title{
J. DEÁK
}

\section{Laboratory diagnosis of Bartonella henselae and Bartonella quintana infections}

\author{
Department of Clinical Microbiology, Albert Szent-Györgyi Medical Center, University of Szeged, \\ Szeged, Hungary
}

Of the currently known 11 Bartonella species 5 can cause different human illnesses. Cats, bobcats, mountain lions and captive wild felids are the reservoirs of Bartonella henselae (B. henselae); the vector is the flea. B. henselae may well be the most frequent cause of chronic lymphadenopathy at a young age. The lymph node lesions may be local or generalized. B. henselae has been detected in cases of Parinaud oculoglandular syndrome, neuroretinitis, osteomyelitis, fever of unknown origin, prolonged fever and inoculation peliosis, and as etiological agent in the acute encephalopathy of 7 children within some weeks in Florida; $62 \%$ of cats $(n=124)$ living near the homes of these children revealed antibodies against $B$. henselae. Bartonella quintana (B. quintana) was earlier known as present in trench fever. Humans acquire the bacterium via transmission by lice. B. quintana is responsible for bacillary angiomatosis, endocarditis and meningoencephalitis. The bacterium has been detected in cases of subcutaneous and bone lesions and peliosis. B. quintana infections are frequent among homeless and alcoholic people who have lice. The agent can cause vascular proliferative diseases in HIV-infected patients. 
Between 1 September, 1998 and 10 May 2000, we carried out tests for the detection of $B$. henselae and $B$. quintana $\operatorname{IgM}$ and $\operatorname{IgG}$ antibodies by an indirect immunofluorescent method. The clinical samples of the patients predominantly revealed lymphadenopathy.

B. henselae $\operatorname{IgM}$ and $\operatorname{IgG}$ were detected in $10.3 \%(\mathrm{n}=291)$ and $31.9 \%(\mathrm{n}=338)$, and $B$. quintana $\operatorname{IgM}$ and $\operatorname{IgG}$ in $4.8 \%(\mathrm{n}=289)$ and $12.6 \%(\mathrm{n}=340)$ of the patients. $B$. henselae and B. quintana antibodies were detected simultaneously in $15 \%(\mathrm{n}=289)$ of the cases.

The distribution of $B$. henselae and $B$. quintana antibodies varies in different human and feline populations throughout the world. $100 \%$ of patients who had suffered cat scratch disease in Germany exhibited antibodies. $29.9 \%$ of cat owners in Spain displayed $B$. henselae-specific antibodies, as compared with only $5.9 \%$ of the control blood donors. Cats have B. henselae-specific antibodies between $9.1 \%$ and $68.0 \%$. B quintana antibodies were detected in $30.0 \%$ of the serum samples of homeless persons in Marseille, in $20.0 \%$ of those in Seattle, and in $12.8 \%$ of the inhabitants of a refugee camp in Burundi. At the same time, the largest epidemic of typhus caused by Rickettsia prowazekii since World War II was likewise observed in Burundi. B. henselae infections were detected serologically in a higher percentage than B. quintana in Hungary. Cross-reactions are presumed in some cases between $B$. henselae and $B$. quintana. The expansion of these almost forgotten and newly discovered bacterial agents may be connected with ecological and economic changes.

\title{
G. DIÓSI, L. GAZSÓ, GY. FARKAS
}

\section{Study of biofilm development in nuclear waste repositories}

\author{
National Center of Public Health, National Research Institute for Radiobiology and Radiohygiene, \\ Budapest, Hungary
}

Six dominant strains were isolated from the interim storage of the spent fuel at the Atomic Energy Research Institute. The metabolism of the isolates and their effects on biocorrosion and heavy metal mobilization were studied. The sulphate reducing capability and the siderophore productivity of the isolates were low, but we found the organic acid productivities positive and also the level of the toxic metal uptake $(\mathrm{Cd}, \mathrm{Cr}$, $\mathrm{Co}, \mathrm{Sr}$ ) was high. These properties show the possible danger of corrosion and metal mobilization. The radiosensitivity of the isolates was determined. The $\mathrm{D}_{10}$ values of the spore-formers were ranging between $1.44-1.88 \mathrm{kGy}$. We checked the biofilm formation and the micromorphology of the biofilm development. In order to make a 
useful model of the microbial effects on the materials at the storage of the spent fuel it is not enough to examine the metabolism of bacterial cells in suspension. The biofilm is the dominant form practically in all realistic systems, that is why it is important to obtain information about the metabolism of the biofilms and its effects on different metal surfaces. We plan to examine the level of the toxic metal uptake by the biofilms and to compare the radiosensitivity of the biofilm bacteria with that of the cell suspensions in the cases of pure and mixed cultures.

\title{
GY. FARKAS, L. G. GAZSÓ, G. DiÓSI
}

\section{Characterization of subterranean bacteria in the Upper Permian Siltstone Formation}

\author{
National Center of Public Health, National Research Institute for Radiobiology and Radiohygiene, \\ Budapest, Hungary
}

The main purpose of this work was to study the microbiology of the Hungarian Upper Permian Siltstone (Aleurolite) Formation from the aspect of the safety of future underground repositories for nuclear waste. Air, groundwater, technical water, rock and surface samples $(n=67)$ were collected aseptically from different depths. The number of aerobic and anaerobic isolates was 300 . The gases produced by the 16 gas forming isolates were $\mathrm{CO}_{2}$ (aerobic isolates) and $\mathrm{CO}_{2}$ and $\mathrm{H}_{2}$ (anaerobic isolates). About $20 \%$ of the aerobic isolates produced siderophores. The proportions of organic acid producers were lowest in aerobic and anaerobic isolates from the aleurolite: $13 \%$ and $14 \%$, respectively. The highest proportions of acid producers in the aerobic and anaerobic isolates from the air samples were $63 \%$ and $54 \%$. Altogether 160 of the aerobic isolates and 52 of the anaerobic isolates were sporeformers. The radiosensitivity of the aerobic and anaerobic isolates was also determined: the $\mathrm{D}_{10}$ values of the aerobic spore-formers were ranging between $0.8-2.44 \mathrm{kGy}$, and those of the anaerobic spore-formers were 1.86-4.93 kGy. Our results indicate that the sulphate-reducing bacteria and the production of complexing agents (siderophores) may contribute to the mobilization of radionuclides from underground repositories. As well, microbial gas production can influence the environmental conditions. The variability in bacterial radiotolerance indicates the biodiversity at this potential disposal site. These facts must be considered during the planning of a nuclear waste repository. 


\section{J. FARKAS ${ }^{1}$, E. ANDRÁSSY ${ }^{1}$, J. BECZNER $^{2}$, I. VIDÁCS ${ }^{2}$, L. MÉSZÁROS $^{1}$}

\section{Studies on competitive growth between Lactococcus lactis and Listeria monocytogenes}

${ }^{1}$ Department of Refrigeration and Livestock Products Technology, Szent István University, Budapest, ${ }^{2}$ Central Food Research Institute, Budapest, Hungary

In the frame of the EU CT97-3129 (PREMIUM)-project, growth of a luxAB bioluminescent transformant of Listeria monocytogenes in co-cultures with an "acid only" Lactococcus lactis strain was studied in their co-cultures in OXOID Brain Heart Broth supplemented with $0.3 \%$ yeast extract and $0.2 \%$ additional glucose concentration, and adjusted to various $\mathrm{pH}$ and $\mathrm{NaCl}$ concentrations. Besides liquid cultures, gelified cultures containing $12 \%$ of low melting-point gelatine were also studied in order to mimic the growth conditions in gelled parts of foods. In various experiments, the effect of the initial $\mathrm{pH}$, incubation temperature, and salt concentration were investigated, together with the effect of the relative proportion of the initial levels of the lactic acid bacteria and the Listeria, on the outcome of the competition.

In the course of incubation the changes of the viable cell counts by plate counting in selective media were estimated from time-to-time, together with the measurement of $\mathrm{pH}$ and the titratable acid contents, and the luminometric light emission of the populations of the bioluminescent transformant of Listeria monocytogenes was measured as well. The obtained growth curves were evaluated for growth parameters by fitting growth data with Baranyi's "D-model".

The light output of the bioluminescent Listeria cultures increased parallel with their viable cell counts during the exponential phase of the growth. At the commencement of the stationary phase of the growth, the bioluminescence activity dropped significantly.

In experiments, where Lactococcus lactis was able to compete with the Listeria, the initial growth rate of the target organism was not influenced, but an early induction of its stationary phase occurred resulting in lower maximal population densities than those during its monoculture growth. The induction of the early stationary phase in cocultures coincided always with a sudden drop of $\mathrm{pH}$ (and thereby a sudden increase of the concentration of the undissociated lactic acid formed in the cultures).

The competitiveness of Lactococcus lactis has been influenced by the salt concentration of the medium. In experiments with an initial $\mathrm{pH}$ of 7.0 and $15{ }^{\circ} \mathrm{C}$ incubation temperature, Lactococcus lactis was more sensitive to the increase of the $\mathrm{NaCl}$ concentration in the growth medium than Listeria monocytogenes, because the specific growth rate values of the latter remained within the same confidence interval in 
the whole concentration range of 0.5 to $4.0 \%$ investigated, while $4 \% \mathrm{NaCl}$ slowed down so much the growth of Lactococcus lactis that it was unable to induce an early stationary state in Listeria monocytogenes.

The financial support of the National Commission for Technological Development (OMFB, Budapest), and the National Science Funds (OTKA, Budapest), Project No. T015518 is highly appreciated.

\title{
P. ZS. FEKETE ${ }^{1}$, J. GERARDIN ${ }^{2}$, J. MAINIL $^{2}$, B. NAGY ${ }^{1}$ \\ Plasmid characterization and replicon typing of verotoxic and enterotoxic Escherichia coli carrying F18 fimbria
}

\author{
${ }^{1}$ Veterinary Medical Research Institute of the Hungarian Academy of Sciences, Budapest, Hungary, \\ ${ }^{2}$ Chaire de Bactériologie et de Pathologie Bacterienne, Faculté de Medicine Vétérinaire, Université \\ de Liege, Belgium
}

The F18 fimbria are characteristic adhesive antigens of porcine enterotoxic $E$. coli (ETEC) and of verotoxic E. coli (VTEC). During the last few years the phenotypic and genotypic characterization of $\mathrm{F} 18^{+}$ETEC and VTEC strains have been done by us in several respects but data about the exact localization of the F18 genes and about their possible plasmids are still needed.

Therefore we have performed investigations on Hungarian $\mathrm{F}^{+} 8^{+}$strains (17 ETEC and 7 VTEC) and concluded that the F18 genes were consequently on their plasmid compartment and that these plasmids belong to the F incompatibility group.

Our methods were: DNA probe fragment preparation by PCR from the reference strain F107/86 and plasmid preparation from the strains to be tested by the method of Kado-Liu. Further DNA hybridization on the plasmids was done by using the following ${ }^{32} \mathrm{P}$ labelled replicon probes: repFIA, repFIB, repFIC, repF2A, repFI1.

The ETEC and VTEC strains investigated all possessed 1-4 plasmids (above 40 $\mathrm{kb})$. The F18 genes were localized on one of these large plasmids, with the exception of one VTEC strain (2206), which proved to be free from large plasmid and free from F18 genes.

The replicon typing of the plasmids indicated that they belonged to the incompatibility complex F and represented the type FIC or one of its subgroups FI1 A or FI1. The plasmids tested had only one replication origin (unireplicon). Further studies on the F18 plasmids are in progress. 


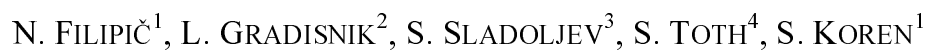

Novel serum replacement based on bovine ocular fluid: a useful tool for cultivation of animal cells in vivo

\footnotetext{
${ }^{1}$ Institute of Microbiology and Immunology, Medical Faculty, 1105 Ljubljana, ${ }^{2}$ Faculty of Agriculture University of Maribor Vrbanska 30, 2000 Maribor, Slovenia, ${ }^{3}$ Institute of Immunology, 1000 Zagreb, Croatia, ${ }^{4}$ Institute of Biotechnology, University of Szeged, Szeged, Hungary
}

Different mammalian cells in culture have individual nutritional requirements, which are mainly fulfilled by the addition of fetal calf serum to the basic medium. Due to the batch to batch variability and relatively high price different serum replacements were introduced. Among them bovine colostrum as a serum substitute for the cultivation of mouse hybridomas should be mentioned. The presented experiments were aimed to introduce the simple and effective serum replacement (SR) based on bovine ocular fluid. Throughout the experiments bovine ocular fluid alone and in combination with sheep's defibrinated plasma and serum albumin was tested for growth of different cells growing as monolayer: (a) cell lines: HeLa, WISH, HAC3/T2, HAC-3/T3 (human amniotic cell lines) WiREF (Wistar rat embryonal fibroblasts) MDBK (bovine kidney), PLA (adult pig kidney), ST (swine testis) (b) primary culture: chicken embryonal fibroblasts. All the growth experiments were made in parallel with Fetal Calf Serum (FCS). All types of cells were cultivated in usual Eagle's medium + antibiotics (Penicilline, Streptomycine, Gentamycine). The most effective was the SR containing approximately $35 \%$ of sheep's defibrinated plasma and $1.5 \%$ of serum albumin in bovine ocular fluid. During the experiments 1, 5 and $1 \%$ of SR or FCS in Eagle's medium were used. After 2, 3 and 5 days of cultivation, the cells were counted. The results show that the use of SR instead of FCS gives higher number of cells. It is also important that practically no adaptation is needed, meaning that the cells could be grown in the Eagle's medium + FCS and in the next passage in Eagle's medium + SR and vice versa. 


\title{
A. FÜZY ${ }^{1}$, Zs. LANGÓ' ${ }^{1}$, E. TÓTH ${ }^{1}$, L. G. TÓTH ${ }^{2}$, I. MUSKÓ ${ }^{2}$
}

\section{Bacteriological data on selected molluses and planktonic crustaceans of Lake Balaton}

\author{
${ }^{1}$ Department of Microbiology, Eötvös Loránd University, Budapest, ${ }^{2}$ Balaton Limnological Research \\ Institute of the Hungarian Academy of Sciences, Tihany, Hungary
}

The molluscs and the planktonic crustaceans are filter-feeding organisms and some of them are considered to be effective bacterial feeders. The aim of our work was to identify the bacterial communities of the hindgut content of two molluscs (Anodonta sp., Unio sp.), the gut content of the Dreissena and Corophium sp., and homogenized body of Bosmina, Daphnia and Eudiaptomus sp. We collected three species of molluscs and four species of planktonic crustaceans at two sampling sites (eastern partTihany and western part-Keszthely) of Lake Balaton. From the seven species we isolated seventy-two representative strains and studied their morphological, physiological and biochemical characters and the strains were identified by the Biolog system, too. Based on eighty-three coded characters a chapteranalysis was performed. Dendogram was obtained by using the UPGMA algorithm and $\mathrm{S}_{\mathrm{SM}}$ coefficient with the help of the SPSS for Windows 7.5 software. Ten dominant phenons were delineated, where the cluster's overall similarity is eighty-ninety percent. The dominant clusters contain the following taxa: Micrococcus sp., Bacillus cereus, Acinetobacter sp., Pseudomonas sp., Klebsiella sp., Aeromonas sp., Bacillus megaterium and two other phenons, identified only on family level: Enterobacteriaceae and Vibrionaceae. These organisms are typical in the water and sediment of the lake, too. Like in case of some fishes the aerobe and facultative anaerobe microbiota of these molluscs and crustaceans can be organized from the dominant organisms of water and sediment. Seventy-nine percent of the strains were Gram negative. The typical enterobacterium Klebsiella oxytoca was found only in the hindgut of the bigger size of molluscs (Anodonta sp., Unio sp.). Most of the facultative anaerobe bacteria were found at the region of Keszthely. 


\author{
I. GRUNTAR ${ }^{1}$, B. KRT ${ }^{1}$, J. MEHLE ${ }^{1}$, A. BIDOVEC ${ }^{2}$ \\ Serological survey on the presence of some zoonoses in European brown \\ hares in Slovenia \\ ${ }^{1}$ Institute of Microbiology and Parasitology, Veterinary Faculty, Ljubljana, ${ }^{2}$ Institute for Breeding \\ and Health Care of Wild Animals, Fishes and Bees, Veterinary Faculty, Ljubljana, Slovenia
}

Objectives: The aim of our study was to evaluate serologically the exposure of European brown hares (Lepus europaeus) in Slovenia to the causative agents of some important zoonoses and consequently consider their involvement in the transmission of these diseases.

Material and methods: European brown hare sera were collected in 1999 from the hares shot in different regions of Slovenia. ELISA and/or seroagglutination (SA) tests were used to determine antibodies against Borrelia burgdorferi (B. burgdorferi) and Francisella tularensis (F. tularensis) in 73 serum samples; 48 sera were examined for the presence of antibodies against Brucella spp., Toxoplasma gondii (T. gondii) and Tick-borne encephalitis (TBE) virus.

Results and discussion: Antibodies against B. burgdorferi were found in $49.3 \%$ of sera (ELISA). $1.3 \%$ of sera were positive in ELISA using F. tularensis antigen whereas all the samples were negative in seroagglutination test. In $4.2 \%$ of sera antibodies against Brucella spp. (ELISA) were found. $41.7 \%$ of sera were positive for the presence of antibodies against $T$. gondii (SA) and 10.4\% of sera against TBE-virus (ELISA).

The results indicate the importance of European Brown hares in the transmission and maintenance of Lyme borreliosis, toxoplasmosis and infection with TBE virus in natural habitat in Slovenia.

\title{
Gy. GunICS ${ }^{1}$, N. MOTHOHASHI ${ }^{2}$, J. MOLNÁR $^{1}$
}

\section{The modification of antibacterial effect of erythromycin in the presence of dihydropyridines

\author{
${ }^{1}$ Department of Microbiology, University of Szeged, Szeged, Hungary, ${ }^{2}$ Meiji Pharmaceutical
} University, Kiyose, Tokyo, Japan}

Sixteen substituted dihydropyridines of nifedipine (NP) analogues were tested on three different E. coli strains by Checkerboard titration. The compounds had high MIC values on the three bacterial strains. When the compound $\mathrm{GB}_{1}-\mathrm{GB}_{16}$ were used in 
combination with erythromycin some of the compounds $\mathrm{GB}_{1}-\mathrm{GB}_{3}, \mathrm{~GB}_{4}-\mathrm{GB}_{10}$ reduced the MIC values of erythromycin on the laboratory E. coli K12 LE 140 F'lac strain. When the substituted dihydropyridines were tested on E. coli $\mathrm{Ap}^{\mathrm{s}}, \mathrm{Er}^{\mathrm{r}}$ strain the reduction of MIC values were similar to the previous strain but not identical. The MIC values of erythromycin were reduced in the presence of $\mathrm{GB}_{1}-\mathrm{GB}_{7}$ in a lower extent on a clinical isolate of $E$. coli polyresistant strain. The $\mathrm{GB}_{12}$ and $\mathrm{GB}_{16}$ were the most effective in the interaction with erythromycin.

The synergistic effect of dihydropyridines depends on their chemical structure, modified by the substituents.

M. Hair-Beio, H. Hafiza, S. P. Phong, A. R. Omar, I. Aini

\section{Pathogenesis and pathogenicity of Malaysian isolates of infectious bursal disease virus}

Faculty of Veterinary Medicine, University Putra Malaysia, 43400 UPM Serdang, Selangor, Malaysia

Outbreak of infectious bursal disease (IBD) in poultry involving a highly pathogenic strain of serotype 1 IBD virus (IBDV) was first reported in Malaysia in 1991. Since then, the disease has become one of the most threatening diseases in poultry industry in the country. Outbreaks of IBD continue to occur in both the vaccinated and non-vaccinated flocks. The outbreaks caused great economic losses due to high mortality, impaired growth, high carcass condemnation and profound immunosuppression. Mixed infection of IBD with other viral or other pathogens are commonly reported. Evaluation on the safety and efficacy of the imported IBD vaccines available in the market commercially for local use demonstrated that most of the vaccines studied were unsafe and not effective to confer full protection against IBDV. Fourteen local isolates of IBDV from the field outbreaks in broilers, layers and village chickens were successfully isolated and propagated in chorioallontoic membrane (CAM), chicken fibroblast (CEF) tissue culture and specific pathogen free (SPF) chickens. The differences in pathogenicity of the isolates were characterized using both the conventional and molecular techniques. A highly pathogenic isolate of IBDV (UPM 94283) caused 100\% mortality in SPF chickens with typical lesions of severe haemorrhages and necrosis in the bursa of Fabricius. Severe haemorrhages also occurred in the muscles and at the junction of the proventriculus and gizzard. A highly immunogenic with low in pathogenicity isolate of IBDV (UPM 93273) was attenuated in CAM and CEF tissue culture. A live attenuated IBD viral seed for vaccine development was successfully established. The viral seed (vaccine) prepared in CAM 
is highly immunogenic and able to induce high level of IBD antibody when inoculated in both the SPF and commercial chickens. The vaccine is also able to neutralize a high level of maternally derived antibody (MDA). It is safe and effective to confer full protection against IBDV when given in chickens either for a single vaccination at day 14 of age or double vaccination at days 14 and 28 of age either through intraocular or oral route of vaccination or as food based vaccine. The vaccine is also safe and effective when used for in ovo vaccination at 18-day-old embryonated chicken egg. Studies on the pathogenicity and immunogenicity of the local IBD viral seed prepared in CEF tissue culture showed unsatisfactory result. Studies on the pathogenesis of the disease following oral route of IBDV inoculation demonstrated that the virus initially replicates in the lymphoid cells in the intestinal tract leading to primary viraemia and replication of the virus in the bursa of Fabricius, the target organ for IBDV. The virus can also enter into the bursa directly through the intestinal lumen. Localization and replication of IBDV in the bursa caused severe bursal necrosis and secondary viraemia leading to destruction of other lymphoid organs, especially the thymus and spleen. The virus was initially replicating in the Harderian gland following intraocular route of inoculation. Only a highly pathogenic strain of IBDV isolate could cause severe lesions both in the bursa of Fabricius and other lymphoid organs. In contrast, the mild pathogenic isolate produced lesions in the bursa of Fabricius with sign of bursal recovery at later stage of infection. The local IBDV isolates are also used for the development of IBD reagents and diagnostic kits and for further development of subunit or recombinant IBD vaccine.

\section{HAJTÓs ${ }^{1}$, R. GLÁVITS ${ }^{2}$, T. KOVÁCS ${ }^{1}$, V. PÁLFI ${ }^{2}$, L. MAKRAI $^{3}$}

Specific enzootic dermatitis in a breeding sheep flock

\footnotetext{
${ }^{1}$ Animal Health and Food Control Station, Miskolc, ${ }^{2}$ Central Veterinary Institute, Budapest, ${ }^{3}$ Department of Microbiology and Infectious Diseases, Szent István University, Budapest, Hungary
}

Between December 1998 and January 1999 a specific, enzootic dermatitis was observed in a crossbreed sheep flock in Northern Hungary. The affected flock comprised 400 pregnant ewes and $65(16.2 \%)$ of them showed clinical signs during the course of the disease. In the first half of November of 1998 these animals grazed on a maize stubble-field, where the left corn-stalks were $35-40 \mathrm{~cm}$ high. It was likely that these corn-stalks injured the skin of the head. Two weeks later the first clinical signs could be observed. 
Clinico-pathological lesions were usually restricted to one side of the head and particularly affected the skin around the eye, over the nasal and maxillary bones. Skin lesions were erythematous, swelled, and irregularly shaped ranging in diameter from $3-$ $8 \mathrm{~cm}$. Affected skin surfaces were covered by serofibrinous or serosanguinous exudate. In some cases the odour of the head was foul-smelling. The circumscribed lesions were covered by reddish-brown or brownish-black scabs and were surrounded by a zone of alopecia.

Untreated ewes showed a self-cure, their skin lesions persisted for five or six weeks and healed without scar formation. Local or parenteral antibiotic treatment was effective, the skin lesions healed within two weeks in these cases.

Histologically the following tissue lesions could be found: necrosis and desquamation of superficial layers of the epidermis, ulceration, leakage of serofibrinous exudate. Subepidermal layers of the dermis were infiltrated by mononuclear cells and neutrophil granulocytes, haemorrhages and cluster of Gram-positive bacteria could also be seen. Bacteriological culture of the scabs originated from six affected ewes yielded coagulase positive Staphylococcus aureus plus coagulase negative staphylococci and streptococci in three cases, while in the other cases arcanobacteria, streptococci and moraxellae grew in mixed culture. S. aureus strains were identified and characterized by conventional tests and commercial kits (BBL Crystal, APIStaph, Staphaurex). Ectoparasites and dermatopathogenic fungi could not be demonstrated. Blood sera of six affected ewes were negative for the presence $\operatorname{orf}$ virus antibodies, but were positive for pestivirus (BVD/BD) antibodies.

The observed clinical signs and the results of bacteriological culture were very similar to those reported by Scott and others in connection with the "Staphylococcal dermatitis of sheep" (Vet Rec 107, 452-454 1980.).

This disease has not been reported earlier in Hungary. 


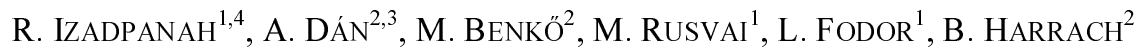 \\ DNA sequence of a small, unidentified plasmid isolated from a Haemophilus somnus strain
}

\author{
${ }^{1}$ Department of Microbiology and Infectious Diseases, Faculty of Veterinary Science, Szent István \\ University, Budapest, ${ }^{2}$ Veterinary Medical Research Institute, Hungarian Academy of Sciences, \\ Budapest, ${ }^{3}$ Central Veterinary Institute, Budapest, Hungary, ${ }^{4}$ RAZI Vaccine and Serum Research \\ Institute, Teheran, Iran
}

One of the plasmids present in a Haemophilus somnus (H. somnus) strain isolated from nasal discharge of a cattle with respiratory disease symptoms was purified and cloned for DNA sequencing. The copy number of the plasmid was enough to use alkaline lysis method for DNA plasmid purification which is widely used for high-copy-number cloning vectors of $E$. coli. The plasmid was found to be 1065 base pairs long and with $39.2 \% \mathrm{G}+\mathrm{C}$ content. Homology search failed to find any similar DNA in the nucleic sequence data bases. The longest putative open reading frame was 261 pairs long. Based on the location of possible translation initiation codons, there is a theoretical possibility on this plasmid to code for a protein of 43 amino acids. The homology search, however, showed no significant similarity with the presently available protein data.

Presence of plasmids in H. somnus was detected by some authors (Fussing and Wegener, 1993; Appuhamy et al., 1998) but this is the first report on the sequencing and DNA analysis of one of the plasmids.

This work was supported by Hungarian Scientific Research Fund grants OTKA T026604, T021060, M027651.

\section{A. JUhÁSZ ${ }^{1}$, G. VERESS ${ }^{1}$, J. KÓNYA $^{1}$, A. $\mathrm{KISS}^{2}$, É. REMENYIK $^{3}$, L. GERGELY $^{1}$ \\ Seroprevalence of humanherpesvirus- 8 in Hungarian myeloma patients and blood donors \\ ${ }^{1}$ Department of Microbiology, ${ }^{2} 2$ nd Internal Medicine and ${ }^{3}$ Dermatology, Faculty of Medicine, University of Debrecen, Debrecen, Hungary}

The seroprevalence of KSHV in the Hungarian population and in clinical groups was determined by recombinant orfK 8.1 and orf65 antigen ELISA and by anti-LANAIFA. ELISA results were confirmed by Western blot. 
In the blood donor group the $\operatorname{IgG}$ seroreactivity was $1.24 \%(6 / 482)$ to recombinant orfK8.1 antigen and $1.45 \%(7 / 482)$ to recombinant orf65 carboxyterminal antigen. Results were comparable with previously determined anti-LANA results $1.87 \%(9 / 482)$. The overall seroprevalence rate in the blood donor group was $3.3 \%$ (16/482) by these methods. The age distribution of antibodies showed a moderate but significant increase with senescence.

IgG antibodies were not detected in 31 multiple myeloma patients with any of the methods.

In a group of classical $\mathrm{KS}$ patients IgG antibodies were detected in $87.5 \%$ $(14 / 16)$ to orfK8.1 antigen, $68.7 \%(11 / 16)$ to orf65 carboxyterminal antigen and $93.7 \%$ $(15 / 16)$ to LANA. 9 of $16 \mathrm{KS}$ patients had antibodies to all three antigens, 15 of $16 \mathrm{had}$ antibodies at least to two antigens.

Our results indicate the low prevalence of KSHV in the Hungarian general population and no serological association of KSHV with multiple myeloma.

\section{B. KAPUSINSKy, E. RUSVAI, J. BROJNAS, Gy. BERENCSI}

\section{Comparative analysis of $\mathrm{HBV}$ antigens and $\mathrm{HCV}$ antibodies using classical ELISA and commercial rapid tests}

Division of Virology, "B. Johan" National Center for Epidemiology, Budapest, Hungary

There are more and more requests to the laboratories for the rapid diagnosis of acute viral diseases. One should exchange or replace first of all diagnostic procedures, which are time consuming, and require expensive equipments or highly specialized technicians.

There are several rapid tests approved by the FDA in the USA (Constantin, 1999). The donors of organ transplantations are prescreened for HBV, HCV, and HIV at the site of the accidents even in Hungary by rapid tests. The results of a systematic comparison are reported here. Series of serum samples pretested with HCV Antibody ELISA (Monolisa HCV Antibody manufactured by Pasteur-Sanofi) and with HBsAg ELISA (IEPANOSTIKA HBsAg ELISA ORGANONTEKNIKA) were reexamined with 4 rapid tests manufactured by 3 different firms. Two of them were specific to anti$\mathrm{HCV}$ antibodies, 2 were able to detect $\mathrm{HBsAg}$ and $\mathrm{HBeAg}$.

The ELISA results are shown in the form of OD/CUTOFF values. The results above 1.0 have been considered to be positive. The results of the rapid tests were considered to be "indeterminate", when the positive result appeared significantly later and weaker than that indicated in the manufacturers' description 


\begin{tabular}{|c|c|c|c|c|}
\hline & $\begin{array}{l}\text { HBsAg R.T. } \\
\text { (whole blood) }\end{array}$ & $\begin{array}{l}\text { HbsAg R.T. } \\
\text { (serum) }\end{array}$ & HCV R.T. ${ }^{1}$ & HCV R.T. ${ }^{2}$ \\
\hline \multirow[t]{2}{*}{ HbsAg ELISA + } & 18 of 28 positives & 12 of 16 positives & & \\
\hline & 2 indeterminates & 1 indeterminate & & \\
\hline Hbs A ELISA - & 9 of 9 negatives & 4 of 4 negatives & & \\
\hline HCV ELISA + & & & $\begin{array}{c}14 \text { of } 23 \text { positives } \\
1 \text { indeterminate }\end{array}$ & 14 of 23 positives \\
\hline HCV ELISA - & & & 11 of 11 negatives & 11 of 11 negatives \\
\hline
\end{tabular}

No false positive results were obtained. Using the rapid tests the proportion of the confirmed ELISA-positive sera found to be negative was 1:5 to $1: 3$ of the total number of samples tested. The OD/Cutoff ratio was between 2 to 6 of the samples found to be false negatives in the rapid test systems. In one case even a PCR-positive HCV sample was found to be negative.

The conclusion of the work is that neither diagnostic nor epidemiological studies may be based only on results of rapid tests without verification by classical ELISA and blotting or IF procedures

\section{G. KAZINCZI ${ }^{1}$, E. POCSAI ${ }^{2}$, J. HORVÁTH ${ }^{3}$}

\section{Role of natural waters and water ecosystems in the epidemiology of plant viruses \\ ${ }^{1,3}$ Georgikon Faculty of Agricultural Sciences, University of Veszprém, Keszthely, ${ }^{2}$ Plant Health and Soil Conservation Station of Fejér County, Velence, Hungary}

During nearly two past decades an increasing and considerable attention has been paid to the research on the occurrence of plant viruses in water ecosystems. Natural waters may play vector role in the epidemiology of plant viruses. The primary source of plant viruses in natural waters may be infected plants living near or even in the water. Besides this, water and uliginal plants - mainly perennials - may be reservoirs of economically important plant viruses. The waters of rivers and lakes are generally used for irrigation. Therefore the knowledge of the contamination of natural waters and water ecosystems with plant viruses is important from the aspect of microbiology, crop production and environmental protection.

In the last years surveys were carried out on the presence of plant viruses in natural waters and water plants in Hungary. Samples of 24 plant species were collected near Lake Balaton, Kis-Balaton and Lake Velence. 57 water and 320 plant samples 
were tested by DAS-ELISA serological method for the presence of 26 plant viruses. The results of serological tests were confirmed by biological assay on herbaceous test plants and in several cases immunosorbent electron microscopy (ISEM) was also used.

According to the results out of the investigated water samples 22 proved to contain plant viruses. Cucumber mosaic virus, potato virus $\mathrm{M}$ and plum pox virus were found most often. Arabis mosaic virus, potato virus M, tomato spotted wilt virus, wheat dwarf virus and zucchini yellow mosaic virus were found for the first time in natural waters. On the basis of serology, cucumber mosaic and Arabis mosaic viruses were present most often in the plant samples. The proportion of the complex infection was very high, especially in case of Mentha longifolia, Lycopus europaeus and Bolboschaenus maritimus. No viruses were detected only in 9 species. Natural occurrence of potato virus $\mathrm{Y}$ and sowbane mosaic virus on Alisma plantago-aquatica was confirmed by immunosorbent electron microscopy as well. As the economically important viruses can occur under natural conditions in natural waters and water plants, examination of the infection chain is necessary in the future.

\section{S. KECSKEMÉTI ${ }^{1}$, I. KISS ${ }^{1}$, T. TUBOLY ${ }^{2}$, E. BAJMÓCY ${ }^{1}$, J. TANYI ${ }^{1}$}

\section{First report of the circovirus caused postweaning multisystemic wasting syndrome of pigs in Hungary}

\footnotetext{
${ }^{1}$ Veterinary Institute of Debrecen, P.O. Box 51, H-4002 Debrecen, ${ }^{2}$ Veterinary Medical Research Institute, Hungarian Academy of Sciences, Budapest, Hungary
}

Porcine circoviruses were first recognized in cultured cells of pig origin in 1974 but they were not until 1991 associated with a characterized disease (postweaning multisystemic wasting syndrome; PMWS) in Canada. The syndrome was first observed in Hungary in December 1999. Since then PMWS has been diagnosed on five occasions.

The clinical signs occurred at the age of 40-50 days, or at a later stage, i.e. between 70-100 days of age. Retarded growth, loss in weight-gain, increased consumption of food and mortality were observed. The animals became dull, pale, anaemic, and underweighed. Additionally, dyspnea and occasionally coughing could be observed. In some cases, diarrhoea, icterus, necrotic dermatitis or abscesses in the skin were seen. The majority of the affected pigs died within two to three weeks, while some animals perished in days. The morbidity was $20-30$ per cent while mortality reached 15 per cent. 
The pathological investigation revealed lung edema, ascites, hydrothorax and hydropericardium. In some cases lymphadenopathy, pneumonia, mulberry heart disease, esophogastric ulcers, E. coli-diarrhoea, hepatodystrophy and the enlargement of the spleen were observed. The histopathological investigations showed lymphohistiocytic to granulomatous interstitial pneumonia, depletion of the lymphoid elements in the lymph nodes, and infiltration by histiocytes and the presence of giant cells. Using polymerase chain reaction porcine circovirus type II (PCV II) was detected in the bone marrow and lymph nodes originating from the thoracic cavity.

Cells negative for the presence but permissive for the cultivation of porcine circoviruses were used for the isolation of PCV II. No cytopathogenic changes were observed even after 6-8 passages, however, the cell culture supernatants proved to be PCR positive after $2-3$ passages.

The decline of production of pig herds between the age of 5-13 weeks in association with anaemia, lung edema, depletion of lymphoid elements and the occurrence of giant cells indicates the presence of PCV II and, consequently PMWS. The correct diagnosis requires special virological investigations including PCR.

\section{KerÉnyi ${ }^{1,3}$, Z. V. MARshall ${ }^{2}$, G. D. PAYNE ${ }^{2}$, H. E. Allison ${ }^{2}$, C. A. Hart ${ }^{3}$, J. R. SAUNDERS ${ }^{2}$}

\section{Comparative studies of virulence associated genes from pathogenic and nonpathogenic Neisseria species}

\footnotetext{
${ }^{1}$ Department of Medical Microbiology and Immunology, Medical School of Pécs, University of Pécs, Pécs, Hungary, ${ }^{2}$ Environmental and Molecular Microbiology Group, School of Biological Sciences, University of Liverpool, Liverpool, UK, ${ }^{3}$ Department of Medical Microbiology and Genito-Urinary Medicine, University of Liverpool, Liverpool, UK
}

The genus Neisseria includes pathogenic and commensal species. Neisseria meningitides and N. gonorrhoeae, which cause meningitis and gonorrhoea, respectively, are the two obligate human pathogens of the genus. The commensal species exist as normal inhabitants of mucosal flora in healthy humans.

Among others pilin, outer membrane proteins, and IgA protease are known virulence factors in gonococcal and meningococcal disease.

In this study the distribution of specific sequence encoding virulence associated proteins in pathogenic and commensal Neisseria was investigated. First we checked the pilin expression by electronmicroscope and by monoclonal antibodies. PCR was used to detect pilE sequences in Neisseria species. 
Class 1 outer membrane protein is a product of por $A$ gene and expressed by most meningococcal isolates. It is responsible for increased resistance to bactericidal antibodies and can thus influence the virulence of the bacterium. PCR of the por $A$ gene can give comprehensive typing or subtyping. In our study no other Neisseria species other than meningococci were detected by PCR.

IgA protease is an extracellular enzyme that specifically cleaves the heavy chain of human IgA. This enzyme may be an important determinant of microbial virulence. DNA slot blot hybridisation was used to determine whether a microorganism carries a particular sequence of IgA protease gene. Southern blot hybridisation was performed to further investigate the similarity. Detection of IgA protease gene by PCR suggests that sequence of this gene is present only in meningococci, demonstrating the specificity of PCR methods.

\section{Z. Kiss ${ }^{1}$, V. ENDRÉSZ ${ }^{1}$, K. BURIÁN ${ }^{1}$, D. VIRÓK ${ }^{1}$, Z. PrOHÁSZKA ${ }^{2}$, K. BODA ${ }^{3}$, GY. FÜST ${ }^{2}$, E. GÖNCZÖL ${ }^{1}$}

Antibody responses to Chlamydia pneumoniae, cytomegalovirus and human heat shock protein 60 in the development of coronary heart disease

\footnotetext{
${ }^{1}$ Department of Medical Microbiology, University of Szeged, Szeged, ${ }^{2} 3$ rd Department of Medicine, Semmelweis University, Budapest, ${ }^{3}$ Department of Medical Informatics, University of Szeged, Szeged, Hungary
}

Although many risk factors for atherosclerosis have been identified, the ethiology of the disease is still not clear. Recent studies have suggested the role of infections and/or autoimmune mechanisms. We have investigated the antibody responses to Chlamydia pneumoniae (C. pneumoniae), cytomegalovirus-immediate early proteins (CMV-IE) and human heat shock protein 60 (hHSP) in patients with coronary disease and control subjects for their independent or joint effects on the development of the disease. C. pneumoniae antibodies were detected by microimmunofluorescence, CMV-IE and hHSP 60 antibodies were measured by ELISA, evaluation of data was carried out by SPSS 9.0 for Windows statistical program. Antibodies to C. pneumonia and hHSP 60 were present in significantly higher percentage and higher titer in patients than in control subjects, and their presence was independent from classical risk factors. There was no significant difference in the presence of CMV-IE antibodies in atherosclerotic and control groups. The high antibody levels to hHSP 60 or C. pneumoniae represented independent risk factors, 
however the presence of both hHSP 60 and C. pneumoniae antibodies increased the probability of the development of atherosclerosis.

This work was supported by MKM FKFP B-25/1997 and OTKA F030404.

\section{B. Kocsis}

Old and new facts in research of bacterial lipopolysaccharides

Department of Medical Microbiology and Immunology, Faculty of Medicine, Pécs University, Pécs Hungary

Endotoxin was discovered by R. Pfeiffer in 1892. During the first half of the next century methods were developed for isolation of endotoxic material from different Gram-negative bacteria: A. Boivin, O. Westphal, C. Galanos and others were successful in this field. The purified endotoxins were analysed by biochemical methods and their chemical structures were determined. An endotoxin molecule consists of a lipid and a polysaccharide component. After this discovery the endotoxin is sometimes called as lipopolysaccharide - LPS (MJ. Shear 1943). In the next period the fine structure, biosynthesis, the genetic background of biosynthesis, chemical synthesis, biological activity, clinical role and detection of LPS was extensively investigated. Nowadays for example we know that the classic enterobacterial LPS molecule contains lipid A component, which is responsible for the great number of toxic biological effects: The variable polysaccharide O-side chains give the serological specificity of Gram-negative bacteria. The core regio connects the lipid A and O-side chain to each other. The LPS molecule has numerous humoral and cellular effects: it can cause disseminated intravascular coagulation, it can activate different cells: $\mathrm{B}$ and $\mathrm{T}$ lymphocytes, monocytes, endothelial cells, it can induce the synthesis and release of cytokines: interleukin 1, tumor necrotic factor and so on. These processes are very important in development of clinical symptoms (e.g. fever, DIC, hypotonia), when a patient is suffering from Gram-negative sepsis. Now we have very sensitive methods (limulus test) for detection of LPS from different samples. Nowadays we know that some antibiotics can easily release LPS from Gram-negative microbes (e.g. cephalosporins) and others cannot (e.g. aminoglycosides). Anti-LPS monoclonal antibodies, soluble receptors, nontoxic LPS fragments are under investigation in the therapy of Gram-negative sepsis and endotoxemia. Nowadays the molecular background of the clinical symptoms, so LPS-binding proteins (LBP), LPS-receptors of different cells (e.g. CD14) and intracellular events after LPS signalling are the main scientific topics in research of bacterial lipopolysaccharides. 
The bio- and immunochemical laboratory in our institute was founded by prof K. Rauss in the early fifties. The most important results from this laboratory: G. Nogrady (1920- ) and M. Rodler developed a useful polytropic medium for identification of enteric bacteria (Act Microbiol Hung 1, 437 1954), T. Kontrohr (1932- ) isolated and identified 2-amino-2-deoxy-L-altruronic acid from Shigella sonnei phase I (Carbohydr Res 58, 498 1977), T. Kontrohr and B. Kocsis determined the chemical structure of nucleotide sugars taking part in biosynthesis of heptose regio of bacterial lipopolysaccharide: ADP-DD-heptose (J Biol Chem 256, 7715 1981) and ADP-LD-heptose (J Biol Chem 259, 11858 1984). They separated these heptose nucleotide sugars by HPLC ( $\mathrm{J}$ Chromat 354, 417 1986) and the eight epimeric 2aminoaldohexoses by GC (J Chromat 291, 119 1984). Nowadays we analyse the bacterial total proteins and outer membrane proteins by capillary electrophoresis (I. Kustos, B. Kocsis, I. Kerepesi, F. Kilar: Electrophoresis 19, 23171998 and Electrophoresis 19, 2324 1998) and the serological cross-reactions between $P$. morganii and other entric bacteria (Z. Peterfi, B. Kocsis: Immunoassay in press).

\title{
J. KÓNYA ${ }^{1,2}$, L. ARNHEIM $^{1}$, Z. HERNÁDI ${ }^{3}$, L. GERGELY $^{2}$, J. DILLNER $^{1}$
}

\section{Detection of human papillomavirus-specific peripheral T lymphocytes using an IFN-gamma ELISPOT assay}

\author{
${ }^{1}$ Microbiology Tumorbiology Center, Karolinska Institute, Stockholm, Sweden; ${ }^{2}$ Department \\ of Microbiology, ${ }^{3}$ Department of Gynecology and Obstetrics, University of Debrecen, Medical School, \\ Debrecen, Hungary
}

Background: The cellular immune responses to HPV are considered important for the regression of virus induced lesions. Quantitative assays of cellular immunity have not been widely used and cell responder cell frequencies and their HPV type specificity are unknown.

Methods: We investigated the peripheral blood $\mathrm{T}$ lymphocyte responses against purified capsids of human papillomavirus (HPV) types 6, 11, 16 and 33 in an IFNgamma ELISPOT assay. The HPV 16-exposed group of 6 patients with cervical intraepithelial neoplasia positive for HPV16 DNA and 2 healthy HPV16-seropositive blood donors was compared with a control group of 12 healthy HPV 16-seronegative blood donors. HPV6 seropositivity was found in 6 of the 8 HPV16-exposed and in 5 of 12 control persons.

Results: The ELISPOT reactivities of the control samples revealed that detection limit of the assay was 10 responder $/ 10^{5}$ lymphocytes. The responses above 
the detection limit were considered positive and ranged up to 82 responder $/ 10^{5}$ lymphocytes. The HPV16-specific IFN-gamma responses were associated with HPV16 exposure $(6 / 8$ cases and $1 / 12$ controls responding, $p=0.004)$. Interestingly, the HPV33 specific responses were also significantly associated with the cases $(4 / 8$ cases and $0 / 12$ controls responding, $\mathrm{p}=0.014$ ). By contrast, the responses against the capsids of HPV types 6 and 11 were not significantly different between the HPV 16-positive patients and the HPV 16-negative controls. There was a significant correlation only between the magnitude of IFN-gamma responses to HPV6 and HPV16 (Pearson's correlation, $\mathrm{r}=0.83, \mathrm{p}<0.001)$.

The corresponding HPV6-specific responder frequencies was lower than the HPV16 specific ones (linear regression coefficient, $B=0.304 \pm 0.048$ ) suggesting that HPV16 induced T lymphocytes are partially cross-reactive with HPV6.

Conclusions: HPV infection induces virus-specific $\mathrm{T}$ lymphocyte memory, which is readily measured in IFN-gamma ELISPOT assay. The T lymphocyte mediated immunity seems to be essentially type-restricted, although HPV6 and HPV16 may be partially cross-reactive.

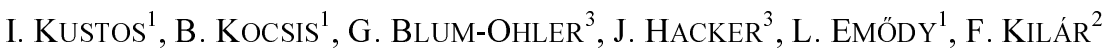 \\ Electrophoretic analysis of outer membrane components in wild type and isogenic mutants of Escherichia coli}

${ }^{1}$ Department of Medical Microbiology and Immunology, ${ }^{2}$ Central Research Laboratory, Pécs University, Faculty of Medicine, Pécs, Hungary, ${ }^{3}$ Institut für Molekulare Infektionsbiologie, Universität Würzburg, Germany

Pathogenicity of E. coli strains is regulated by several virulence factors. Expression of these factors is influenced by various regulatory mechanisms, among them the global regulators have particular significance. One of the most important global regulators is the product of the leuX gene, which is regulates the expression of $\alpha$ haemolysin, fimbrial adhesins and motility.

The aim of our study was to analyze the role of this regulator in the expression of outer membrane proteins (OMP) and lipopolysaccharides (LPS). Experiments were performed by the wild type and four isogenic variants of urinary E. coli isolate: 536 (wild type), 536/21 (deletion mutant), 536A102 (leuX mutant), 536 121 pSU2716 (leuX mutant with vector plasmid) and 536/21pGBB51 (leuX mutant with vector plasmid complemented with the leuX gene). 
Examination of bacterial proteins was performed by a new method, dynamic sieving capillary electrophoresis (DSCE), which is a well applicable, suitable, automated and quantitative method in protein analysis.

In the first step of our work outer membrane protein profiles were investigated. All E. coli 536 variants possessed 5-6 major protein peaks in their OMP patterns. The profile of the wild type of E. coli 536 could be characterized by the presence of five dominating peaks, with molecular weights of $17,19,27,35$, and $37 \mathrm{kDa}$, respectively. In the patterns of the leuX mutants the absence of the $19 \mathrm{kDa}$ protein, the significant decrease in the quantity of the $35 \mathrm{kDa}$ protein, and the appearance of a $42 \mathrm{kDa}$ peak could be observed. In the profile of the pGBB51 mutant an additional characteristic peak could be detected in the $48 \mathrm{kDa}$ region.

LPS molecules were investigated by conventional SDS-PAGE and silver staining. All E. coli strains examined possessed a ladder pattern in the gel, characteristic for "S" bacteria, so leuX mutation did not influence the expression of "S" character.

Capillary electrophoresis was suitable for the investigation of protein profiles in different genetic variants. The significance of these examinations is that the outer membrane components of Gram-negative bacteria participate in several bacterial functions (pore formation, colicin and bacteriophage receptors, adhesion to the host cells, etc.). Thus changes of these factors can indicate modified permeability, pathogenicity, or colicin and phage sensitivity of bacterial cells. Further investigations are needed to elucidate how these changes in OMP profiles influence the above functions.

\section{J. LUKÁCS ${ }^{1}$, CS. BOGNÁR ${ }^{2}$, Á. CSOHÁN ${ }^{2}$, M. KÁDÁR ${ }^{3}$}

\section{Legionellosis: epidemyology, national incidence}

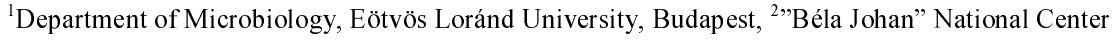
for Epidemiology, Budapest, ${ }^{3{ }^{\prime \prime}}$ József Fodor" National Centre for Public Health, Budapest, Hungary

Legionellosis has become a considerable nosocomial disease by the end of the 90s. It is well known that Legionella gets into the respiratory system through the usage of industrial cooling towers, fountain, gardening houses and the hot water systems of hospitals and households (washbasins, showers etc.), with the developed contaminated aerosol. Patients who are treated with immunodeficiency in hospitals and get immunosupressive therapy are endangered the most. By the application of modem diagnostic methods the number of legionellosis, confirmed with laboratory 
investigations, has increased in Hungary. Most diagnostic methods of legionellosis are adopted successfully in the Bacteriological Department of National Center for Epidemiology (OEK) (revealing of antibodies and antigenes by IF and ELISA methods, breeding). In 1999112 blood tests out of 708 were positive. Out of 77 urine samples the antigene was revealed in 3 cases. Out of 76 BAL and sputum specimens 27 ones were positive by direct IF. In 199927 legionellosis were reported, which lead to death in 4 cases. Among our cases - according to the probable origin of the infection there were nosocomial infections, diseases in connection with travelling, and occupational diseases as well. In contrast foreign data the most illnesses occurred among 16-30 year old people. The ratio of males and females (near 1:1) differs from the literary data as well. Most of our isolated strains - contrary the literary data - did not belong to L. pneumophila 1 serogroup and some of them proved to be ciprofloxacin resistant.

\title{
T. MAG ${ }^{1}$, E. BALLA $^{2}$, CS. BOGNÁR ${ }^{2}$
}

\section{Detection and examination of hydrogen peroxide producing lactobacilli in lower genital tract samples}

\author{
${ }^{1}$ Department of Microbiology, Eötvös Loránd University, Budapest, ${ }^{2 "}$ Béla Johan” National Center \\ for Epidemiology, Budapest, Hungary
}

Lactobacilli are known as predominating protective microorganisms of normal vaginal flora, however, there are still unknown details of their protective microbial mechanisms against pathogens. Hydrogen peroxide produced by some strains may play an important role in control of human vaginal ecosystem, besides the low $\mathrm{pH}$-value generated by main metabolites. The detection of quantity and distribution of species of $\mathrm{H}_{2} \mathrm{O}_{2}$ producing and nonproducing lactobacilli would help diagnostic efforts of bacterial infections and anaerobic vaginosis. Authors worked out a specific culture medium for isolating $\mathrm{H}_{2} \mathrm{O}_{2}$ producing lactobacilli from routine clinical samples. Selectivity of the culture medium is based on low $\mathrm{pH}$-value, differentiation is associated with benzidine-reaction. Due to the chromogenic substrate $\mathrm{H}_{2} \mathrm{O}_{2}$ producing lactobacilli strains form characteristic blue colonies. Microscopically and macroscopically suspect colonies were confirmed by API 50 CHL tests. 


\title{
L. MAKRAI ${ }^{1}$, Gy. Pelle ${ }^{2}$, L. FODOR ${ }^{1}$, M. DoBos-KovÁCs ${ }^{3}$
}

\section{Actinomycosis of dogs caused by Actinomyces hordeovulneris}

\author{
${ }^{1}$ Department of Microbiology and Infectious Diseases, Faculty of Veterinary Science, Szent István \\ University, Budapest, ${ }^{2}$ Animal Clinic Nyíregyháza, ${ }^{3}$ Department of Pathology and Forensic Medicine, \\ Faculty of Veterinary Science, Szent István University, Budapest, Hungary
}

Actinomyces hordeovulneris was isolated from the lesions of chronic pyogranulomatous pleuritis and pericarditis of one of three dogs showing similar symptoms. The parietal pleura and the pericardium were markedly thickened and covered with fine short threads of angiofibroblastic tissue. About 500-1000 ml reddish, purulent exudate accumulated in the thorax of all dogs examined containing large number of rice-sized, soft, yellowish-white granules ("sulphur granules"). When they were stained using the Gram method, a central core of branching filaments of Grampositive bacteria embedded in thick granulation tissue could be observed. The parietal pleura, the mediastinal sheets and the pericardium were infiltrated predominantly with neutrophils, and to a lesser extent with lymphocytes and plasma cells. A small number of eosinophils and giant cells were also observed. A large number of pyogranulomas embedded in the granulation tissue were composed of a core of necrotized granulation tissue, mixed with clusters of Gram-positive branching bacteria, surrounded by an area of intact and degenerating neutrophils and lymphocytes. Bacteria were detected in the lesions by Brown-Brenn staining and they were isolated from one of the affected animals. The isolated bacteria were identified as $A$. hordeovulneris. This is the first isolation of $A$. hordeovulneris in Hungary.

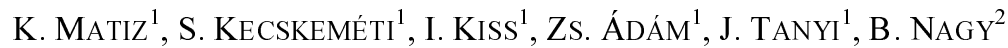

\section{Torovirus detection in diarrheal calves and in weaned pigs in Hungary}

${ }^{1}$ Veterinary Institute of Debrecen, Debrecen, ${ }^{2}$ Veterinary Medical Research Institute, Hungarian Academy of Sciences, Budapest, Hungary

Toroviruses belong to the Torovirus genus of the Coronaviridae family, order Nidovirales. These viruses are morphologically similar and antigenically related. The bovine torovirus is an established etiological agent of disease in cattle, although the porcine torovirus was isolated from healthy animals. Evidence for the existence of toroviruses has been described in many European countries and in the United States. In 
Hungary virions were detected in diarrhoeic calves by one of us (1986), which were identified as "Breda Agent" based on their morphology.

We planned a RT-PCR survey in order to detect toroviruses in Hungary. The study covered ten swine-, and nine bovine - randomly chosen - stocks. Rectal swabs and faecal specimens were collected from diarrhoeic calves and from healthy piglets after weaning. Altogether 200 porcine and 111 bovine samples were tested by RT-PCR with torovirus specific primers. We found positive specimens from calves (4) and pigs (10), respectively. In these cases we strengthened the specificity of our result by sequencing the RT-PCR product of 135 bases size.

As a result of our work we detected, first time in Hungary, toroviruses in two cattle-, and in two pig herds.

The authors would like to thank Prof. Éva Nagy and Prof. M. C. Horzinek for providing primers and positive controls.

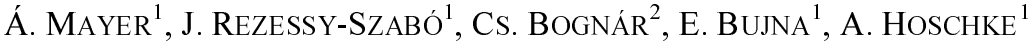

\section{Nutrition-biological role of probiotic Bifidobacteria and their growth stimulating prebiotics}

${ }^{1}$ Department of Brewing and Distilling, Faculty of Food Science, Szent István University, 2 "Béla Johan" National Center of Epidemiology, Budapest, Hungary

For decades it has been well known that fermented dairy products play an important role in nutrition, because they contain living lactic acid bacteria which have beneficial effects on the host's health. Among the food products, which nowadays are on the market, there are more and more so-called functional foods, which contain probiotic, prebiotic and symbiotic additives. Probiotics are living microorganisms that upon entering the host take part in the life-process of the colonic microbiota and have positive effects on its balance. Prebiotics are not living substances but non-digestible food ingredients (e.g. oligosaccharides) that beneficially affect the host by selectively stimulating the growth of the beneficial bacteria resident in the colon. Symbiotics food contains both probiotic microorganisms and prebiotics, which selectively support the growth of the probiotic strains. In the process of screening probiotic strains attention has to be paid to several criteria. Besides technological requirements (oxygen tolerance, fermentation capability), physiological features (acid tolerance, colonisation capability) and the positive effects to the human health should not been neglected. Many producers use starter culture containing Bifidobacteria. Several positive effects of Bifidobacteria have been experimentally proved (production of vitamins, stimulation of immune 
system and reduction of cholesterol level). Among the positive effects the most important one is the following: Bifidobacteria produce short chain fatty acids as endproducts of their metabolism acidifying the $\mathrm{pH}$ of the colon, thus inhibiting the growth of most of the harmful bacteria.

Our work was done in two directions. The first aim was to isolate Bifidobacteria, which have better features than the strains nowadays used in the dairy industry (having good adhesion capability and antagonistic effects to enteropathogenic bacteria) and to search a growth substrate, which is non-digestible and selectively stimulates their growth. The second part of our work was to test the effect of Bifidobacteria and different kinds of oligosaccharides on the colonic microbiota in in vivo animal experiments.

From our results it can be concluded that the strains isolated from human faeces have better adhesion capability and their antagonistic effects against several enteropathogenic bacteria are more effective than the type strains examined. As prebiotic the isomalto-oligosaccharide containing product was the most convenient, because this supports the growth of Bifidobacteria but does not support the growth of several enteropathogenic bacteria. In the experiments with mice - when they were fed functional food containing Bifidobacteria and oligosaccharides - we did not find any significant change in the composition of faecal microbiota. When the colonic microbiota of mice were eliminated by antibiotic treatment, they recovered after the 4 week feeding period with synbiotic food. The final goal of this project is the creation of pre-, pro- and synbiotic functional foods.

The research was supported by the INCO-COPERNICUS CIPA CT-96-1000 and the Hungarian Ministry of Agriculture FK-76/7/99 projects.

\section{Y. MÁNDI ${ }^{1}$, A. TISZAI $^{2}, Z_{\text {S. }}$ LÉNÁRT $^{2}$, J. LONOVICS $^{2}$ \\ Mucosal and peripheral cytokine production in patients with Helicobacter pylori-related duodenal ulcer}

\footnotetext{
${ }^{1}$ Department of Medical Microbiology, ${ }^{2}$ Department of 1st Internal Medicine, Faculty of Medicine, University of Szeged, Szeged, Hungary
}

In Helicobacter pylori infection both bacterial and host factors contribute to gastroduodenal mucosal damage. Cytokines play a crucial role in the initiation and modulation of gastrointestinal inflammation. The aim of this comparative study was to investigate the mucosal production of TNF- $\alpha$, IL- 6 and IL- 8 in patients with duodenal 
ulcers, compared with the peripheral cytokine patterns. In addition we investigated the presence of antibodies against CagA and VacA virulence factors.

A considerable TNF- $\alpha$, IL- 6 and IL- 8 expression was detected by ECL Western blot assay in both the antrum and corpus biopsy samples from 10 of the $12 \mathrm{H}$. pylori positive patients. On the contrary, the cytokine levels in their peripheral blood was not significantly different from that of normal healthy donors. Similarly, no significant difference concerning the in vitro cytokine production was observed comparing the activity of their peripheral leukocytes and that of healthy controls. All of the patients had antibodies against Cag A and Vac A antigens, as it was tested by Western blot and ELISA assays. The in vitro cytokine inducing capacity of different strains of Helicobacter pylori with and without virulence factors was also investigated.

Conclusions: Inflammatory cytokines generated locally within the gastric mucosa could be relevant to the gastric physiology of $H$. pylori infection. These results suggest a possible pathogenic role of these cytokines in $H$. pylori-associated duodenal ulcer. Further in vitro studies are required to determine the mechanism of cytokine induction.

\section{J. MOLNÁR, GY. GUNICS, CS. MisKOLCI, K. WOLFÁRD}

\section{Models for reversal of resistance}

Institute of Medical Microbiology, University of Szeged, Szeged, Hungary

Many of the potent antibiotics have lost their effectiveness in the last decades. Antibiotic resistant bacteria are known to be responsible for more than $50 \%$ of hospital acquired infections. The multiple resistance means that patients with infections are ill for a longer time and they are at a greater risk of dying. At the same time too few drugs are developed to replace those which have lost their effectiveness. To solve these problems new compounds or combinations of compounds could be introduced to overcome drug resistance by blocking the genetic code or the membrane proteins responsible for drug-, or multidrug resistance.

The elimination of the genetic code of the resistance or inhibition of membrane transporter proteins were supposed to result in synergy with chemotherapeutics. Extrachromosomal genetic elements of prokaryotes and eukaryotes could be eliminated from bacteria and yeast and in addition expression of multidrug resistance gene was reduced in cancer cells in the presence of some heterocyclic compounds. Apparently the effective compounds could affect plasmid DNA and membrane function, as well. As a consequence some representative compounds such as calmodulin antagonists, 
calcium channel blockers, proton pump inhibitors, etc. were able to synergize the effects of antibiotics. The resistance reversing effect was dependent on the chemical structure of the resistance modifiers. Based on the synergy between chemotherapeutics and non-conventional antibiotics we suppose that some resistance modifiers may help to overcome antibiotic resistance of bacteria in vivo.

\title{
J. MURÁNYI-BROJNÁS ${ }^{2}$, E. RUSVAI ${ }^{2}$, Á. CSOHÁN ${ }^{1}$, K. LENDVAI $^{1}$, K. ÖRDÖGH, GY. BERENCSI ${ }^{2}$
}

\section{Serological findings of children of HBsAg carrier mothers following the introduction of preventive treatment upon birth}

\author{
Divisions of ${ }^{1}$ Epidemiology and ${ }^{2}$ Virology, "B. Johan" National Center for Epidemiology, Budapest, \\ Hungary
}

The complex hepatitis prevention programme has been introduced on the 1st of January 1995 in Hungary. Since that time all pregnant women are screened for the presence of HBsAg. Those found to be carriers are registered, educated and the newborn babies are immunized with hyperimmune gamma globulin and with recombinant $\mathrm{HBs} \mathrm{Ag}$ vaccine on separate injection sites.

Altogether 420.000 pregnant women were tested for the presence of $\mathrm{HBsAg}$ between 1995 and 1998 (about four years) in the 20 regional laboratories of the SERVICE. The number of HBsAg-carrier persons was 2135. The mean prevalence was calculated to be 0.5 per cent. There were observed, however, significant regional differences.

Up to the date of the last reporting 1.655 children became 18 months of age when the results of the active-passive preventive treatment can be serologically tested. The number of HBs Ag negative children was 1642 (99.2\%). The concentration of antiHBsAg antibodies was found to be more than 10 miliunits (International Unit) in the case of 1.295 children (78\%). Only 347 children had to be revaccinated.

Three of the 13 children (unsuccessful preventive treatment i.e. $0.8 \%$ of the children) were born from one single mother, who seroconverted last year, and the preventive treatment was also successful in the case of her 4th baby born in 1999 . 


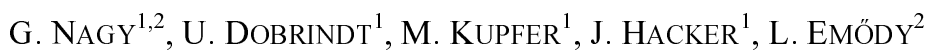

\section{$\mathrm{RfaH}$ influences expression of the hemin receptor $\mathrm{ChuA}$ and in vivo virulence of a uropathogenic $E$. coli strain}

${ }^{1}$ Institute for Molecular Biology of Infectious Diseases, University of Würzburg, Germany, ${ }^{2}$ Institute of Medical Microbiology and Immunology, University of Pécs, Pécs, Hungary

$\mathrm{RfaH}$ is a global regulator in E. coli, influencing expression of long operons encoding factors that are important for virulence and fertility. The affected operons contain a conserved motif termed JUMPStart sequence, the presence of which is required for the $\mathrm{RfaH}$-derived regulation.

We report that $\mathrm{RfaH}$ - beside several other virulence determinants - affects expression of the hemin receptor ChuA in the uropathogenic E. coli strain 536. The chuA-transcript level was significantly reduced in an $r f a H$ mutant compared to the wild type. The decrease of specific mRNA resulted in a lower amount of ChuA detected in Western blot. In the $\mathrm{rfaH}^{-}$mutant strain, the decrease in the amount of hemin receptor, however, did not significantly alter the ability to utilize hemin as an iron source in comparison to the wild type strain. Nevertheless, in vivo virulence in a mouse model as well as serum resistance of the $\mathrm{rfaH}^{-}$mutant were significantly lower than those of the wild type strain. Complementation of the mutant $536 \mathrm{rfaH}$ with a plasmid carrying an intact $r f a H^{-}$gene, restored higher chuA transcript- and ChuA receptor levels as well as increased virulence and serum resistance.

The nucleotide sequence of chuA along with its $700 \mathrm{bp} 5$ '-flanking region was determined. A motif resembling the JUMPStart sequence was identified within chuA. Furthermore, we identified two variants of the chuA determinant differing in their neighbouring regions and exhibiting a well-defined distributional pattern among different pathogroups of $E$. coli.

Since $\mathrm{RfaH}$ was reported to be a major regulator of $\alpha$-haemolysin, we propose a common regulatory pathway of the toxin that gains access to the intracellular heme reservoir and the hemin uptake system. This would be energetically advantageous for pathogenic bacteria since utilization of heme compounds liberated from eukaryotic cells is considered to be an important iron acquisition strategy during infection. 


\section{NAGY ${ }^{1}$, É. NAGY ${ }^{2}$, T. TUBOLY ${ }^{1}$}

\section{Sequence analysis of porcine adenovirus serotype five}

${ }^{1}$ Veterinary Medical Research Institute, Hungarian Academy of Sciences, Budapest, Hungary, ${ }^{2}$ University of Guelph, Guelph, Canada

The complete nucleotide sequence of porcine adenovirus serotype-5 (PAdV-5) was determined and the transcription map was constructed. The size of the genome was found to be 32621 nucleotides. The early promoter regions, the major late promoter (MLP) and polyadenilation sites were predicted and the early and late transcription units were determined. The PAdV-5 genome could be divided into four early and six late transcription units. The E1A 173R $(19.88 \mathrm{kDa})$ and E1A 67R $(7.76 \mathrm{kDa})$ proteins were encoded by two overlapping open reading frames (ORF), which were similar in length to the CAdV-1 E1A proteins. In the E2B region, the full length of the precursor terminal protein ( $p T P$ ) and the DNA polymerase genes were determined by sequence alignment to known adenovirus pTP and DNA polymerase cDNA sequences.

The MLP of PAdV-5 was similar to the MLPs of human adenoviruses and other previously studied mastadenoviruses. The canonical TATA-box of the MLP was located at nt 5122-5128, an inverted CAAT box (nt 5084-5088), an upstream promoter element (nt 5104-5109), initiator element (nt 5150-5156), and two downstream activating elements DE1 (nt 5225-5235) and DE2 (nt 5240-5255) were identified.

Twenty-seven putative proteins were located by their homology with other adenoviruses. The pVIII (79\%), penton (77\%) hexon (77\%), and the protease $(75 \%)$ proteins showed the highest identities to known adenovirus protein sequences. Further 8 genes were predicted according to their homology with hypothetical adenovirus genes and other viral and eukaryotic genes. Several special protein sequence motifs were characterized by their homology to similar protein motifs. The penton base protein lacked the integrin binding motif RGD, but the LDV motif was completely present. The fiber protein contained nineteen recognizable pseudorepeats. Interestingly, the highly conservative TLWT motif was missing from the predicted fiber protein. Based on sequence analysis and RNA secondary structure prediction, sequences for virus associated RNAs could not be recognized between the genes coding for pTP and $52 / 55 \mathrm{kDA}$ proteins. 


\section{K. N. SZOMOR ${ }^{1}$, I. JANKOVICS ${ }^{1}$, M. TAKÁCS ${ }^{1}$, Á. CSOHÁN $^{1}$, É. VISNYOVSZKY $^{1}$, S. BENKOVICS ${ }^{2}$, GY. BERENCSI ${ }^{1}$ in Hungary, by using multiplex nested RT-PCR, in seasons 1998-99 and 1999-2000 \\ Monitoring of influenza-like illnesses, and detection of influenza viruses}

1“B. Johan" National Center for Epidemiology, Budapest, ${ }^{2}$ National Public Health Institute, Budapest, Hungary

About 300.000 patients with acute respiratory diseases consult their general practitioners in an average wintertime in Hungary. The illnesses occurred in different age groups in the two examined seasons: in 1998-99, and 1999-2000. The results of tests for respiratory tract infections in these two periods showed a conspicuous difference: in 1998-99 there was a regular influenza outbreak, but in 1999-2000 the outbreak was polyaetiologic, different pathogenic agents were detected, mostly RSV, adeno-, parainfluenza viruses, and chlamydia and mycoplasma were also detected. Even the number of double-infections were higher in 1999-2000 than in the previous season.

The clinical samples (nasal-, or throat swabs in Virus Transport Medium, paired sera) sent to the Epidemiological Center's laboratory, were tested by numerous methods to detect the presence of respiratory tract viruses or confirm recent or past viral infections.

For isolation of influenza viruses we used the inoculation of samples in embryonated hens' eggs. Parallel to this, the multiplex RT-PCR was applied for detecting the viral RNA of influenza A and B in infected cells. The isolated influenza strains were similar to A/H3N2 Sydney 5/97, and the B/Beijing 184/93 prototype strains in 1998-99, and we have not isolated any influenza strains in 1999-2000. The advantage of the PCR method is that it provides a rapid typing and subtyping of influenza viruses in a single step. The multiplex RT-PCR was more sensitive than the inoculation in eggs: the percentage of positive results were $\sim 10 \%$ with inoculation, and 24\% with PCR. 131 (in 1998-99) and 231 (in 1999-2000) samples were tested by direct immunofluorescence for adeno-, corona-, parainfluenza-, RS, Influenza A and B viruses, and for mycoplasma and chlamydia. Serological method was used in 113 (in 1998-99) and 232 (in 1999-2000) paired sera, for confirming recent or previous infections caused by adeno-, parainfluenza-, and RS viruses. 


\section{Growth inhibition studies on Salmonella typhimurium under strict anaerobic conditions}

Veterinary Medical Research Institute of Hungarian Academy of Sciences, Budapest, Hungary

In the Salmonella-control programs of poultry, in addition to the commonly used prevention methods - last but not least on the basis of the successful application of Zoosaloral- $\mathrm{H}^{\circledR}$ - vaccination with live, attenuated Salmonella vaccines is becoming more attractive and applicable. A potential aim of vaccine development can be a Salmonella vaccine strain, which is able to induce cross-protection among the different Salmonella serotypes. An important finding of the last years: the colonizationinhibition can serve as a basis of the aim mentioned above. Colonization-inhibition means that if the gut of a day-old chick is colonized by a non-virulent, well-colonizing Salmonella strain, then this protects the chick against the infection with a second Salmonella. A parallel phenomenon with the colonization-inhibition is the growthinhibition, found in the nutrient broth cultures of Salmonella strains. This means that inoculating a small amount of a given Salmonella strain into a stationary-phase nutrient broth culture of an other Salmonella strain, it is not able to grow and not because of the absence of available nutrients. For the deeper understanding of these two phenomena we have to identify the genes (and operons) that take part in these inhibitory mechanisms, for example by creating numerous mutants by transposon mutagenesis and investigating the Tn-insertion sites by PCR and sequencing them in the mutants that have lost their inhibitory capacity.

In poultry $S$. typhimurium F98 is a well-colonizing and strongly inhibitory strain. The authors have tested 2.800 S. typhimurium F98 Tn5-TcI mutants under strict anaerobiosis by adapting the standard aerobe growth-inhibition micro-plate assay to anaerobic conditions. The stationary-phase old LB-cultures of the mutants (marked by naladixic acid antibiotic resistance and stored on micro-plates) were inoculated by a special replica system with $10^{3}-10^{4} \mathrm{cfu} / \mathrm{ml}$ amount of the spectinomycin resistance marked but isogenic $S$. typhimurium F98 parent strain. After 24 hours incubation the growth of the $S$. typhimurium F98 $\mathrm{Spe}^{\mathrm{r}}$ was tested on bromothimol-blue plates containing Spe. Mutants that have lost their inhibitory phenomenon were selected. In this way we have found 34 non-inhibitory mutants and the characterization of these mutants and the comparison of our results with those that were found under aerobiosis is in progress. So far 26 mutants seem to have lost their growth inhibiting capacity under anaerobic conditions only. 


\section{A. R. Omar, M. Hair-Bejo, I. Aini, M. M. Hoque, L. K. ChOnG, S. P. PhONG}

\section{Pathogenicity and molecular characterization of Ssp1 positive very virulent infectious bursal disease virus}

Faculty of Veterinary Medicine, University Putra Malaysia, 43400 UPM, Serdang, Selangor, Malaysia

Infectious bursal disease virus (IBDV) is the etiological agent of infectious bursal disease (IBD) which causes significant losses to the poultry industries either by causing high mortality in an acute disease or as a consequence of immunosuppression in young chickens. On the basis of restriction fragment length polymorphism (RFLP) patterns, serotype I IBDV can be divided into 6 groups. Groups 1 and 2 consist of variant viruses, groups 3 and 4 consist of classical viruses, group 5 consists of the Lukert strain viruses and recently group 6 which consists of $S s p 1$ positive very virulent IBDV (vvIBDV) from outside the Central and South America. Recently, we studied the molecular pathogenicity of three Malaysian, 92/04, 94/273 and 97/61 and one Bangladeshi 99/B551 isolates that are Ssp1 positive. Pathogenicity studies of specificpathogen-free (SPF) chickens infected with the respective isolates except 94/273 demonstrated typical clinical signs of vvIBDV including haemorrhage of the musculature and bursas with a mortality rate of $80 \%$ within 3 to 4 days postinfection. Fifty percent of the chickens also demonstrated moderate haemorrhage at the junction of the proventriculus gizzard region. On the other hand, SPF-chickens infected with 94/273 did not show any abnormal signs and no mortality was observed. Regardless the type of the isolates, all infected chickens show comparable histopathology lesion in the bursa and significant reduction $(\mathrm{p}<0.05)$ of the average bursal weight; average body weight index at day 4 and 8 postinfection. Sequencing of the IBDV genome primarily the whole VP2 region $(\sim 1.35 \mathrm{~kb})$ revealed that all the isolates have a conserve motif of SWSASGS at the hypervariable region. In addition, all the isolates have 3 aa residues, 222A, 2561 and 2941 that are unique to all vvIBDV. Another common feature for the isolates except $94 / 273$ is the presence of Styl site at position 254, which encodes for amino acid (aa) glycine. This residue has been demonstrated among the vvIBDV, classical and vaccine strains. However, in the 94/273, the aa 254 undergo substitution from glycine to serine. Interesting, this aa variation has also been demonstrated in variant strains. The $94 / 273$ also demonstrated an unique aa variation at position 270 from alanine to glutamic acid as found on serotype 2, OH strain. In addition, the aa at position 270 is also different among the STC and vaccine strains, where the alanine residue is substituted by threonine. Even though the 94/273 do not cause mortality in SPF-chickens, phlyogenetic analysis of the VP2 gene classified the virus as vvIBDV with very close divergence to other vvIBDV from Malaysia as well as from Israel, 
Hong Kong, Japan and China but differ from the Holland, Turkey and classical virulent USA isolates. In addition, based on the gross and histopathological data as well as other conserved RFLP markers it is unlike that the 94/273 is a variant or attenuated strain. Even though the isolate has the three characteristic aa at the position 222, 256 and 294 as found on other vvIBDV, the aa variation at position 254 and 270 might be associated with the low virulence of the virus. So far, the well documented aa variations found in IBDV of low virulence is the reduction or lack of S residue at the conserve motif SWSASGS as well as the presence of aa residue $279 \mathrm{~N}$ and $284 \mathrm{~T}$. However, both characteristic changes were not found in the 94/273. Currently, we are sequencing the whole genome of $94 / 273$ for identifying further nucleotide changes. The discrepancy between molecular and pathological classification of IBDV strain $94 / 273$ might be due to the constant evolution of the virus. Similar to other RNA viruses, it is likely that emergence of new IBDV with unique characteristic changes will be identified in the future.

\title{
T. PAPP ${ }^{1,2}$, Á. DÁN $^{1,3}$, V. PALYA ${ }^{4}$, T. RÉVÉSZ ${ }^{3},{\text { É} . \text { IVANICS }^{3}, \text { R. GLÁVITS }}^{3}$, E. SÁGI ${ }^{4}$, B. HARRACH ${ }^{1}$
}

\section{Study of fowl adenoviruses by PCR and DNA sequencing}

\author{
${ }^{1}$ Veterinary Medical Research Institute, Hungarian Academy of Sciences, Budapest, ${ }^{2}$ Faculty \\ of Veterinary Medicine, Szent István University, Budapest, ${ }^{3}$ Central Veterinary Institute, Budapest, \\ ${ }^{4}$ CEVA-Phylaxia Inc., Budapest, Hungary
}

Until recently, all adenoviruses isolated from birds were classified into one genus called Aviadenovirus. This genus contained three groups (I-III) separating the viruses based on their different biological and immunological properties. By now, the genome of at least one representative from all the three groups has been fully sequenced. The comparison of these sequences revealed that the members of group II and III share more homology with certain adenoviruses of non-avian host origin, and should therefore be placed into other genera (Atadenovirus, 4th genus).

The genus Aviadenovirus (former group I) contains twelve chicken serotypes (FAdV 1-12), but DNA sequences were published only from four of these serotypes. A dependable phylogenetic analysis requires the usage of utmost homologous gene parts, therefore we aimed to obtain DNA sequences from all serotypes. We also wanted to estimate the variance within the genus for the correct definition of the new taxonomic category of the aviadenovirus species. 
Raue and Hess (1998) reported a PCR method feasible for the amplification of two segments from the hexon gene from all the twelve FAdV serotypes. We have tested the primers on the prototype strains and four field isolates. The PCR products were sequenced, the received data compared and analysed by the PHYLIP programme package. The results will be presented by phylograms.

So far, we obtained DNA sequences from all but one isolate, from either both or one segment of the hexon gene. The level of variance within one serotype was found surprisingly high in some cases. For example, two extremely pathogenic strains (both of them isolated in Pakistan) from hydropericardium syndrome proved to be slightly different from each other and from the prototype FAdV-4 strain. Such kind of variance within one type has not been reported regarding viruses of other genera (e.g. EDS virus and HEV). We could not get amplification with serotype FAdV-5 as yet, although we have optimized the PCR conditions and prepared new virus stocks. It seems to be a failure of the primers, which had been originally designed considering only two sequences (FAdV-1 and 10) known at that time. This finding would suggest significant divergence of FAdV-5 (the single representative of species Fowl adenovirus B) from the other serotypes. We managed to amplify and sequence the viral DNA directly from a Hungarian field sample from the liver of a chick showing pathognomic lesions of inclusion body hepatitis. The amplified virus seemed to belong to species Fowl adenovirus $\mathrm{E}$, but the serotype has not been defined yet.

Our results correlate well with the findings of Zsák and Kisary (1984), who had classified FAdVs into 5 groups based on restriction enzyme analysis. Their grouping became the basis of demarcation of the species (FAdV-A-E) of aviadenoviruses.

Supported by OTKA grants T 022369 and T 022405.

M. PÁLMAI, G. KISKÓ

Study on the suppression of Listeria monocytogenes by Lactobacillus casei in milk in function of the initial cellcount ratio and the incubation temperature

Department of Microbiology and Biotechnology, Faculty of Food Science, Szent István University, Budapest, Hungary

There is increasing interest in the food industry for new biological preservation methods. The preservative effect of the different metabolites of lactic acid bacteria has been known for a long time. Numerous researchers studied the preventive effect of the 
LAB metabolites to increase the safety of foods by suppressing the growth of foodborne pathogenic bacteria.

The aim of our work was to examine the possibility of growth of Listeria monocytogenes in milk in the presence of lactic acid bacteria. The pathogen is known to cause food-borne illness in raw or post-contaminated milk products (e.g. soft cheese).

In our study we examined the effect of the lactic acid production of Lactobacillus casei on the growth characteristics of Listeria monocytogenes in milk. Since the metabolic activity, thus the inhibitory effect of lactic acid bacteria is influenced by environmental factors, the interaction of the two microorganisms in the co-culture was examined at three different temperatures $\left(7,13,20^{\circ} \mathrm{C}\right)$. The initial cell count of $L b$. casei varied from $10^{3} \mathrm{cfu} / \mathrm{ml}$, to $10^{6} \mathrm{cfu} / \mathrm{ml}$ to result 1:1, 10:1, and 1000:1 ratio comparing to the number of L. monocytogenes $\left(10^{3} \mathrm{cfu} / \mathrm{ml}\right)$.

Based on the obtained growth curves a model was constructed on the growth characteristics of $L$. monocytogenes in the function of $L b$. casei cell count and temperature.

\section{J. PÁSZTI ${ }^{1}$, A. SZENTMIHÁLYI ${ }^{1}$, I. GADÓ1 ${ }^{1}$ T. ERDÖSI ${ }^{1}$, K. KRISZTALOVICS ${ }^{1}$, K. TÁRKÁNYI ${ }^{2}, Z s$. V. HUNYADI ${ }^{1}$, J. KIRÁLY ${ }^{1}$}

\section{Characterization of Neisseria meningitidis isolated from Hungary by RAPD method}

\footnotetext{
${ }^{1}$ Department of Phagetyping and Molecular Epidemiology, "B. Johan” National Center for Epidemiology, ${ }^{2}$ Department of Microbiology, Szent László Hospital for Infectious Diseases, Budapest, Hungary
}

Invasive diseases caused by Neisseria meningitidis occurred mainly sporadically in Hungary in the recent years. In December 1999 a community outbreak was observed in a military barrack, which concerned soldiers and civil population, too. To help in the investigation of epidemiological connections and to characterize the Hungarian isolates the Random Amplified Polymorphic DNA method was applied. Out of the 29 strains examined 22 belonged to serogroup $\mathrm{C}, 6$ to $\mathrm{B}$ and I to $\mathrm{W} 135$. Out of $N$. meningitidis strains of serogroup $\mathrm{C} 14$ were isolated from the present outbreak and 4 during the previous months, 11 strains ( 4 C, 6 B, $1 \mathrm{~W} 13$ 5) were obtained before 1999. The RAPD examinations were performed using the modified method of Woods et al. [1]. As primers 1283 and 1290 were used, as templates the supernatants of boiled bacterial suspensions (1) or genomic DNA-s (2) prepared with Wizard kit were applied. The 
amplicons were stained after agarose gel electrophoresis with ethidium-bromide. Determination of the sizes of amplicons was carried out in Gel Doc apparatus with Quantity One evaluation software using pGEM standard. It was found that the strains belonging to different serogroups could be differentiated with both primers on the basis of the size and number of their amplicons. While the differences within the strains of serogroup B and C isolated from sporadic cases before 1999 could be demonstrated with both primers, in case of the epidemic strains of serogroup $\mathrm{C}$ identical pattern was obtained with primer 1283 , therefore these strains were studied with primer 1290, using templates type (1) and (2). Many amplicons appeared in both cases, but only a part of them was reproducible in repeated experiments, in accordance with literary data. For evaluation only the reproducible products were taken into account. The strains, isolated from the throat samples of 12 patients and 1 healthy person in December 1999 and January 2000 had identical patterns using template (1). The pattern of one strain differed, this was supported also by its different serotype. Dissimilar pattern was found in 3 strains of serogroup C, one strain was isolated in April 1999 and two earlier than 1999. Using template (2) 7 outbreak strains and 4 strains obtained before the outbreak belonged to identical group, but seven outbreak strains differed from this group in the number and size of their amplicons. Summarizing our results, it was found that the applied method was suitable to characterize the isolates and to follow the connections between the strains obtained during a given period.

1. J. P. Woods, D. Kersulyte, R. W. Tolan, Jr., C. M. Berg., D. E. Berg: Use of Arbitrarily Primed Polymerase Chain Reaction analysis to type disease and carrier strains of Neisseria meningitidis isolated during a university outbreak. J Infect Dis 169, 1384-1389 (1994).

\section{G. REUTER ${ }^{1,2}$, A. KÁtAI ${ }^{3}$, M. KÁLMÁN ${ }^{3}$, T. FARKAS $^{4}$, T. BERKE ${ }^{4}$, K. BÁNYAI $^{1}$, XI JIANG ${ }^{4}$, D. O. MATSON ${ }^{4}$, GY. SZÜCS ${ }^{1}$ \\ First detection of human calicivirus in a food-borne outbreak in Hungary}

\footnotetext{
${ }^{1}$ Regional Laboratory of Virology, Baranya County Institute of the State Public Health Service, Pécs, ${ }^{2}$ Department of Medical Microbiology and Immunology, Medical Faculty, Pécs University, Pécs, ${ }^{3}$ Department of Laboratory, Csongrád County Institute of the State Public Health Service, Szeged, Hungary, ${ }^{4}$ Center for Pediatric Research, Eastern Virginia Medical School, Norfolk, VA, USA
}

Human caliciviruses (HuCVs) classified as members of the family Caliciviridae are a major cause of acute non-bacterial gastroenteritis cases and outbreaks in persons of all ages worldwide. They are subdivided into two genera: Norwalk-like viruses and 
Sapporo-like viruses. The aim of the study was to detect HuCV infection in Hungary. We used reverse transcription-polymerase chain reaction (RT-PCR) with a primer pair p289/p290 designed upon the available sequence data of the conservative RNAdependent RNA polymerase (ORF1) region of different $\mathrm{HuCV}$ strains from both genera. The definite identification was achieved by amplicon sequencing and phylogenetic analysis.

$\mathrm{HuCV}$ isolated from fecal samples collected from a food-borne outbreak in nurseries and elementary school in Szeged and Algyö areas in November 1998 caused a total of 80 illnesses with typical CV-related clinical symptoms and epidemiology. Phylogenetically, the HuCV/Szeged-Algyö/98/HUN strain belonged to the genogroup GII of Norwalk-like viruses and had $91 \%$ nucleotide sequence and $96 \%$ amino acid identity with the closest reference strain, the Lordsdale virus.

According to our knowledge this is the first detection of $\mathrm{HuCV}$ in a food-related epidemic in Hungary and Central-Eastern Europe, as well.

\section{A. RÉTHY ${ }^{1}$, GY. BÁTHORI ${ }^{2}$, L. RÉTHY}

\section{Cationic lipid (DDA-Cl) + bacterial BRM complexes: increased survival times in tumorous mice}

\footnotetext{
Independent Research Group for Genetics and Immunology, Budapest, ${ }^{1} \mathrm{Hrc}$ - Bethesda Childrens' Hospital, Budapest, ${ }^{2} 1$ st Department of Physiology, Semmelweis University, Budapest, Hungary
}

Background: (i) The manipulative amplification of antitoxic immune response by DDA-chloride (a quaternary ammonium base: cationic lipid) was applied first by one of us, in 1968 [1]. Nowadays cationic lipids are widely used as vectors for gene therapy [2]. (ii) The role of BRMs of bacterial origin was also investigated previously by us in experiments aimed at increasing the level of both the antitoxic-type immunity and the non-specific resistance of tumor-infested mice [3-5].

At present the antitumor activity of bacterial BRM-s (biological response modifiers of bacterial origin: bacterium vaccines and derivatives) complexed with the cationic lipid DDA-chloride was defined. Mice $\left(18 \mathrm{~g}\right.$ each) were infested with $10^{8}$ living cells of EHRLICH ascites tumor. Therapy with the above-mentioned complexes was done on -3 and +3 days with the time of tumor-infestation on 0 day. Medium Survival Time (MST, in days) was defined in each group.

Biometrics: Kolmogorov and Smirnov two-sample test, ANOVA $\chi^{2}$ "p" value of reliability. Detailed results are displayed in Table. 


\begin{tabular}{|c|c|c|c|}
\hline & $\mathrm{N}$ & MST & SD \\
\hline Untreated controls & 15 & 19.6 & 4.36 \\
\hline Controls treated with DDA-chloride & 15 & 22.7 & 5.21 \\
\hline C. parvum & 15 & 32.40 & 8.62 \\
\hline C. parvum + DDA-chloride & 15 & 41.10 & 12.24 \\
\hline C. granulosum & 14 & 35.60 & 11.96 \\
\hline C. granulosum + DDA-chloride & 15 & 45.94 & 12.94 \\
\hline P40 (derivate of C. granulosum) ${ }^{*}$ & 14 & 32.73 & 6.51 \\
\hline P40 + DDA-chloride & 15 & 44.40 & 10.93 \\
\hline Brucella abortus & 15 & 28.06 & 6.41 \\
\hline Brucella abortus + DDA-chloride & 15 & 38.66 & 8.44 \\
\hline
\end{tabular}

* Courtesy of Institute Pasteur, Paris

Results: MST values of EHRLICH tumor infested mice increased significantly following bacterial BRM-treatments. An additional significant increase was observed following BRM-DDA-chloride treatment. DDA-chloride alone did not affect survival. C. granulosum + DDA-chloride complex exhibited the most pronounced life-span prolonging activity. Biometrics proved a high and statistically significant degree of homogeneity and reliability of results in all cases.

Summary: According to our observations, the useful gene therapy vectors, cationic lipids significantly improved the effectivity of bacterial BRM-based antitumor therapy in tumorous animals.

This work was partly supported by a grant from ETT for L.A.R: Grant No: 05054/99.

1. Réthy, L. et al.: Kísérl Orvostud (Exper Med) 20, 138 (1968). 2. Zelphati, O., Szoka, F. C. Jr.: J Liposome Res 7, 31 (1997). 3. Géresi, M. et al.: Acta Vet Acad Sci Hung 28, 281 (1980). 4. Báthori, Gy. et al.: Ann Immunol Hung 22, 443 (1982). 5. Réthy, L. et al.: Acta Vet Hung 31, 43 (1983). 


\title{
L. A. RÉTHY ${ }^{1}$, F. SÓLYOM ${ }^{2}$, GY. BÁTHORI ${ }^{3}$
}

\section{Increasing the oncolytic activity of IBDV virus by traditional and cationic liposome complexes}

\begin{abstract}
Independent Research Group for Genetics and Immunology, ${ }^{1} \mathrm{Hrc}$ - Bethesda Childrens' Hospital, Budapest, ${ }^{2}$ Independent Veterinary Laboratory, Érd, ${ }^{3} 1$ st Department of Physiology, Semmelweis University, Budapest, Hungary
\end{abstract}

Introduction: Authors recently reported the beneficial effect of liposomes on the oncolytic activity of certain viruses [1,2]. At present they compared the supposed oncolysis-increasing activity of Infectious Bursal Disease Virus (strain: IBDV/ BLB90; -single dose: $5 \times 10^{5} \mathrm{TCID}_{50}$ ), complexed with "traditional" liposomes containing lecithin, cholesterol and stearylamine [3] and with a cationic lipid, DDA-chloride, which was used first as an immuno-modulant agent [4]. Nowadays cationic lipids are widely used as vectors for gene therapy [5].

Methods: Swiss albino mice infested with $10 \mathrm{~g}$ living cells of EHRLICH ascites tumour were treated with "plain" IBDV and IBDV complexed with DDA-chloride and/or traditional liposome. Values of Medium Survival Times (MST, in days) were analysed statistically to define Student's $\mathrm{p} \%$, ANOVA $\chi^{2}$, reliability $\mathrm{p} \%$. Results are disclosed in Table.

\begin{tabular}{llll}
\hline Treatments & $\mathrm{N}$ & MST & SD \\
\hline Untreated controls & 16 & 19.6 & 4.3 \\
IBDV & 15 & 40.8 & 11.1 \\
IBDV + Liposome & 16 & 60.1 & 22.1 \\
IBDV + DDA-chloride & 16 & 55.0 & 15.1 \\
IBDV + (Liposome + DDA-chloride) & 15 & 59.2 & 13.5 \\
\hline
\end{tabular}

Results unequivocally prove that the MST values increased significantly following treatment of tumour-infested mice with "plain" IBDV. A more pronounced increase of MSTs were achieved following application of DDA-chloride and/or traditional liposomes. ANOVA $\chi^{2}$ and the reliability $\mathrm{p}(\%)$ proved the homogeneity and reproducibility of the experimental results.

In summary, the oncolytic activity of IBDV was significantly enhanced in a complex with liposomes. Although in gene therapy cationic lipids are preferred as vectors in order to neutralise the negatively charged DNA, during our experiments we could not detect significant difference between the effects of the investigated liposome 
complexes: DDA-chloride-Liposome-complex exhibited the same oncolysisenhancing/immuno-modulant activity as the liposome or DDA-chloride alone.

This work was partly supported by a grant from ETT for L.A.R.: Grant No: 05054/99.

1. Sólyom, F. et al.: EFIS2000 Congress, Poznan (accepted). 2. Réthy, L. A. et al.: EFIS2000 Congress, Poznan (accepted). 3. Báthori, Gy. et al:: Ann Immunol Hung 22, 443 (1982). 4. Réthy, L. et al.: Kísérl Orvostud (Exper Med) 20, 138 (1968). 5. Zelphati, O., Szoka, F. C. Jr.: J Liposome Res 7, 31 (1997).

\section{RUPNIK}

\section{Variability of Clostridium difficile strains}

Department of Biology, Biotechnical Faculty, University of Ljubljana, Večna pot 111, 1000 Ljubljana, Slovenia

Clostridium difficile is an anaerobic, sporogenic Gram-positive bacterium. It causes intestinal infections as antibiotic associated diarrhoea (AAD) and pseudomembranous colitis (PMC). The main virulence factors are two large toxins, toxin A (TcdA, enterotoxin) and toxin B (TcdB, cytotoxin). In our studies we have established a method for differentiation of $C$. difficile strains into groups called toxinotypes based on differences in their toxin genes. Toxinotypes have proven to be a good basis for studying pathogenesis, virulence factors and molecular biology of $C$. difficile.

Region coding for both toxins in $C$. difficile is called pathogenicity locus (PaLoc) and consists of five genes, two of them are toxin genes (tcdA and tcdB) and three additional genes are associated with regulation and transport (tcdC, D and E). The entire $19 \mathrm{~kb}$ sequence of PaLoc is known for reference strain VPI 10463. We use ten overlapping fragments for amplification of PaLoc region. Two of them amplifying 5region of tcdB gene and 3'-region of tcdA gene, are used routinely in screening for variant strains. The changes observed in PaLoc region are deletions, insertions and polymorphism of restriction sites. Toxinotype is a group of strains with identical changes in PaLoc when compared to reference strain. At the time fifteen toxinotype's are known (I to XV).

Studies of variant $C$. difficile strains have contributed significant information in different research areas. For instance, a group of variant strains produce only TcdB. This variant toxin $B$ is changed and resembles in its properties to $C$. difficile toxin as well as $C$. sordellii toxin. As such strains are reported also to cause disease, they have 
changed the dogma that both toxins act synergistically and are needed for full virulence. Therefore the diagnostic tests of $C$. difficile are currently changing. Further, a new form of genetic element was found in variant strains of $C$. difficile (toxinotype XIV) combining the properties of intron and insertion element. And finally, only strains with changed toxin genes were shown to produce a third toxin, binary toxin.

\section{E. RuSVAI, J. BRoJNÁS, I. MEZEY, J. DANKA, Gy. BERENCSI}

\section{A high percentage of the Hungarian young population is not protected against HAV}

National Center for Epidemiology, Budapest, Hungary

A seroepidemiological study was conducted in Hungary in 1999-2000 to determine the seroprevalence of anti-HAV in the general population.

5216 subjects ( 2528 men and 2688 women) were stratified by age $0-5,6-19$, $20-29,30-39,40-49,50-59$, more than 60 . The presence of total anti-HAV antibody was investigated using commercial enzyme immunoassay (Hepanostika HAV antibody Organon Teknika).

$22.57 \%$ of the subjects were found positive for anti-HAV antibody. Prevalence of seropositivity increased with increasing age, being $2.19 \%, 4.44 \%, 8.35 \%, 22.79 \%$, $54.31 \%, 81.94 \%, 91.50 \%$ for the various age groups, respectively.

The results show a large number of susceptible subjects in the young adolescent population, which could cause public health problem in the country during disasters.

\section{K. SALÁNKI, E. HUPPERT, E. BALÁZS}

\section{The compatibility of the 3a protein and the coat protein of cucumoviruses is required for cell-to-cell movement}

Agricultural Biotechnology Center, Gödöllö, Hungary

It is well known that movement protein and coat protein are both essential for cell-to-cell movement of cucumoviruses, but the exact function and the possible interactions of the proteins are not characterized yet.

In our previous work we constructed recombinant viruses between two cucumoviruses, the cucumber mosaic virus (CMV) and tomato aspermy virus (TAV) by exchanging the $3 \mathrm{~A}$ protein and the coat protein of the two viruses. The recombinant 
containing the $3 \mathrm{~A}$ protein of $\mathrm{CMV}$ and the coat protein of TAV caused systemic infection on different test plants, while the other recombinant containing the $3 \mathrm{~A}$ protein of TAV and the coat protein of CMV was not able to move from cell-to-cell, however it was able to replicate in protoplast system.

In our present work we constructed further recombinants between the two viruses in order to identify which parts of the two proteins should be compatible for the local movement of the viruses. In case of the 3 a protein we chose the recombination sites based on the sequence similarity of the two proteins, while in case of the coat protein we selected the sites for recombination by the known three dimensional structure. The recombinant virus unable to move from cell-to-cell was able for local movement if we exchanged the carboxy terminal 30 amino acids of the TAV $3 \mathrm{~A}$ protein for the similar region of the CMV $3 \mathrm{~A}$ protein, or if we replaced the amino terminal 70 amino acids of the CMV coat protein for the similar part of the TAV coat protein. So the compatibility of the carboxy terminal part of the $3 \mathrm{~A}$ protein and the amino terminal part of the coat protein is required for the cell-to-cell movement of cucumoviruses, and presumable the interaction of these two proteins is necessary in this process.

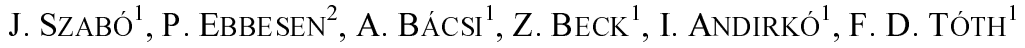

\section{Infection of human syncytiotrophoblast with pseudotypes of vesicular stomatitis virus bearing envelope antigens of various HIV-1 strains}

${ }^{1}$ Institute of Microbiology, Medical Faculty, Medical and Health Science Center, University of Debrecen, Debrecen, Hungary, ${ }^{2}$ Department of Virus and Cancer, Danish Cancer Society, Aarhus, Denmark

Mother-to-child transmission is clearly an important mode of spread for human immunodeficiency virus type 1 (HIV-1). The placental syncytiotrophoblast (ST) forms a continuous multinucleated epithelium in direct contact with maternal blood. Although HIV-1 has been detected in the ST layer in situ, there is conflicting evidence regarding infection of ST cells with cell-free virus. We used the phenotypic mixing between HIV-1 and vesicular stomatitis virus (VSV) to assay the susceptibility of human ST cells to penetration by various HIV-1 strains. We found that VSV(HIV-1 $\left.{ }_{\text {IIIB }}\right)$ and VSV(HIV-1 $\left.1_{\text {Ba-L }}\right)$ pseudotypes entered ST cells, whereas VSV pseudotyped with envelope antigens of RF, MN or Ada-M strains of HIV-1 did not infect ST cells. Neutralizing sera to HIV-1 ${ }_{\text {IIIB }}$ and HIV-1 $1_{\text {Ba-L }}$ were able to completely inhibit entry of $\operatorname{VSV}\left(\mathrm{HIV}-1_{\text {IIIB }}\right)$ and VSV(HIV-1 $\left.{ }_{\text {Ba-L }}\right)$ into ST cells. These findings indicated that 
infection of ST cells with VSV(HIV-l) pseudotypes was mediated by Envs from IIIB and Ba-L strains of HIV-1. Monoclonal antibodies (MAb) to CD4, CXCR4, CCR5 and CCR3 were tested for their ability to block VSV(HIV-1) infection of ST cells. Neither the anti-CD4 nor the anti-CXCR4, anti-CCR5 and anti-CCR3 MAbs had any inhibitory effect upon infection of ST cells with VSV(HIV-1) pseudotypes. Our data suggest that ST cells can be infected with cell-free HIV-1 and the susceptibility of ST cells to penetration by the virus is strain dependent. The mechanism of entry into ST cells remains to be revealed.

D. SZAKÁL, K. SZÖKE, T. PÁL

\section{The colony im munoblot method adapted for detecting Shigella and EIEC from milk}

Department of Medical Microbiology and Immunology, University Medical School, Pécs, Hungary

Dysentery-causing Shigella and EIEC strains usually spread by the feco-oral route, but frequently contaminated water and food, particularly milk and dairy products are the vehicles of transmission. The identification of these bacterial agents from these samples is rather laborious by the classical laboratory methods. A rapid Ipa-C specific colony immunoblot method has already been successfully used for the detection of these bacteria from water and stool samples. This work presents its successful adaptation for milk samples.

Samples contaminated artificially with Shigella or EIEC were tested by the colony immunoblot technique, with the necessary changes of the method due to the consistency of the samples. As a control technique, samples were spread onto selective media, followed by IpaC-specific ELISA of selected colonies. Our experiments showed that the colony blot method was equally sensitive as the other method, but was significantly faster. 


\title{
E. SZÁNTAI ${ }^{1}$, CS. BOGNÁR ${ }^{2}$, CS. FERENCZI ${ }^{3}$
}

\section{Leptospirosis: state of epidemiology, diagnostical news}

\footnotetext{
${ }^{1}$ Department of Microbiology, Eötvös Loránd University, Budapest, 2"Béla Johan" National Center for Epidemiology (OEK), Budapest, ${ }^{3}$ Institute of National Public Health of Hajdú-Bihar County
} (ÁNTSZ), Debrecen, Hungary

Leptospirosis has been considered to be a relatively infrequent disease in Hungary up to now. The number of diseases caused by Leptospira interorrgans has been increased presumably due to the rainier weather of late years and the multiplication of rodents, mainly of rats. In 1997 out of 2141 examined samples 91 (4\%), in 1998 out of 158661 (4\%), whilst in 1999 out of 2331341 samples (15\%) have been proved to be positive by the test of lysis-agglutination. The examination by lysisagglutination is applied routinely only in the OEK and in the Institute of National Public Health of Hajdú-Bihar county, Debrecen, because of the increased danger of infection, and as special culture-medium and evaluation by microscope of dark visual field is needed.

In the last two years a comparative examination was carried out among the following commercial tests: two ELISA, one IF and one antibody revealing LATEX agglutination test. The examined ELISA kits did not fulfil the expectations. The results received by the IF and LATEX tests showed outstanding agreement with those obtained by lysis-agglutination. On the basis of the examinations the IF and LATEX tests seem to be suitable for screening tests in the laboratory diagnostic of leptospirosis but for confirmation and serotypifying the lysis-agglutination method of the two abovementioned laboratories should be used in the future, too.

\section{Gy. SZladeK, J. KÓNYA, A. JuHÁSz, K. SZARKA, L. GERGEly}

\section{The prevalence of TT virus (TTV) in renal transplant recipients}

\author{
Department of Microbiology, Medical School, University of Debrecen, Debrecen, Hungary
}

TTV is a novel unenveloped DNA virus first isolated from a Japanese patient with fulminant liver disease of unknown origin. The virus has a single stranded circular DNA genome, and so is thought to belong to the Circoviridae family, and related with chicken anaemia virus (CAV), porcine circovirus (PCV), beak and feather disease virus (BFDV). The pathogenic role of the human circovirus TTV is yet poorly known. TTV 
can be detected also in the peripheral blood of $5-20 \%$ of the healthy blood donors. TTV has recently been reported to be excreted via faeces, although data indicating faecal-oral transmission are not available.

To detect the viral DNA in DNA extracted from peripheral blood mononuclear cells (PBMC) of renal transplant recipients and healthy blood donors we used the polymerase chain reaction (PCR) method with primers designed for the ORF I region of the viral genome. Our results show that the prevalence of TTV is significantly higher in renal transplant recipients [61\% (53/87)] than in healthy blood donors $[19 \%(5 / 26)]$. The cause of the higher prevalence detected in renal transplant recipients may be attributed to the blood products received because of the illness, to the transplant organ, or the immune suppression.

\section{K. SZÖKE, J. KÓNYA, K. SZARKA, GY. VERESS, A. JUHÁSZ, L. GERGELY}

\section{Quantification of human cytomegalovirus DNA using the polymerase chain reaction}

Department of Microbiology, Medical School, University of Debrecen, Debrecen, Hungary

In organ transplant recipients the latent cytomegalovirus (CMV) infection can be easily reactivated because of the immunosuppression. The most important diagnostic sign of the reactivation is the developing viremia. The viral gene-expression or the detection of viral structure proteins by antigenemia test can indicate the replicating virus in the peripheral blood. The viral genome can be detected in low copy number in the latent phase of the infection because in this phase the viruses are mostly in the circulating monocytes. In the viremic phase the viral genome can be detected in the plasma or if the viral DNA is tested in whole blood then the amplification of the viral genome can be. Our goal was to develop a quantitative PCR method, which is based on the competition of a mutant sequence developed by us and the wild sequence. The oligonucleotide primers amplificated a $149 \mathrm{bp}$ long section from the glycoprotein $\mathrm{B}$ gene. The amplimer was cloned (wild sequence) thereafter a $200 \mathrm{bp}$ long indifferent insert was ligated in to the $B g l$ II cleavage site inside the cloned sequence (mutant sequence). The amount of cytomegalovirus DNA was measured in the peripheral blood of organ transplant recipients. We detected elevated CMV DNA level in the blood of transplant patients during the antigenemia positive phase. In the non-antigenemia phase the DNA levels of the transplant patients were in the same range as those of the healthy blood donors. 
In conclusion, we developed a quantitative PCR method, that is to be tested on clinical samples in large scale.

\author{
E. SZIGETI ${ }^{1}$, J. FARKAS ${ }^{2}$
}

\title{
Use of a conductimetric technique for data capture in predictive microbiology
}

${ }^{1}$ Department of Microbiology and Biotechnology, ${ }^{2}$ Department of Refrigeration and Livestock Products
Technology, Szent István University, Faculty of Food Science, Budapest, Hungary

Conductimetry as an alternative data capture method for following microbial growth has a great potential as a research tool of predictive microbiology. In spite of this fact there is only a limited number of applications using conductimetric data for model generation. In this study the growth of single strains of Listeria monocytogenes and Lactococcus lactis was tested in 5 media using a RABIT ${ }^{\circledR}$ instrument. The goal of the work was to find selective growth media for Listeria and Lactococcus, respectively, in order to study their interaction in mixed-culture using the conductimetric technique. Whitley Anaerobic broth, Whitley Impedance broth and modified Whitley Impedance broth (Whitley Impedance broth + Chloramphenicol $(7 \mathrm{mg} / \mathrm{l})$ ) were not suitable for following selectively the growth of Lactococcus lactis or Listeria monocytogenes in a mixed culture of the two bacteria. BiMedia 630 A for Lactococcus lactis and Bimedia 403 A for Listeria monocytogenes satisfied the demands raised by conductance measurement. Linear correlations were established between the graphically estimated detection time (TTD) values of the conductance curves and the logarithmic numbers of colony forming units (cfu). The correlations were very strong in each case (determination coefficients $\left(\mathrm{R}^{2}\right)$ of the linear regression were higher than 0.98 at both medium-strain combinations). However, in BiMedia 630 Listeria monocytogenes was capable of slow growth, therefore, this medium will be suitable for studying microbial interactions only when Listeria are present in the mixed culture in concentrations less than $10^{6} \mathrm{cfu} / \mathrm{ml}$. 


\section{E. SZIGETI}

\section{Interaction between Lactococcus lactis strains and Listeria monocytogenes in mixed-cultures} Department of Microbiology and Biotechnology, Faculty of Food Sciences, Szent István University,
Budapest, Hungary

Competition of a bacteriocinogenic and a non-bacteriocinogenic Lactococcus lactis strain and a Listeria monocytogenes strain was studied in two semi-syntetic liquid media at various temperatures. The media used for the study were ST I and modified ST I broth (ST I broth $+1 \mathrm{~g} / 1$ Tween 80 ). Incubation temperatures were 30 ${ }^{\circ} \mathrm{C}, 20{ }^{\circ} \mathrm{C}$ and $10{ }^{\circ} \mathrm{C}$. In this study the role of inoculum levels of the competing strains in the suppression of growth of L. monocytogenes was investigated. Furthermore, the bacteriocin activity of nisin produced by the bacteriocinogenic Lac. lactis strain against L. monocytogenes was determined in the mixed cultures of the two bacteria.

The competition studies showed that the growth of the bacteriocinogenic Lac. lactis and L. monocytogenes in a co-culture did not differ significantly in ST I and modified ST I broth at $30{ }^{\circ} \mathrm{C}$, when the initial cell numbers of the two bacteria were about equal. In both media, the inactivation of L. monocytogenes could occur only when the cell concentration of the bacteriocinogenic competitor reached the level of at least $10^{7} \mathrm{cfu} / \mathrm{ml}$ required to produce sufficient bacteriocin concentration. Although bacteriocin activity was not detectable against $L$. monocytogenes when the co-culture was inoculated into ST I broth, the decrease of the viable cell count of Listeria seemed to follow the same manner as in modified ST I broth. This observation suggests that the bacteriocinogenic Lac. lactis also produced nisin in ST I broth, although this activity was not detectable by the agar spot test.

When the two competitors were present in the same initial level (approx. $10^{5}$ $\mathrm{cfu} / \mathrm{ml}$ ), the non-bacteriocinogenic Lac. lactis did not affect the growth of $L$. monocytogenes at $30{ }^{\circ} \mathrm{C}$ in modified ST I broth. I conclude from this observation that the considerable decline of the viable cell counts of $L$. monocytogenes found in the aforementioned case was not caused alone by the lactic acid produced by Lac. lactis.

From the competition studies with different initial cell numbers of the bacteriocinogenic strain and L. monocytogenes at $30{ }^{\circ} \mathrm{C}, 20{ }^{\circ} \mathrm{C}$ and $10{ }^{\circ} \mathrm{C}$ in the modified medium the following conclusions can be drawn: The two bacteria grew in a mixed culture the same way as in their monocultures at $30{ }^{\circ} \mathrm{C}$, until nisin reached the detectable concentration, when a five log-cycles decrease of the viable count of $L$. monocytogenes occurred. The same phenomenon was also observed when the initial level of the lactic acid bacteria was one log-cycle higher or lower than that of the 
Listeria. The effect of nisin production was noted only in the earlier or later induction of Listeria inactivation.

Incubation of the mixed cultures at $20{ }^{\circ} \mathrm{C}$ gave similar results but the bacteriocinogenic activity resulted only in a three log-cycles decline of the cell count of L. monocytogenes. Furthermore, the suppression of the pathogen was induced much later at this temperature than at $30^{\circ} \mathrm{C}$.

At $10{ }^{\circ} \mathrm{C}$ Lactococcus lactis produced much less bacteriocin than at $30{ }^{\circ} \mathrm{C}$, therefore a drastic decrease of the listeria cell count was not observed. Suppression of the Listeria growth was expressed in its decreased maximum population level (i.e. in an earlier appearance of the stationary phase).

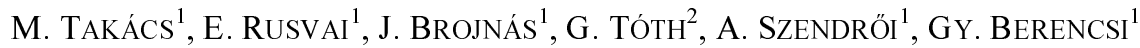

\section{Prevalence of TTV and HGV in Hungary}

\author{
${ }^{1}$ Division of Virology, "B. Johan" National Center for Epidemiology, Budapest, \\ ${ }^{2}$ Department of Genetics, Eötvös L. University, Budapest, Hungary
}

The majority of the viral hepatitis is caused by five hepatitis viruses $(A, B, C, D$, E). In 1995 three new flaviviruses were discovered, GBV-A, GBV-B and GBV-C (also known as HGV) viruses. TT virus was discovered in 1997. To reveal the RNA of the GBV-A, -B, and HGV viruses in the sera of patients, RT-PCR was applied using the primers published in the literature. Seminested PCR was used to detect the DNA of TTV. The nucleotide sequences of nested PCR products were determined.

Specific PCR products were not found in cases of GBV-A and GBV-B viruses in accordance to the literature. The RNA of the HGV virus was found in the sera of patients suffering from hepatitis of unknown origin or from aplastic anaemia. Twentyone sera of 252 were positive. Eight PCR products were sequenced and these sequences were found to be different from each other. In case of this virus, sequences of 2000 nucleotides are needed to construct a reliable phylogenetic tree. It could not be done, because the length of the PCR products was only 400 nucleotides. More tests and sequences are needed for further studies.

The antibodies of the GBV-C virus were found in the sera of patient suffering from hepatitis of unknown origin or aplastic anaemia. Seventy-four sera were tested and 21 were found to be positive. The sera of 255 healthy persons above 60 years were tested for the presence of GBV-C antibodies, and 71 were positive.

Eighty-five sera of patients with hepatitis of unknown origin were tested for the presence of TTV-DNA. Thirty of them were positive. Seven PCR products were 
directly sequenced. Four sequences were homogeneous, 3 indicated mixed infections. A phylogenetic tree was constructed from sequence of the main genotypes and from our data. In each case the genotype 2 was found in our samples. Mixed sequences will be cloned.

\section{TÓBIÁs ${ }^{1}$, L. PALKOVICS ${ }^{2}$, L. TZEKOVA², E. BALÁZS ${ }^{2}$}

Replacement of coat protein gene of PPV infectious clone by zucchini yellow mosaic virus coat protein does not extend the virus host range

${ }^{1}$ Plant Protection Institute, Hungarian Academy of Sciences, Budapest, ${ }^{2}$ Agricultural Biotechnology Center, Gödöllö, Hungary

Many informations are available on the consequences of gene transfer between distantly related viruses in different virus genera but not in the potyvirus genus. In this study two members of the potyvirus genus, plum pox virus (PPV-SK68) and zucchini yellow mosaic virus (ZYMV) were used. Both of these viruses have different host range, pathogenicity and the size of their CP is also different (PPV CP is $990 \mathrm{nt}$ and ZYMV CP is $837 \mathrm{nt}$ long). Comparison of the nucleotide and amino acid sequence of these two isolates showed $58 \%$ and $65 \%$ homology, respectively. PPV infects mainly Prunus species while ZYMV infects Cucurbitaceae plants. Both viruses have different herbaceous test plants, too. To investigate the function of the coat protein of potyviruses for pathogenicity and host specificity the coat protein gene of an infectious plum pox virus clone was replaced by the ZYMV CP gene. Three different constructs were analysed but only one was infectious when the secondary structure between the CP and the 3' NTR could be formed. This hybrid clone was infectious on Nicotiana benthamiana and Nicotiana clevelandii plants and the hybrid nature of this virus was verified by Western blot using specific PPV and ZYMV antibodies.

Our results provide direct evidence that the coat protein is exchangeable between these two potyviruses, the coat proteins have similar functions and this heterologous ZYMV CP is able to cooperate with other proteins of the PPV. 


\title{
I. TÓTH $^{1}$, B. SZABÓ $^{2}$, I. BARCS ${ }^{3}$, L. EMŐDY $^{4}$, E. OSWALD $^{5}$
}

\section{Virulence markers of human uropathogenic Escherichia coli in Hungary}

\author{
${ }^{1}$ Veterinary Medical Research Institute of the Hungarian Academy of Sciences, Budapest, \\ ${ }^{2}$ Microbiology Institute of the Medical University, Debrecen, ${ }^{3}$ Clinical Microbiology Laboratory \\ of the Bajcsy-Zsilinszky Hospital, Budapest, ${ }^{4}$ Institute of Microbiology and Immunology of the Medical \\ University, Pécs, Hungary, ${ }^{5}$ Molecular Microbiology Laboratory of the INRA-ENVT, Toulouse, France
}

A collection of 190 human uropathogenic Escherichia coli (UPEC) and 12 other extraintestinal E. coli strains have been investigated for the presence of genes of cytotoxic necrotic factors (CNF) and cytolethal distending factors (CDT) using specific PCR primers. As a result, $42(22.1 \%)$ of the UPEC strains were $\mathrm{CNF}^{+}, 12$ strains were $\mathrm{CNF}^{+}$and $\mathrm{CDT}^{+}$, and 3 strains were $\mathrm{CDT}^{+}$only.

CNF and CDT production of selected strains was proven by HeLa cell assay. When haemolytic abilities were tested as much as 80 strains $(42.1 \%)$ proved to be haemolytic. Extraintestinal strains were negative for both CNF and CDT (3 of them were haemolytic). The presence of pap-, sfa- and afa-adhezin genes was determined by multiplex PCR which resulted in a $86.6 \%$ positivity for $s f a, 71.1 \%$ positivity for pap and no strains were detected with afa genes. As many as 44 strains contained several virulence genes. These virulence genes have formed 7 virulence clusters, the most frequent being the $\mathrm{CNF}^{+}, \mathrm{P}^{+}, \mathrm{S}^{+}, \mathrm{Hy}^{+}$, in which the third of the strains was $\mathrm{CDT}^{+}$as well.

These results suggest that CDT is a virulence marker characteristic for human UPEC.

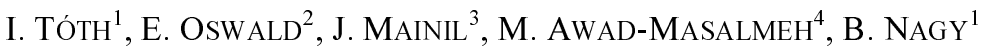 \\ Urovirulence markers of Escherichia coli isolated from cases of postweaning diarrhea and oedema disease of swine}

\footnotetext{
${ }^{1}$ Veterinary Medical Research Institute of the Hungarian Academy of Sciences, Budapest, Hungary, ${ }^{2}$ Molecular Microbiology Laboratory of the INRA-ENVT Toulouse, France, ${ }^{3}$ Chaire de Bactériologie et de Pathologie Bacterienne, Faculté de Medicine Vétérinaire, Université de Liege, Belgium,

${ }^{4}$ II. Medizinische Universitätsklinik für Klauentiere Veterinärmedizinische Universität Wien, Austria
}

Postweaning diarrhea of swine is a multifactorial disease in which enterotoxic E. coli (ETEC) is playing a crucial role. Verotoxic E. coli (VTEC) in swine is known to produce oedema disease. Both porcine ETEC and VTEC have their characteristic 
adhesive fimbriae (F4, F18). The goal of these studies was to see whether further toxins and adhesins could also play a role in postweaning diarrhea. Here we have tested 204 such $E$. coli strains by PCR for the presence of CNF genes and found $12 \mathrm{cnfl}+$ strains $(5.9 \%)$ that were all haemolytic. The phenotypic expression of CNF1 was confirmed by HeLa cell assay as well as in rabbit skin test. The $12 \mathrm{CNF} 1+$ strains were further PCR tested for the presence of genes of cytolethal distending toxin (CDT) and pap and $s f a$ fimbria, and all were found to harbour genes of either or both fimbria, but none possessed $a f a$. On the other hand, 10 haemolytic postweaning porcine intestinal isolates which were cnf- were also negative for pap or $s f a$ fimbrial genes. Further studies of 10 extraintestinal porcine E. coli strains detected $3 \mathrm{cnfl}+$ strains, one of which had both pap and $s f a$, while the others had either pap or $s f a$ genes.

These results confirm two earlier reports on the presence and clustering of urovirulence characters among porcine intestinal and extraintestinal E. coli strains and indicate that CDT can also be a virulence factor of porcine enteric E. coli.

\title{
A. TUSNÁDI ${ }^{1}, \mathrm{~K} \cdot \mathrm{KATONA}^{2}$
}

\section{Methicillin-resistant staphylococci in a County Hospital in Hungary}

\author{
${ }^{1}$ Department of Infectious Diseases, ${ }^{2}$ Department of Microbiology, County Hospital Szolnok, Hungary
}

Objectives: To assess the frequency and the distribution of methicillin-resistant Staphylococcal (MRS) infections in a 1521-bed county hospital.

Methods: Clinical, epidemiological and bacteriologic observations related to MRS infections were made.

Results: Between January 1999 and October 1999, 1323 different Staphylococcus strains [815 Staphylococcus aureus (SA) and 508 coagulase-negative Staphylococcus (CNS)] were isolated from clinical sources, out of which 207 (15.6\%) specimen proved to be methicillin-resistant. Methicillin resistance is especially frequent among CNS strains (185 were methicillin resistant out of $508-36.4 \%$ ) while that is far less among SA strains (22 out of $815-2.7 \%$ ).

Out of the 174 cases investigated only ten patients were infected with MRS strains, and the vast majority of patients were only colonized without infections. The sites of infections were wounds (4 MRSA, 1 MRCNS), blood (1 MRSA, 1 MRCNS) respiratory tract (1 MRSA) urinary tract (1 MRSA), ventrico-atrial shunt (1 MRCNS).

The sites colonization with MRS strains were blood (40 MRCNS), wounds (41 MRCNS, 5 MRSA), urinary tract (15 MRCNS, 1 MRSA) respiratory tract (58 MRCNS, 1 MRSA, others (3 MRCNS). 
Resistance of the MRS strains to various antibiotics was studied with disk susceptibility tests. All strains were still susceptible to glycopeptides. 5.9\% of the MRS strains were aminoglycoside-resistant and $20.3 \%$ fluoroquinolone-resistant.

Conclusions: Fortunately, infections due to MRS strains are not frequent in our hospital, but the prevalence of colonization with MRS strains are quite high and under certain circumstances these strains may become pathogens.

\section{K. URSU ${ }^{1,2}$, P. ÉLÖ ${ }^{1}$, L. TOKAJI ${ }^{2}$, K. MEKLI ${ }^{2}$, M. BENKÖ², B. HARRACH ${ }^{2}$}

Cloning and sequencing of the genome of the ovine adenovirus 1

${ }^{1}$ Central Veterinary Institute, ${ }^{2}$ Veterinary Medical Research Institute, Hungarian Academy of Sciences, Budapest, Hungary

There are 7 adenovirus serotypes isolated from sheep. Five of them (OAdV-1 to 5) belong to the genus Mastadenovirus. The isolate OAV287 is proven to be the member of the genus Atadenovirus although this type has not received a serotype number yet. The taxonomic position of OAdV-6 is so far unclarified. OAdV serotypes 2-5 belong to the same species (Ovine adenovirus $A$ ) according to the newest DNA sequence comparisons and phylogenetic calculations. Based on the restriction enzyme digestion patterns and on the results of hybridization experiments with the DNA of OAdV-3, it is most likely that OAdV-1 is a specimen of another species. We have decided the detailed investigation of the genome of this serotype.

The virus DNA was cut with the restriction enzyme Pst I. The fragments were cloned randomly into plasmid vector. The isolated clones contained more than half of the virus genome inserted. The clones were sequenced in the Central Veterinary Institute. We obtained more than 8000 bp DNA sequence data so far by sequencing both ends of each fragment. The examinations carried out with these sequences confirmed our preliminary assumption that $\mathrm{OAdV}-1$ belongs to a distinct species (Ovine adenovirus $B$ ) of the genus Mastadenovirus.

Support: TéT Balaton 


\section{T. VÁG ${ }^{1,2 *}$, K. BECKER $^{2}$, B. KEMÉNY ${ }^{1}$, S. KÁRPÁTI ${ }^{2}$, I. MEZEY ${ }^{3}$, A. HORVÁTH $^{1,2}$, J. ONGRÁDI ${ }^{1}$}

\section{HHV-7 and human parvovirus B19 in "gloves-and-socks" syndrome}

${ }^{1}$ National Institute of Dermato-Venereology, ${ }^{2}$ Department of Dermato-Venereology, Semmelweis University, ${ }^{3} \mathrm{JB}$ National Institute for Epidemiology, Budapest, Hungary

Nearly 30 cases of papular-purpuric "gloves-and-socks" syndrome (PPGSS) in the Europe and the USA have been known since 1990. Its ethiology is unknown, although HPV B 19, morbilli, CMV, Coxsackie B6, HBV and HHV-6 infections were described. In adolescence and early adulthood after prodromes symmetric, painful papules and purpures develop on the swollen skin followed by healing without scars in one or two weeks.

High fever, leukopenia with relative lymphocytosis, microhematuria, prolonged Quick-time, elevated level of liver enzymes accompany the clinical picture. Authors here describe the case of a 13-year-old girl, and independently from her an other family with symptom-free mother, but disease in the 29-old father and their nearly two-yearold son. Up to date, they are the oldest and youngest patients described. Antibody levels of the girl were: HHV-6B IgM, IgG 1:20, HHV-7 IgM, IgG >1:640, HPV B19 IgM positive, EBV negative. In the serum sample taken five months later from the son of the family, HHV-7 IgM $<1: 10$, high avidity (HA) IgG and total IgG 1:80, HPV B19 negative; in the father HHV-7 IgM 1:80, HA-IgG and IgG 1:160, HPV B 19 IgG positive; in the mother HHV-7 IgM $<1: 10$, HA-IgG and IgG 1:160, HPV B 19 negative were. HHV-7 PCR from their peripheral blood lymphocytes: strong positivity was found in the mother and son, but very faint in the father. Based on these results, one can presume that in case of the 13-year-old girl interactions of the simultaneous HHV-7 and HPV B 19 infections might contribute to the clinical outcome. In case of the son and father, primary HHV-7 infection accompanied by HPV B 19 and possibly another virus infection might induce symptoms. In such a rare disease, it would be desirable to study infection by a large panel of viruses to reveal the exact pathomechanism.

*Medical student. Supported by OTKA T-029299. 
Gy. Veress, K. SZARKA, M. Murvai, J. Kónya, A. JuhÁsz, L. Gergely

\section{Transcriptional activity of human papillomavirus type 16 variants} having deletions in the long-control region

Department of Microbiology, Medical School, University of Debrecen, Debrecen, Hungary

Transcription of the E6 and E7 viral oncogenes of human papillomavirus (HPV) type 16 is regulated by the P97 major early promoter and enhancer and silencer elements found a in the long-control region (LCR). The central part of the LCR contains an epithelial-specific enhancer, while the 3' part contains two adjacent silencer elements: one which is YY1-dependent and an other which is down regulated by the differentiation-specific factor CDP/Cut.

In this study, we wanted to check the transcriptional activity of natural HPV 16 variants having long deletions in the LCR. The HPV 16 LCR regions were amplified from HPV 16 positive invasive cervical cancer specimens and cloned into the promoter-free reporter vector pALuc. Transcriptional activity of the different clones was measured by luciferase test after transient transfection into HeLa cells.

From case \#936, in addition to a full-length LCR clone (936LCR), two deletion variants were isolated. One variant (936LCRd1) contained a 212 bp deletion (nt 7521 nt 7732) in the tissue-specific enhancer region. The other variant (936LCRd2) had a 378 bp deletion (nt 7564 - nt 35) encompassing a great part of the enhancer and both 3 , silencer regions. In spite of these deletions, both variants had comparable transcriptional activity to that of the full-length 936LCR clone. From the other case (\#33), again a full-length clone (33LCR) and two deletion variants were isolated. A large part of the enhancer region and the total YY1-dependent silencer region were deleted (292 bps, nt 7566 - nt 7857) in isolate 33LCRd1. This clone had a reduced activity compared to the full-length 33LCR clone. The other deletion variant (33LCRd2) contained a 563 bp deletion (nt 7363 - nt 19) encompassing the total enhancer and 3' silencer regions. In fact, this clone contains only the 3' part of the L1 gene and a 210 bp upstream LCR element, in addition to the P97 promoter region. Interestingly, 33LCRd2 had about fourfold higher transcriptional activity than the fulllength 33LCR clone.

In conclusion, deletions of both the YY1-dependent and the CDP-dependent silencer elements of the HPV 16 LCR seem to be responsible for possible mechanisms to up-regulate the expression of E6 and E7 oncogenes in cervical cancer. In addition, our results also point to the existence of a novel transcriptional enhancer element at the 5' part of the LCR. 


\section{Presence of Rhodococcus equi in lymph nodes of pigs suspected on avian tuberculosis}

Institute of Microbiology and Parasitology of Veterinary Faculty of Ljubljana, Gerbiceva 60, Slovenia

Objectives: Avian tuberculosis of pigs is quite common disease in Slovenia and it is very important from the viewpoint of food hygiene. It is a contagious disease and a potential zoonosis. Rhodococcus equi is a facultative, intracellular, Gram-positive coccobacillus that causes chronic suppurative bronchopneumonia and enteritis in 2-4 month old foals and abscesses in older foals. The bacterium can multiply in soil enriched with equine faeces and may be a commensal in intestine. There are, however, some reports of the isolation of $R$. equi from the lymph nodes of pigs with or without lesions resembling those of tuberculosis. According to recent data $R$. equi has been recognized as a human pathogen preferably in immunosuppressed individuals. The purpose of this study was to investigate the presence of $R$. equi in pigs' lymph nodes suspected to Mycobacterium avium infections.

Material and methods: 45 samples of mesenteric and mandibular lymph nodes of pigs from different households were observed. Microscopically the lymph nodes displayed granulomatous lymphadenitis with epitheloid cell reminiscent of tuberculosis. The material was treated with classical method with N-acetyl-L-cystein (NALC). Sediment was inoculated on the following media: egg media with pyruvate (IUT-P), egg media with glycerol (IUT-G), Stonebrink, Middlebrook 7H10 and fluid media MGIT. The mycobacteria were determined by the classical methods, as well as with ACCUPROBE for $M$. avium complex. $R$. equi suspected colonies were subcultured on agar supplemented with $5 \%$ of ovine blood. A presumptive diagnose of $R$. equi was established initially based on Ziehl-Nielsen stain. Biochemical characteristics were tested by commercial system Api Coryne (BioMerieux, France) according to the producers' instructions.

Results and discussion: Rhodococcus equi were isolated from 17 (37.8\%) of specimens studied while mycobacteria were isolated from 19 (42.2\%) specimens. Both species of microorganisms were isolated from 4 (8.9\%) specimens.

From our investigation it is obvious that Rhodococcus equi is frequently present in lymph nodes of pigs suspected to avian tuberculosis. Since $R$. equi causes similar gross pathology in lymph nodes as mycobacteria, the veterinary inspectors in slaughterhouses in such cases have to take all measurements as in cases of tuberculosis. 


\section{M. ŽIGMAN ${ }^{1}$, A. ČERNE ${ }^{1}$, V. TURK ${ }^{2}$, D. STOPAR ${ }^{1}$}

\section{Virus abundance in northern Adriatic sea}

${ }^{1}$ Department of Food Technology, Biotechnical Faculty, University of Ljubljana, Večna pot 111, 1000

Ljubljana, ${ }^{2}$ Marine Biological Station, National Institute of Biology, Fornače 41, 6330 Piran, Slovenia

Viruses exert significant control on marine bacterial and phytoplankton communities with respect to both biological production and species composition, influencing the pathways of matter and energy transfer in the system. Viruses infecting specific bacterial isolates from Northern Adriatic See, as well as virus community in situ were studied by electron transmission microscopy, epifluorescence microscopy and virus growth assays. Bacterial direct counts were determined by SYBR Green epifluorescence, chlorophyll a was measured spectrophotometrically. The experimental sites were characterized by different physico-chemical parameters (i.e. temperature, salinity, nitrogen and phosphorus content). The density profiles of viruses were determined in surface coastal waters, estuarine waters and sahpan waters. Temporal and vertical distribution of viruses were measured in coastal waters. The results indicate that viruses were consistently the most abundant biological group of microorganism in the Northern Adriatic See. Viral abundance ranged between $10^{8}$ and $10^{10}$ per litre and was dependent on seasonal and diurnal cycles. Virus densities in a shallow Northern Adriatic See were only moderately correlated with depth, chlorophyll, temperature, salinity, nitrogen and phosphorus. However, in all cases studied viruses strongly correlate with bacteria. Viruses to bacteria ratio varied between 5 and 22 in different environments. In addition, 28 fast growing bacteria isolated from different environments of Northern Adriatic Sea were examined for lysogeny by treatment with Mitomycin-C. After prophage induction $71 \%$ of all bacterial isolates yielded phage particles of varying morphology. The number of lysogenic bacterial isolates was significantly higher in coastal waters as compared to estuarine and saltpan waters. A significant proportion of bacterial isolates were polylysogenic (46\%). Our results indicate that viruses are important and very dynamic plankton components in the Northern Adriatic Sea, capable of controlling bacterial population. 